\title{
Implementação de um Sistema da Qualidade na rotina de um laboratório de pesquisa em química
}

Maria Olímpia de Oliveira Rezende

Maria Diva Landgraf Otávio Henrique Passarelli

Paula Rezende da Silva Gabriela Marques Salviano

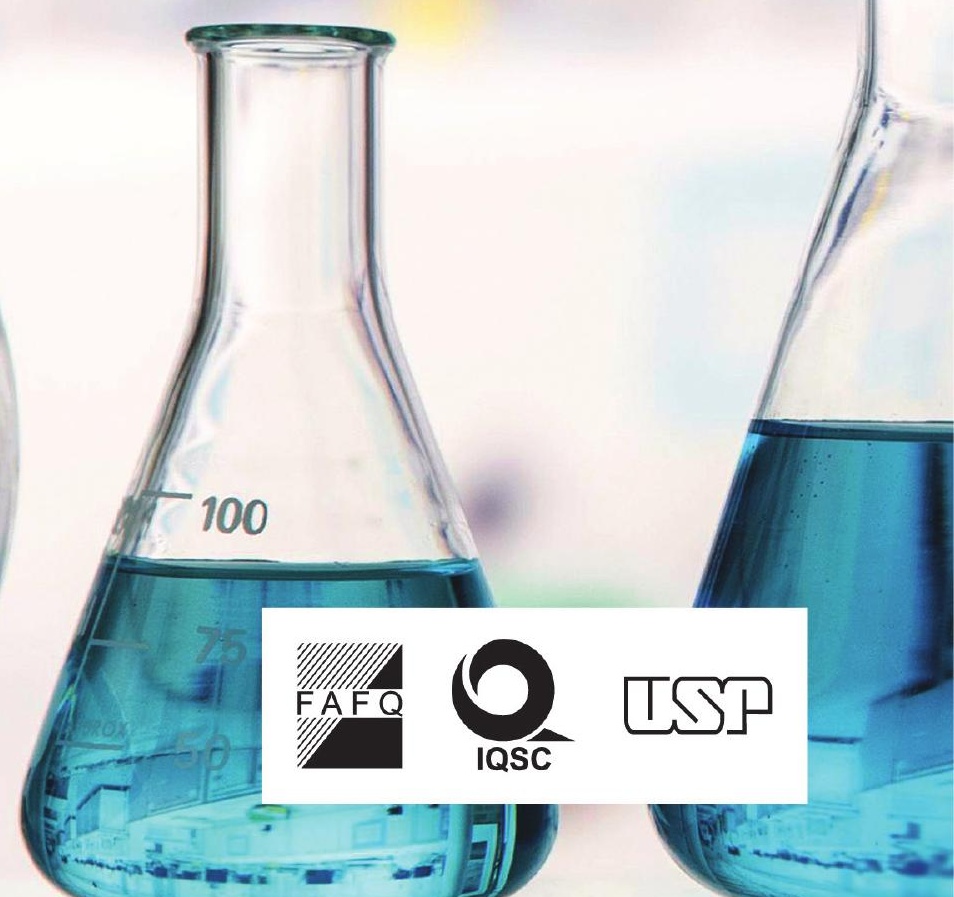


Maria Olímpia de Oliveira Rezende

Maria Diva Landgraf

Otávio Henrique Passarelli

Paula Rezende da Silva

Gabriela Marques Salviano

\section{Implementação de um Sistema da Qualidade na rotina de um laboratório de pesquisa em química}


Rezende, Maria Olímpia de Oliveira

Implementação de um sistema da qualidade na rotina de um laboratório de pesquisa em química / Maria Olímpia de Oliveira Rezende ... [et al.]. - São Carlos : Editora Cubo, 2017.

$141 \mathrm{p}$.

Idioma: Português

ISBN 978-85-60064-76-2

ISBN online 978-85-60064-74-8

1. Acreditação de laboratórios. 2. BPL. 3. ISO 17.025. 4. Sistema da qualidade. 5. Rastreabilidade. I. Título.

http://doi.org/10.4322/978-85-60064-74-8

Capa, projeto gráfico, revisão e diagramação

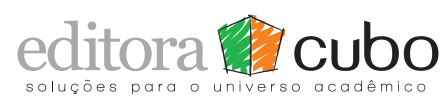




\section{Sobre os Autores}

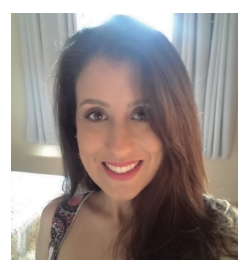

\section{Gabriela Salviano}

Graduada em Química com ênfase em Gestão da Qualidade pelo Instituto de Química de São Carlos da Universidade de São Paulo. Possui MBA em Gestão de Projetos pelamesmauniversidade, campus de Piracicaba. Fez partedo Laboratório de Química Ambiental de2012 a 2014, primeiro como estagiária e posteriormente como analista da qualidade. Atualmente, trabalha com assuntos regulatórios na área de segurança de produtos químicos em uma empresa multinacional.

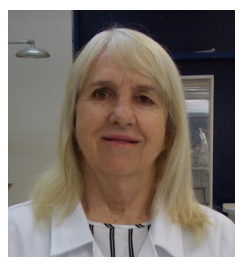

\section{Maria Diva Landgraf}

Trabalha comgerenciamento técnico eépesquisadora do Laboratório de Química Ambiental. Possui mestrado e doutorado em Química Analítica pela Universidade de São Paulo. Atualmente, atua na área de Química Analítica, com ênfase em Química Ambiental no Laboratório de Química Ambiental.

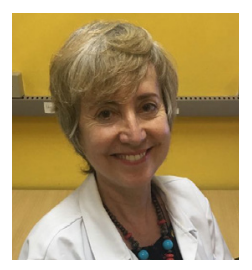

\section{Maria Olímpia de Oliveira Rezende}

Licenciada e bacharel em Química pelo Instituto de Química da Universidade de São Paulo e doutora em Química (Química Analítica, com ênfase em Química Ambiental) pela mesma universidade. Foi professora visitante juntoà Oklahoma State University, em Stillwater, Oklahoma, Estados Unidos, de junho de 1992 a junho de 1994, e na Université de Nantes, em Nantes, França, no ano de 1996.É professora associada da Universidade de São Paulo, no Instituto de Química de São Carlos, desde 1989. Atua, principalmente, em química ambiental, gestão e análise ambiental e gestão da qualidade. É orientadora do Programa de Pós-Graduação em Química (área de Química Analítica do Instituto de Química de São Carlos da Universidade de São Paulo), do Programa de Pós-Graduação em Biotecnologia da Universidade Federal de São Carlos e do Programa de Pós-Graduação em Rede para o Ensino das Ciências Ambientais.

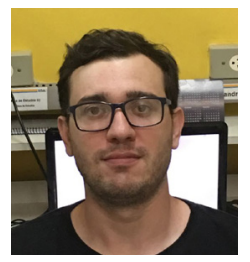

\section{Otávio Henrique Passarelli}

Licenciado em Ciências Exatas com Ênfase em Química pela Universidade de São Paulo, campus de São Carlos, e atuou como coordenador da qualidade no Laboratório de Química Ambiental, desenvolvendo pesquisa na área de gestão da qualidade, estatística aplicada à validação de métodos e análises de espécies metálicas por espectrofotometria.

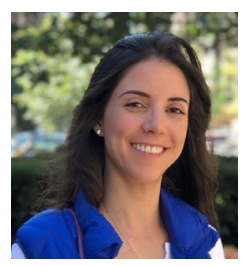

\section{Paula Rezende da Silva}

Especialista em Gestão da Qualidade. Atualmente é empresária do ramo da alimentação. 
Os autores dedicam este livro a todos aqueles que contribuíram para sua execução.

Em especial, Paula Rezende da Silva dedica este livro à sua mãe, que com seu exemplo lhe ensinou o valor do trabalho e a alegria das realizações. E Maria Olímpia de Oliveira Rezende dedica este livro aos valorosos professores do Instituto de Educação Estadual Conde José Vicente de Azevedo. 


\section{Agradecimentos}

Os autores agradecem à Universidade de São Paulo e ao Instituto de Química de São Carlos. Agradecem também à Fundação de Apoio à Física eà Química e aos órgãos de fomento FAPESP, CNPq e CAPES pelo apoio financeiro. Em especial, agradecem a todos os alunos do Laboratório de Química Ambiental.

Gabriela Salviano agradece à Dra. Maria Olímpia e à Paula Rezende da Silva por todo o conhecimento adquirido no tempo em que teve o prazer de fazer parte do Laboratório de Química Ambiental.

Paula Rezende da Silva agradece à Dra. Maria Olímpia pela oportunidade de ter participado da implementação de um sistema da qualidade; por ter colocado seu grupo de pesquisa à disposição desde os estágios iniciais. O trabalho em grupo, colocado em prática, permitiu-lhe o desenvolvimento de uma documentação dinâmica e condizente com o trabalho de pesquisa. Por fim, agradece à Gabriela Salviano pela parceria que lhe possibilitou aprender a pensar de forma sistemática e insistente - aprendizado este que carregará para toda a vida. 


\section{Lista de Figuras}

Figura 1. Foto da capa (A) e da contracapa (B) do 'Caderno de Anotações Experimentais'. . .......... 5

Figura 2. Cópia ilustrativa do POP 004 - Estrutura de POP e Formulários..................... 10

Figura 3. Sumário do Manual da Qualidade utilizado no LQA-IQSC-USP $\ldots \ldots \ldots \ldots \ldots \ldots \ldots \ldots \ldots \ldots \ldots$

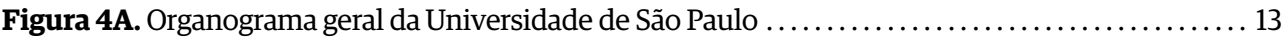

Figura 4B. Organograma do Laboratório de Química Ambiental do Departamento de Química e Física Molecular do Instituto de Química de São Carlos da Universidade de São Paulo . . . . . . . . . 14

Figura 5. Cópia ilustrativa do POP 003 - Agenda Mestra................................. 19

Figura 6. Cópia ilustrativa de uma página da Agenda Mestra (ANEXO 1) do POP 003 -

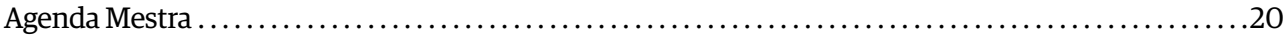

Figura 7. Cópia ilustrativa do Modelo de Procedimento Operacional Padrão (ANEXO 1) do POP 004 - Estrutura de POP e Formulários ........................................ 21

Figura 8. Cópia ilustrativa da Lista Mestra de Procedimentos (ANEXO 3) do POP 004 -

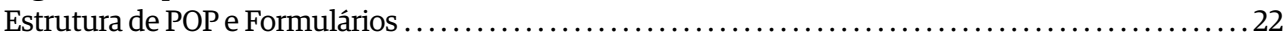

Figura 9. Cópia ilustrativa do Mapa de Distribuição dos Procedimentos do Sistema de Qualidade (ANEXO 4) do POP 004 - Estrutura de POP e Formulários . . . . . . . . . . . . . . . . . . 23

Figura 10. Cópia ilustrativa do Controle de Registros (ANEXO 6) do POP 004 - Estrutura de

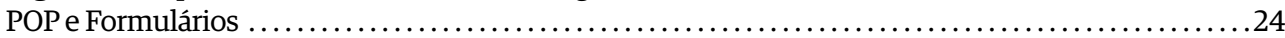

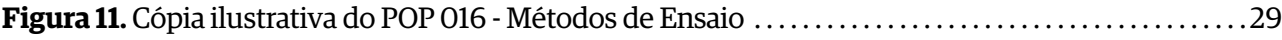

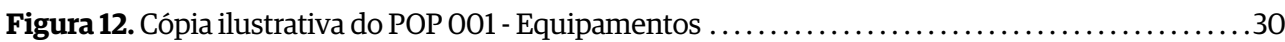

Figura 13. Cópia ilustrativa do Modelo de Instrução Operacional (ANEXO 1) do POP 001 -

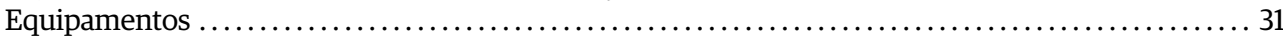

Figura 14. Cópia ilustrativa do Modelo de Registro de Gerenciamento de Equipamento

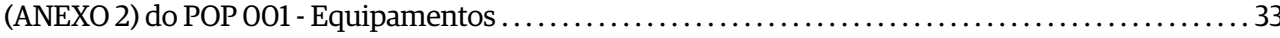

Figura 15. Cópia ilustrativa do Modelo de Etiqueta de Identificação de Equipamento

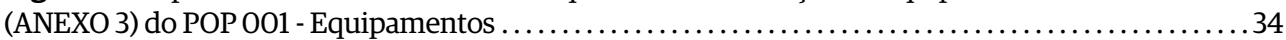

Figura 16. Cópia ilustrativa da Lista Mestra de IOs (ANEXO 4) do POP 001 - Equipamentos .......... 35

Figura 17. Cópia ilustrativa de uma página da Ficha do Equipamento (ANEXO 5) do

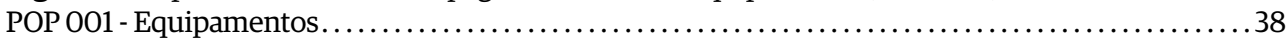

Figura 18. Cópia ilustrativa do POP 020 - Planejamento da Pesquisa ........................ 39

Figura 19. Cópia ilustrativa do POP 005 - Limpeza do Laboratório . . . . . . . . . . . . . . . . . . . . . 41

Figura 20. Cópia ilustrativa do Treinamento de Pessoas Externas (ANEXO 1) do POP 019 -

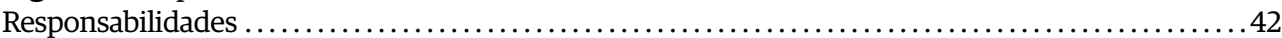

Figura 21. Cópia ilustrativa da Cartilha do Ingressante (ANEXO 2) do POP 019 -

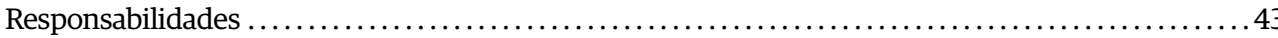

Figura 22. Cópia ilustrativa do Termo de Conhecimento (ANEXO 3) do POP 019 Responsabilidades

Figura 23. Cópia ilustrativa do Termo de Conduta Profissional (ANEXO 4) do POP 019 -

Responsabilidades

Figura 24. Cópia ilustrativa do Termo de Desligamento (ANEXO 5) do POP 019 -

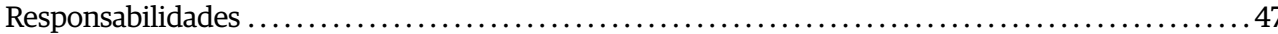

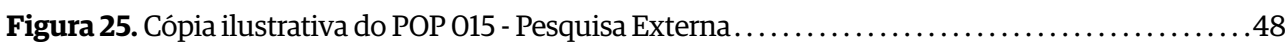

Figura 26. Cópia ilustrativa de uma página da Análise de Pesquisa Externa (ANEXO 1)

do POP 015 - Pesquisa Externa 
Figura 27. Cópia ilustrativa do POP 017 - Prestação de Serviço

Figura 28. Cópia ilustrativa de uma página da Análise Crítica de Pedidos, Propostas e Contratos (ANEXO 1) do POP 017 - Prestação de Serviço .56

Figura 29. Cópia ilustrativa do Contrato de Prestação de Serviço (ANEXO 2) do POP 017 Prestação de Serviço . .

Figura 30. Cópia ilustrativa do Plano de Amostragem (ANEXO 3) do POP 017 - Prestação

de Serviço.

Figura 31. Cópia ilustrativa da Conservação de Amostras (ANEXO 4) do POP 017 - Prestação de Serviço.

Figura 32. Cópia ilustrativa da Cadeia de Custódia (ANEXO 5) do POP 017 - Prestação de Serviço. ... 63

Figura 33. Cópia ilustrativa da Inspeção de Amostras (ANEXO 6) do POP 017 - Prestação de Serviço.

Figura 34. Cópia ilustrativa do Relatório de Reclamação de Cliente (ANEXO 7) do POP 017 Prestação de Serviço

Figura 35. Cópia ilustrativa de uma página da Anotação de Satisfação de Clientes (ANEXO 8) do POP 017 - Prestação de Serviço.

Figura 36. Cópia ilustrativa do Relatório de Amostras, Identificação e Planejamento de Ensaios (ANEXO 9) do POP 017 - Prestação de Serviço

Figura 37. Cópia ilustrativa do Relatório de Ensaio (ANEXO 10) do POP 017 - Prestação

de Serviço.

Figura 38. Cópia ilustrativa de uma página do Controle de Relatórios de Ensaio (ANEXO 11) do POP 017 - Prestação de Serviço.

Figura 39. Cópia ilustrativa de uma página da Lista de Verificação Técnica dos Resultados (ANEXO 12) do POP 017 - Prestação de Serviço

Figura 40. Cópia ilustrativa da Lista de Verificação de Recursos e Documentação (ANEXO 13) do POP 017 - Prestação de Serviço 75

Figura 41. Cópia ilustrativa do POP 010 - Aquisição de Serviços e de Suprimentos .............. 77

Figura 42. Cópia ilustrativa de uma página da Solicitação de Compra (ANEXO 1) do POP O1O Aquisição de Serviços e de Suprimentos .79

Figura 43. Cópia ilustrativa de uma página do Relatório de Inspeção de Serviços (ANEXO 2) do POP 010 - Aquisição de Serviços e de Suprimentos.

Figura 44. Cópia ilustrativa de uma página do Relatório de Inspeção de Produtos (ANEXO 3) do POP 010 - Aquisição de Serviços e de Suprimentos............................... 81

Figura 45. Cópia ilustrativa do POP 011 - Insumos.

Figura 46. Cópia ilustrativa do Local de Armazenamento de Insumos (ANEXO 2) do

POP 011 - Insumos.

Figura 47. Cópia ilustrativa de uma página do Registro de Controle de Materiais de Referência (ANEXO 3) do POP 011 - Insumos

Figura 48. Cópia ilustrativa de uma página do Registro de Controle de Reagentes (ANEXO 4) do POP 011 - Insumos

Figura 49. Cópia ilustrativa de uma página do Registro de Controle de Gases (ANEXO 5)

do POP 011 - Insumos

Figura 50. Cópia ilustrativa do Modelo de Etiqueta de Identificação de Insumos (ANEXO 6) do POP 011 - Insumos

Figura 51. Cópia ilustrativa do Modelo de Etiqueta de Identificação de Soluções (ANEXO 7) do POP 011 - Insumos

Figura 52. Cópia ilustrativa do Modelo de Etiqueta de Identificação de Insumos Vencidos (ANEXO 8) do POP 011 - Insumos

Figura 53. Cópia ilustrativa do POP 013 - Cadastro de Fornecedores 
Figura 54. Cópia ilustrativa do Cadastro de Fornecedores (ANEXO 1) do POP 013 - Cadastro

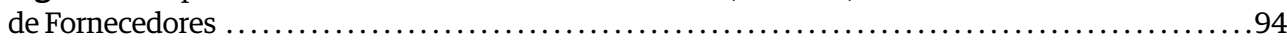

Figura 55. Cópia ilustrativa do POP 014 - Controle das Não Conformidades ................... 96

Figura 56. Cópia ilustrativa de uma página do Relatório de Não Conformidade (ANEXO 1)

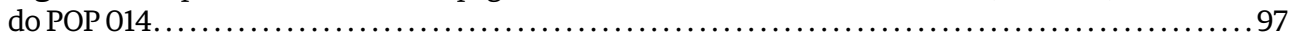

Figura 57. Cópia ilustrativa do POP 012 - Auditoria ..................................... 99

Figura 58. Cópia ilustrativa de uma página do Relatório de Auditoria (ANEXO 1) do POP 012 -

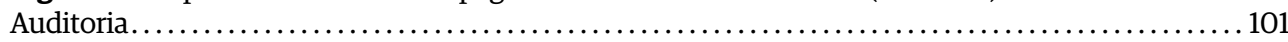

Figura 59. Cópia ilustrativa de uma página do Monitoramento de Auditoria (ANEXO 2) do

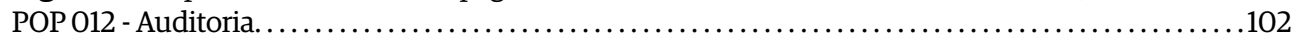

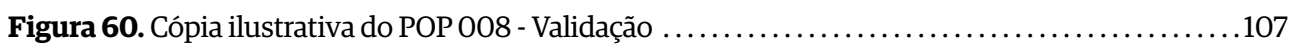

Figura 61. Cópia ilustrativa do POP 007 - Verificação de Balanças ........................... 112

Figura 62. Cópia ilustrativa de uma página do Registro de Gerenciamento da Balança x*.......... 115

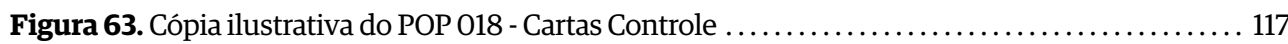

Figura 64. Cópia ilustrativa do Registro de Controle Estatístico (ANEXO 2) do POP 018 -

Cartas Controle.................................................................. 121

Figura 65. Cópia ilustrativa de uma página da Planilha de Carta Controle (ANEXO 3)

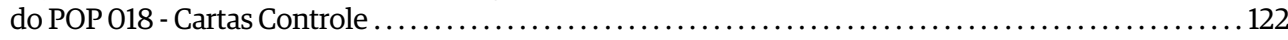

Figura 66. Cópia ilustrativa do POP 006 - Descarte de Resíduos Químicos ...................... 135

Figura 67. Cópia ilustrativa do Anexo 1 - Diagrama de Perigo do POP 006 - Descarte de

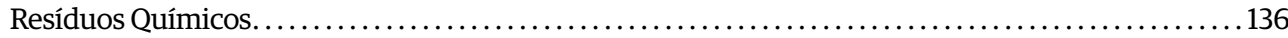

Figura 68. Cópia ilustrativa do POP 009 - Limpeza de Vidraria........................... 137 


\section{Lista de Tabelas}

Tabela 1. Relação dos Procedimentos Operacionais Padrão (POP) adotados pelo LQA-IQSC-USP ..... 9

Tabela 2. Pesquisadores internos ao LQA: objetivos do cargo e respectivas funções . . . . . . . . . . . . 14 


\title{
Lista de Abreviaturas
}

\author{
AM: Agenda mestra \\ BPL: Boas práticas de laboratório \\ CI: Cartilha do ingressante \\ CR: Controle de registros \\ DA: Diretora acadêmica \\ GQ: Gerente da qualidade \\ GT: Gerente técnica \\ ID: Identificação \\ IO: Instrução operacional
}

IQSC: Instituto de Química de São Carlos

LAI: Local de armazenamento de insumos

LMP: Lista mestra de procedimentos

LQA: Laboratório de Química Ambiental

LR: Lista de reagentes

LRQ: Laboratório de Resíduos Químicos

LMR: Lista de materiais de referência

MDPSQ: Mapa de distribuição dos procedimentos do sistema da qualidade

ME: Método de ensaio

MEII: Modelo de etiqueta de identificação de insumos

MEIS: Modelo de etiqueta de identificação de soluções

MEIIV: Modelo de etiqueta de identificação de insumos vencidos

POP: Procedimento operacional padrão

RCG: Registro de controle de gases

RCMR: Registro de controle de materiais de referência

RCR: Registro de controle de reagentes

RE: Relatório de ensaio

RIP: Relatório de inspeção de produtos

RIS: Relatório de inspeção de serviços

RNC: Relatório de não conformidade

SC: Solicitação de compra

TC: Termo de conhecimento

TCP: Termo de conduta profissional

TD: Termo de desligamento

TPE: Treinamento de pessoas externas

USP: Universidade de São Paulo 


\section{Sumário}

1 Prefácio

3 Apresentação

7 CAPÍTULO 1

Estrutura do Sistema

de Gestão da Qualidade

17 CAPÍtulo 2

Procedimentos Necessários

dentro do Sistema de Gestão

da Qualidade

105 CAṔ́tulo 3

Controle da Qualidade

133 CAPÍTULO 4

Limpeza de Vidraria e Descarte de Resíduos Químicos

139 CAPÍtulo 5

Epílogo 


\section{Prefácio}

Prof. Dr. Igor Renato Bertoni Olivares

A gestão de qualidade deixou de ser apenas uma tendência para os laboratórios de rotina e se tornou praticamente uma obrigatoriedade para várias áreas de atuação laboratorial. Considerando os últimos 10 anos, podemos notar um aumento de $600 \%$ no número de laboratórios acreditados na norma ISO/IEC 17025 no Brasil (atualmente, com cerca de 1.200 laboratórios), um valor bastante expressivo quando consideramos um aumento de $100 \%$ nas acreditações dos mais de 112 países que apresentam acordo de reconhecimento mútuo de acreditação com o ILAC (International Laboratory Accreditation Cooperation), o qual conta, na atualidade, com aproximadamente 50 mil laboratórios.

A obrigatoriedade na adoção de um sistema de gestão de qualidade para laboratórios se faz devido ao impacto que um resultado analítico pode proporcionar no diagnóstico de uma área contaminada, no controle de qualidade dos medicamentos, na análise forense, entre outros. Dessa maneira, inúmeros órgãos reguladores criam legislações as quais obrigam a adoção de sistemas de gestão de qualidade pelos laboratórios. Podemos citar, por exemplo: órgãos estaduais, como a Secretaria de Meio Ambiente do Estado de São Paulo (para laboratórios ambientais), federais, como o Ministério da Agricultura, Pecuária e Abastecimento (para laboratórios de alimentos), e até internacionais, como o World Anti-Doping Agency (para laboratórios de doping nos jogos olímpicos).

Atualmente, os laboratórios de pesquisa sofrem a mesma pressão devido ao impacto que suas pesquisas podem proporcionar. Discussões sobre a baixa reprodutibilidade dos experimentos publicados em artigos científicos pressionam os pesquisadores a ter um maior controle no desenvolvimento das atividades de seus laboratórios, o qual pode ser realizado com a aplicação de conceitos de sistemas de gestão de qualidade. A integral adoção de normas, como a ISO/IEC 17025 ou as BPL (Boas Práticas de Laboratório) para laboratórios de pesquisa, muitas vezes pode não ser adequada por causa de características particulares desses tipos de laboratório. Dessa maneira, este livro traz uma proposta prática embasada na experiência de um laboratório renomado em pesquisa, o qual tem aplicado os conceitos de gestão de qualidade por vários anos. Assim, o leitor poderá compartilhar dessa experiência, a qual envolve a estrutura do sistema de gestão de qualidade desenvolvido (capítulo 1 ), os procedimentos adotados (capítulo 2) e uma abordagem de procedimentos técnicos dolaboratório (capítulos 3e 4). Com uma linguagem simples e prática, este livro pode ser uma boa ferramenta para pesquisadores que desejam dar seus primeiros passos na adoção de sistemas de gestão de qualidade em seus laboratórios, buscando, cada vez mais, a confiabilidade e a rastreabilidade de seus resultados! 


\section{Apresentação}


Este texto refere-se à implantação de um Sistema de Gestão da Qualidade no Laboratório de Química Ambiental do Instituto de Química de São Carlos da Universidade de São Paulo (LQA-IQSC-USP). OLQA-IQSC-USPéum laboratório de pesquisa que recebe alunos que desenvolvem suas pesquisas experimentais com a finalidade de complementar seus estudos na graduação, com estágios e desenvolvimento de projetos de iniciação científica, e alunos que buscam a obtenção de títulos de mestre e doutor, além de estagiários de pós-doutorado. Pode-se afirmar que a rotatividade de pesquisadores é grande: permanência que se estende de dias a cerca de três a quatro anos. Formar os pesquisadores dentro de um Sistema de Gestão da Qualidade, considerando-se essa curta permanência (aténos casos de quatro anos!!!), é uma tarefa hercúlea. Para que o Sistema de Gestão da Qualidade seja cumprido, as pessoas devem ser orientadas e treinadas e devem, sobremaneira, compreender que o Sistema de Gestão da Qualidade visa, acima de tudo, a facilitar a melhoria constante das pesquisas.

A organização facilita a vida. No entanto, a entropia do universo aumenta. Isso significa que um laboratório organizado tende a se desorganizar à medida que os pesquisadores trabalham. Meu interesse como coordenadora do LQA-IQSC-USP e como orientadora das pesquisas aqui desenvolvidas é manter o laboratório organizado e altamente produtivo; assim, quanto mais pesquisadores em contínua atividade, melhor será. Busco mais trabalho e mais organização, o que parece antagônico.

Há, ainda, as frases (errôneas) de efeito, como "um laboratório organizado é sinal de pouca atividade" ou "eu entendo a minha bagunça". Na prática não é assim. Perde-se tempo e dinheiro se não há organização. Pior: não há rastreabilidade nos resultados se não existe organização. E sem rastreabilidade não se faz ciência!!!!

Vamos pensar em entropia negativa, então! Um bom sinônimo para 'entropia negativa' é 'informação'. Quanto mais informação, menos desordem. O adjetivo negativo aqui empregado serve para que mudemos o paradigma, para que nosso cérebro possa mudar o pensamento, mudar o estágio de 'caos' para 'informação' (e quanto mais informação, menos desordem!).

O Instituto de Química de São Carlos (IQSC) tem, em seu currículo de bacharelado, várias disciplinas que contemplam conteúdos sobre sistemas de qualidade. Por exemplo, temos 'Ferramentas da qualidade', 'Introdução à gestão da qualidade em química', 'Sistema NBR ISO/ IEC 17025', 'Sistemas de gestão aplicados à área de saúde e meio ambiente'. Ademais, desde o início de 2015, quando do ingresso do aluno na pós-graduação, ele recebe um 'Caderno de Anotações Experimentais' cujo objetivo é "facilitar o acesso às informações e novos conhecimentos gerados no âmbito do programa de pós-graduação do IQSC, bem como permitir o acompanhamento periódico pelo orientador". Cada caderno, após completo, fica de posse do laboratório e do grupo de pesquisa. Na Figura 1, encontra-se uma foto da capa e da contracapa do referido caderno.

Este texto descreve, então, nossa vivência no que se refere à gestão da qualidade aplicada a um laboratório de pesquisa. Essa vivência vai desde a implantação do Sistema de Gestão da Qualidade até sua manutenção cotidiana, levando em conta a volatilidade do corpo discente do próprio laboratório e dos pesquisadores externos que se utilizam eventualmente da infraestrutura do LQA-IQSC-USP para realizar suas atividades de pesquisa e de extensão.

O Sistema de Gestão da Qualidade aqui descrito e seguido tem por base a norma ABNT NBR ISO/IEC 17025:2005 e os princípios das Boas Práticas de Laboratório adaptados à rotina diária de um laboratório de pesquisa.

O objetivo deste texto é facilitar a implementação e a manutenção de um Sistema de Gestão da Qualidade em um laboratório com parecidas especificidades e, assim, pular várias etapas de tentativa e erro. 
Figura 1. Foto da capa (A) e da contracapa (B) do 'Caderno de Anotações Experimentais'. No segundo parágrafo da contracapa, lê-se: “Caderno com valor legal, que pode ser exigido em disputas de patentes e propriedade intelectual. Mais do que isso, é um instrumento de ética e boa conduta científica. Por esses motivos, não é recomendada sua remoção, mesmo que temporária, do laboratório ou grupo de pesquisa".
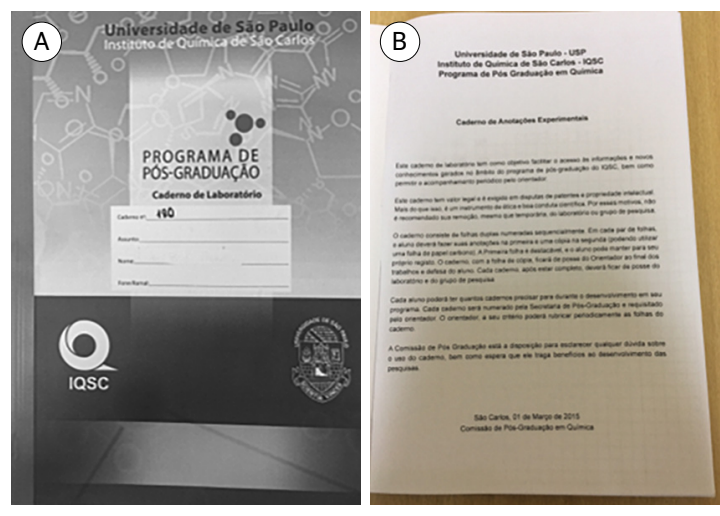

Após anos de trabalho construindo o Sistema de Gestão da Qualidade fundamentado na norma ABNT NBR ISO/IEC 17025:2005, chegamos à conclusão de que, para um laboratório de pesquisa, como é este o caso, é inviável seguir a referida norma em sua totalidade. As dificuldades encontradas foram a complexidade do cálculo da estimativa da incerteza de medição em cromatografia, o tempo necessário para aplicação e monitoramento da qualidade, o excesso de documentos gerados e a gestão de pessoas.

Vale salientarmos que o LQA-IQSC-USP, além de suas atividades de pesquisa, exerce atividades de extensão, as quais se relacionam, na maioria das vezes, à consultoria a outros pesquisadores e a clientes que nos procuram para prestação de serviços a empresas ligadas à fabricação de fertilizantes orgânicos e à qualidade de águas e solos. Seguindo-se restritamente a norma ISO 17025, o conflito de interesse gerado limitaria as atividades do laboratório.

Em nosso laboratório, a comunicação com o cliente acontece com o mesmo pesquisador que executa as análises, pois nossos clientes procuram na universidade um serviço muito além de um resultado - eles querem discutir com quem tem experiência/conhecimento na área.

OLQA-IQSC-USP não se restringe apenas à apresentação de resultados; vai muito além disso: desenvolvimento de novas metodologias, avaliação e adaptação de metodologias já em uso etc.

Assim, este texto foi elaborado com base em nossa experiência, adaptando os requisitos da norma ISO 17025 e os princípios das Boas Práticas de Laboratório à rotina diária desse laboratório de pesquisa. O documento ABNT NBR ISO/IEC 17025:2005 foi utilizado aqui como modelo. Todos os itens foram adaptados para a rotina do laboratório.

Apresentamos este texto como um modelo viável de implantação e manutenção de um Sistema de Gestão da Qualidade adaptado para um laboratório de pesquisa inserido em uma instituição de ensino superior.

Ousamos transcrever e, assim, disponibilizar todos os documentos do Sistema de Gestão da Qualidade, pois nosso objetivo é fazer com que este texto seja usado e abusado. Na literatura, encontram-se bons livros e artigos descrevendo com precisão os fundamentos de um Sistema de Gestão da Qualidade e os benefícios de sua aplicação. No entanto, após a leitura criteriosa 
de vários desses textos, eu sempre ficava em dúvida do como começar, como escrever, o que contemplar mais ou menos enfaticamente etc. Nada melhor do que começar: primeiro feito, depois (se possível) perfeito. Por isso escrevi 'ousamos'. Todos os documentos que escrevemos e que aplicamos na nossa rotina diária estão aqui para serem lidos e criticados e, o que nos daria grande satisfação, usados.

Este texto pode ser lido a começar pela Apresentação e seguir por sua ordem natural ou por qualquer capítulo (por isso, às vezes, alguns parágrafos se repetem). Se, ainda, o leitor preferir, pode começar pelo “Capítulo 5 - Epílogo" eir seguindo a leitura conforme a 'pesquisa caminha'. 
CAPÍTULO 1

\section{Estrutura do Sistema de Gestão da Qualidade}


Neste capítulo, são apresentados os procedimentos operacionais padrão que compõem o sistema de gestão, assim como a importância do Manual da Qualidade, no que se refere à missão e à política do laboratório e sua correspondência com a norma ABNT NBR ISO/IEC 17025:2005 e com os Princípios das Boas Práticas de Laboratório - BPL.

OSistema de Gestão da Qualidade implantado noLQA-IQSC-USP teve como base os documentos reportados na ABNT NBR ISO/IEC 17025:2005 - Requisitos gerais para a competência de laboratórios de ensaio e calibração; no VIM (Vocabulário internacional de termos fundamentais e gerais de metrologia)- Portaria INMETRO número29, de10 de março de 1995, emitido por BIPM, IEC, IFCC, ISO, IUPAC, IUPAP e OIML; e nos Princípios das Boas Práticas de Laboratório - BPL.

O uso da norma ABNT NBR ISO/IEC 17025:2005 “facilita a cooperação entre laboratórios e outros organismos, auxiliando na troca de informação e experiência e na harmonização de normas e procedimentos", conforme reportado na introdução da referida norma.

OLQA-IQSC-USP realiza suas atividades com base nos conceitos da norma ABNT NBR ISO/IEC 17025:2005, além de conceitos de BPL.

\subsection{Sistema de Gestão da Qualidade Implantado no LQA-IQSC-USP}

\subsubsection{Procedimentos Operacionais Padrão}

O objetivo geral de se adotar um Procedimento Operacional Padrão é seguir um protocolo que nos auxilie a reproduzir um resultado. Sempre pensando que oLQA-IQSC-USP, reportado como LQA daqui em diante, é um laboratório de pesquisa cuja missão, em primeiro lugar, 'é formar profissionais que possam atuar como pesquisadores independentes', é lícito e esperado supor que determinado procedimento possa ser modificado com vistas à melhoria constante, o que vem ao encontro da nossa política da qualidade: 'O Laboratório de Química Ambiental busca a melhoria constante dos processos operacionais, tecnológicos, científicos e de gestão, graças à excelência de nossas pesquisas, tendo como objetivo foco incentivar o desenvolvimento das competências de nossos pesquisadores'. No entanto, cada modificação - após testada - deve ser anotada para garantir a rastreabilidade de todos os procedimentos.

NoLQA, adotamos 20 Procedimentos Operacionais Padrão(POP), discriminados na Tabela1, assim como os objetivos de cada um deles.

\subsubsection{Estrutura dos Formulários}

Para a elaboração dos POPs, segue-se uma estrutura preestabelecida, a qual também é documentada em um procedimento operacional padrão: POP 004 - Estrutura de POP F Formulários (Figura 2). 
Tabela 1. Relação dos Procedimentos Operacionais Padrão (POP) adotados pelo LQA-IQSC-USP

\begin{tabular}{|c|c|c|}
\hline Número & Nome & Objetivo \\
\hline POP 001 & Equipamentos & $\begin{array}{l}\text { Estabelecer a sistemática para manutenção, identificação, elaboração } \\
\text { de registros e instruções operacionais para equipamentos do LQA. }\end{array}$ \\
\hline POP 002 & $\begin{array}{l}\text { Manuseio de materiais } \\
\text { de referência e preparo } \\
\text { de soluções estoque }\end{array}$ & $\begin{array}{l}\text { Estabelecer a sistemática para o manuseio de materiais de referência e } \\
\text { preparo de soluções estoque. }\end{array}$ \\
\hline POP 003 & Agenda mestra & $\begin{array}{l}\text { Estabelecer a sistemática para o registro e controle de observações } \\
\text { originais e dados derivados. }\end{array}$ \\
\hline POP 004 & $\begin{array}{l}\text { Estrutura de POPs e } \\
\text { formulários }\end{array}$ & $\begin{array}{l}\text { Estabelecer a sistemática para emissão, elaboração, correção, revisão, } \\
\text { arquivamento e descarte de Procedimentos Operacionais Padrão - POP } \\
\text { e Formulários. }\end{array}$ \\
\hline POP 005 & Limpeza do LQA & Estabelecer a sistemática para limpeza das instalações do LQA. \\
\hline POP 006 & $\begin{array}{l}\text { Descarte de resíduos } \\
\text { químicos }\end{array}$ & $\begin{array}{l}\text { Estabelecer a sistemática para o descarte dos resíduos químicos } \\
\text { gerados no laboratório durante a rotina diária e de pesquisa do LQA, } \\
\text { assim como o descarte das amostras contaminadas. }\end{array}$ \\
\hline POP 007 & Verificação de balanças & $\begin{array}{l}\text { Estabelecer a sistemática para a análise crítica da verificação de } \\
\text { balanças. }\end{array}$ \\
\hline POP 008 & Validação & Estabelecer a sistemática para construção de curvas de calibração. \\
\hline POP 009 & Limpeza de vidraria & $\begin{array}{l}\text { Estabelecer a sistemática para limpeza de vidrarias e garantir que a } \\
\text { limpeza não acrescente interferentes nos resultados analíticos. }\end{array}$ \\
\hline POP 010 & $\begin{array}{l}\text { Aquisição de serviços e } \\
\text { de suprimentos }\end{array}$ & Estabelecer a sistemática para aquisição de serviços e de suprimentos. \\
\hline POP 011 & Insumos & $\begin{array}{l}\text { Estabelecer a sistemática para identificação, registros de controle } \\
\text { e armazenamento de materiais de referência, reagentes, gases e } \\
\text { soluções. }\end{array}$ \\
\hline POP 012 & Auditoria & $\begin{array}{l}\text { Estabelecer a sistemática para realização das auditorias e seu } \\
\text { monitoramento. }\end{array}$ \\
\hline POP 013 & $\begin{array}{l}\text { Cadastro de } \\
\text { fornecedores }\end{array}$ & Estabelecer a sistemática de cadastro de fornecedores. \\
\hline POP 014 & $\begin{array}{l}\text { Controle das não } \\
\text { conformidades }\end{array}$ & $\begin{array}{l}\text { Estabelecer a sistemática de controle das não conformidades oriundas } \\
\text { do Sistema da Qualidade. }\end{array}$ \\
\hline POP 015 & Pesquisa externa & Estabelecer a sistemática para planejamento da pesquisa externa. \\
\hline POP 016 & Métodos de ensaio & $\begin{array}{l}\text { Estabelecer a sistemática para a estruturação e formatação dos } \\
\text { métodos de ensaio. }\end{array}$ \\
\hline POP 017 & Prestação de serviço & $\begin{array}{l}\text { Estabelecer a sistemática para análise crítica das propostas, pedidos e } \\
\text { contratos de prestação de serviço e pesquisa de outros laboratórios. }\end{array}$ \\
\hline POP 018 & Cartas controle & $\begin{array}{l}\text { Estabelecer a sistemática para elaboração e análise crítica de cartas } \\
\text { controle. }\end{array}$ \\
\hline POP 019 & Responsabilidades & $\begin{array}{l}\text { Identificar as responsabilidades de cada cargo, orientações de conduta } \\
\text { ética profissional e estabelecer a sistemática de identificação das } \\
\text { necessidades de treinamento do pessoal. }\end{array}$ \\
\hline POP 020 & $\begin{array}{l}\text { Planejamento da } \\
\text { pesquisa }\end{array}$ & $\begin{array}{l}\text { Dar condições para o desenvolvimento de um projeto de pesquisa que } \\
\text { possa ser divulgado cientificamente e que promova a formação de } \\
\text { pessoas. }\end{array}$ \\
\hline
\end{tabular}


Figura 2. Cópia ilustrativa do POP 004 - Estrutura de POP e Formulários

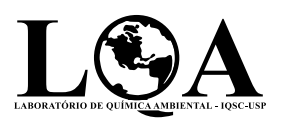

ESTRUTURA DE POP E FORMULÁRIOS

POP 004

REV: X FL 1 DE 1

DATA $/ / 20$

\section{OBJETIVO}

1.1 Estabelecer a sistemática para emissão, elaboração, correção, revisão, arquivamento e descarte de Procedimentos Operacionais Padrão (POP) e Formulários.

\section{PROCEDIMENTO}

2.1 Emissão de POPs, IOs e MEs

2.1.1 Adota-se o Modelo de Procedimento Operacional Padrão - MPOP (ANEXO 1) para a estruturação e formatação de procedimentos operacionais padrão.

2.1.2 Adota-se o POP 001 - Equipamentos para as instruções de elaboração de IOs.

2.1.3 Adota-se o POP 016 - Métodos de Ensaio para as instruções de elaboração de MEs.

2.2 Formulários

2.2.1 Adota-se o Modelo de Formulário - MF (ANEXO 2) para a formatação de formulários.

2.3 Alteração em Registros

2.3.1 Alterações em registros só são realizadas quando ocorre um erro de preenchimento.

2.3.2 Alterações em registros em papel: os erros são tachados. A informação correta é colocada ao lado, com data e rubrica do responsável pela alteração.

2.4 Alteração em Formulários ou POPs

2.4.1 O gerente técnico é responsável pela elaboração dos documentos referentes aos requisitos técnicos, e o gerente da qualidade, pela elaboração dos documentos referentes aos requisitos da direção. Todos os documentos devem ser aprovados pela Alta Direção.

2.4.2 Alterações na estrutura do formulário ou POP deverão ser feitas de modo a tachar o erro e inserir a correção ao lado em negrito e itálico. Alteram-se o número da revisão e a data no cabeçalho.

2.5 Arquivamento, armazenamento e descarte de registros

2.5.1 Um registro não se torna obsoleto. Depois de preenchido, ele é mantido por tempo pré-determinado. O local de armazenamento de registros obsoletos é o Armário de Registros Obsoletos.

2.5.2 A Lista Mestra de Procedimentos - LMP (ANEXO 3) é uma relação de todos os POPs do laboratório e o status de sua revisão, necessária para o controle e para evitar o uso de documentos obsoletos. A LMP encontra-se afixada em uma das paredes do laboratório 1.

2.5.3 O Mapa de Distribuição dos Procedimentos do Sistema de Qualidade - MDPSQ (ANEXO 4) contém a relação dos locais de armazenamento dos Procedimentos Operacionais Padrão, assim como a definição de responsáveis por cada documento da qualidade. O MDPSQ encontra-se afixado em uma das paredes do laboratório 1.

2.5.4 Lista Mestra de Documentos - LMD (ANEXO 5) controla documentos externos e, assim, evita o uso de documentos obsoletos. A LMD encontra-se afixada em uma das paredes do laboratório 1.

2.6 Controle de Registros

2.6.1 O ANEXO 6 - Controle de Registros (CR) contém informações referentes a todos os registros gerados no LQA. Essas informações são procedimentos operacionais padrão relacionados a cada registro, responsável pelo registro, tempo de retenção, local de disposição final, forma de disponibilização do registro e sua denominação. O CR encontra-se afixado em uma das paredes do laboratório 1.

\section{APROVAÇÕES}

\begin{tabular}{|l|l|l|}
\hline Autor & Aprovado / Assinatura & Data \\
\hline & & \\
\hline
\end{tabular}


Assim, todos os procedimentos operacionais seguem uma padronização, o que torna o Sistema de Gestão da Qualidade mais eficiente e mais agradável visualmente.

\subsubsection{Manual da Qualidade}

O Manual da Qualidade seguido pelo LQA foi elaborado após anos de trabalho construindo o Sistema de Gestão da Qualidade fundamentado na norma ABNT NBR ISO/IEC 17025:2005 e nos Princípios das Boas Práticas de Laboratório. Chegamos à conclusão de que, para um laboratório de pesquisa, como é este o caso, é inviável seguir a referida norma em sua totalidade. As dificuldades encontradas foram a complexidade do cálculo da estimativa da incerteza de medição em cromatografia, o tempo necessário para aplicação e monitoramento da qualidade, o excesso de documentos gerados e a gestão de pessoas.

Vale salientarmos que o LQA, além de suas atividades de pesquisa, exerce atividades de extensão, as quais se relacionam, na maioria das vezes, à consultoria a outros pesquisadores e a clientes interessados na prestação de serviços a empresas ligadas à fabricação de fertilizantes orgânicos e à qualidade de águas e solos. O LQA tem como principal responsabilidade ajudar a comunidade não somente com os resultados, mas também com consultoria a respeito dos métodos, descarte adequado etc., sempre com base nos preceitos da química verde. De acordo com a norma NBR ISO/IEC 17025, o analista deve estar livre de qualquer pressão por parte do cliente para que a confiança dos resultados não seja afetada. Porém, na rotina de um laboratório de pesquisa, esse conflito de interesse inviabiliza o trabalho realizado pela pesquisa desenvolvida nesse segmento.

Em nosso laboratório, a comunicação com o cliente acontece com o mesmo pesquisador que executa as análises, pois nossos clientes procuram na universidade um serviço muito além de um resultado - eles querem discutir com quem tem experiência/conhecimento na área.

O LQA não se restringe apenas à apresentação de resultados; vai muito além disso. As atividades do LQA incluem desenvolvimento de novas metodologias, avaliação e adaptação de metodologias já em uso etc.

Assim, nosso Manual da Qualidade foi elaborado com base na nossa experiência, adaptando os requisitos da norma ISO 17025 e os princípios das Boas Práticas de Laboratório à rotina diária desse laboratório de pesquisa. O documento ABNT NBR ISO/IEC 17025:2005 foi utilizado aqui como modelo. Todos os itens foram adaptados para a rotina do laboratório. Na Figura 3 , apresentamos o sumário do referido Manual.

O objetivo do Manual da Qualidadeé especificar os requisitos gerais para a competência em realizar pesquisas visando à divulgação científica, à formação de pessoas e ao aprimoramento constante do Sistema de Gestão da Qualidade e das operações técnicas e administrativas.

\subsubsection{Organograma}

O Laboratório de Química Ambiental está alocado no Departamento de Química e Física Molecular do Instituto de Química de São Carlos da Universidade de São Paulo. A representação gráfica da posição do LQA e de cada um de seus membros dentro da estrutura da USP é representada nas Figuras 4A e 4B.

Conforme ilustrado na Figura 4B, no LQA, no que se refere à pesquisa, desenvolvimento e extensão, a equipe é constituída por diretor acadêmico, gerente técnico, gerente da qualidade, graduandos e pós-graduandos. Para a manutenção de um Sistema de Gestão da Qualidade, é mandatória a figura do gerente da qualidade.

Na Tabela 2, ilustram-se os objetivos e as funções de cada pesquisador. 
Figura 3. Sumário do Manual da Qualidade utilizado no LQA-IQSC-USP

APROVAÇÃO DO MANUAL

APRESENTAÇÃO

REQUISITOS GERAIS DO LABORATÓRIO DE QUÍMICA AMBIENTAL

\section{OBJETIVO}

\section{REFERÊNCIAS NORMATIVAS}

\section{TERMOS E DEFINIÇÕES}

\section{REQUISITOS DA DIREÇÃO}

4.1 Organização

4.2 Sistema de gestão da qualidade

4.3 Controle de documentos

4.4 Análise crítica dos pedidos, propostas e contratos

4.5 Subcontratação

4.6 Aquisição de serviços e de suprimentos

4.7 Atendimento ao cliente

4.8 Reclamações

4.9 Controle das não conformidades

4.10 Melhoria

4.11 Ação corretiva

4.12 Ação preventiva

4.13 Controle de registros

4.14 Auditorias

4.15 Análise crítica pela direção

4.16 Planejamento de pesquisa e divulgação científica

\section{REQUISITOS TÉCNICOS}

5.1 Generalidades

5.2 Pessoal

5.3 Acomodações e condições ambientais

5.4 Métodos de ensaio e validação de métodos

5.5 Equipamentos

5.6 Rastreabilidade da medição

5.7 Amostragem

5.8 Manuseio de amostras

5.9 Garantia da qualidade de resultados de ensaios

5.10 Apresentação de resultados

5.11 Limpeza de vidraria

5.12 Descarte de resíduos 


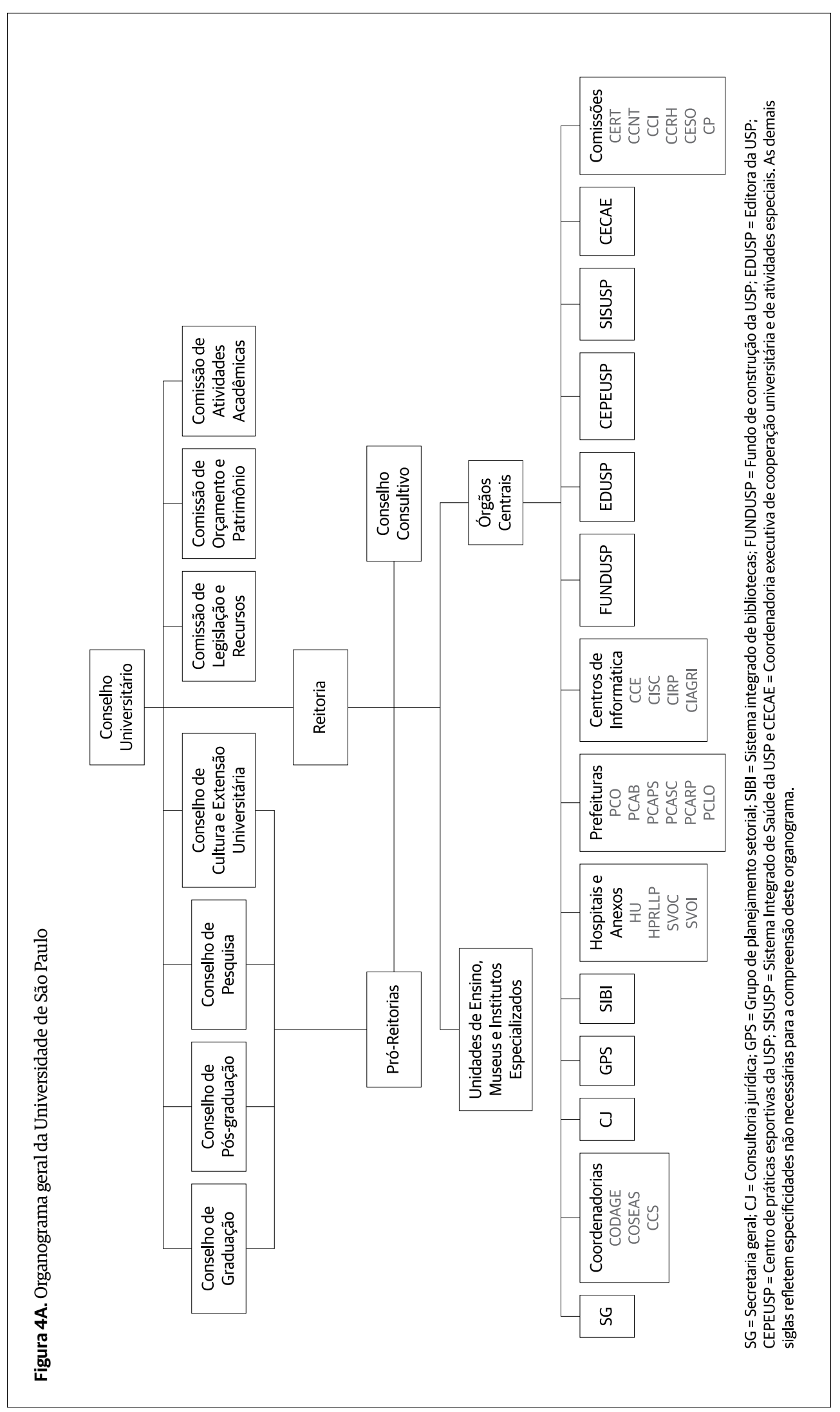


Figura 4B. Organograma do Laboratório de Química Ambiental do Departamento de Química e Física Molecular do Instituto de Química de São Carlos da Universidade de São Paulo

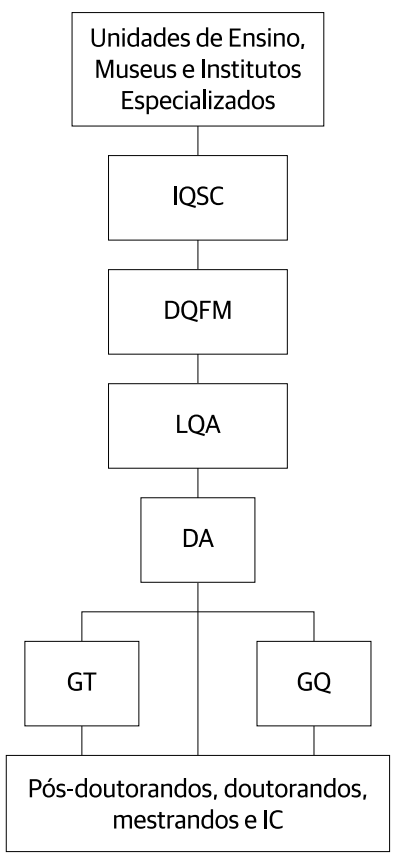

IQSC = Instituto de Química de São Carlos; DQFM = Departamento de Química e Física Molecular; LQA = Laboratório de Química Ambiental; DA = Diretora acadêmica; $\mathrm{GT}$ = Gerente técnico e GQ = Gerente da qualidade.

Tabela 2. Pesquisadores internos ao LQA: objetivos do cargo e respectivas funções

\section{DIRETORA ACADÊMICA}

\section{OBJETIVOS DO CARGO}

- Planejar e coordenar o trabalho científico e de extensão desenvolvido no laboratório, incluindo escolha de linhas de pesquisa e adoção, desenvolvimento e validação de metodologias; orientar os pesquisadores a escrever; coordenar projetos; supervisionar os pesquisadores dentro do Sistema de Gestão da Qualidade; verificar os resultados e relatar opiniões e interpretações nos Relatórios de Ensaio.

\section{DESCRIÇÃO DAS FUNÇÕES}

- Geral: gerir os recursos financeiros do laboratório; buscar e desenvolver novas metodologias; manter-se atualizada em relação às legislações pertinentes; manter relação direta com os gerentes técnico e da qualidade; supervisionar os trabalhos realizados no LQA em relação ao Sistema de Gestão da Qualidade; acompanhar as auditorias.

- Prestar consultoria científica à comunidade; ter disponibilidade para sanar dúvidas relacionadas ao trabalho; supervisionar e conferir Relatórios de Ensaio; emitir opiniões e interpretações.

- Pesquisa: escrever, coordenar e desenvolver projetos para angariar recursos financeiros; orientar os pesquisadores; manter-se atualizada quanto às linhas de pesquisa similares às desenvolvidas no LQA; manter contato com outros pesquisadores desta e de outras instituições.

- Prestação de serviço: construir um relacionamento com os clientes; discutir com os gerentes técnico e da qualidade os Relatórios de Ensaio; garantir a confidencialidade dos resultados. 
Tabela 2. Continuação...

\section{GERENTE TÉCNICA}

\section{OBJETIVOS DO CARGO}

- Supervisionar e auxiliar todos os pesquisadores em suas atividades de pesquisa dentro do Sistema de Gestão da Qualidade.

\section{DESCRIÇÃO DAS FUNÇÕES}

- Geral: supervisionar os pesquisadores e prover auxílio para a execução das atividades de ensaio dentro dos procedimentos do Sistema de Gestão da Qualidade; controlar os processos de compra de produtos e serviços, mantendo contato com fornecedores e com a contabilidade terceirizada; monitorar o estoque de reagentes e materiais; fiscalizar o descarte adequado das amostras e dos resíduos químicos gerados; manter relação direta com o diretor acadêmico e o gerente da qualidade; acompanhar as auditorias e realizar as auditorias internas, desde que sejam em áreas diferentes daquelas de sua atuação.

Pesquisa: manter-se atualizada em relação às linhas de pesquisa similares às desenvolvidas no LQA; manter contato com outros pesquisadores desta e de outras instituições.

- Prestação de serviço: construir um relacionamento com os clientes; emitir contratos de prestação de serviço; receber amostras, realizar e/ou supervisionar os ensaios; emitir os Relatórios de Ensaio; garantir a confidencialidade dos resultados.

\section{GERENTE DA QUALIDADE}

\section{OBJETIVOS DO CARGO}

- Manter e aprimorar o Sistema de Gestão da Qualidade, monitorando as atividades do laboratório, de modo a assegurar que estas sejam executadas de acordo com o Sistema de Gestão da Qualidade implantado.

\section{DESCRIÇÃO DAS FUNÇÕES}

- Supervisionar o trabalho dos pesquisadores durante a rotina e assegurar a manutenção do Sistema de Gestão da Qualidade; com base nos registros gerados e na análise crítica pela gerência, aprimorar continuamente o Sistema de Gestão da Qualidade; acompanhar e planejar as auditorias; manter-se atualizado quanto às legislações relacionadas ao Sistema de Gestão da Qualidade; manter relação direta com a diretora acadêmica e a gerente técnica; discutir com a diretora acadêmica e com a gerente técnica os Relatórios de Ensaio; garantir a confidencialidade dos resultados.

\section{Pós-doutorandos}

\section{OBJETIVOS DO CARGO}

- Desenvolver pesquisa junto ao LQA, cooperando com o Sistema de Gestão da Qualidade.

\section{DESCRIÇÃO DAS FUNÇÕES}

- Desenvolver pesquisas próprias que gerem o maior número possível de publicações internacionais; dar suporte às atividades de orientação de alunos de iniciação científica (IC), de mestrandos e de doutorandos e às atividades didáticas.

\section{Mestrandos e Doutorandos}

\section{OBJETIVOS DO CARGO}

- Desenvolver pesquisa junto ao LQA, cooperando com o Sistema de Gestão da Qualidade.

\section{DESCRIÇÃO DAS FUNÇÕES}

- Desenvolver pesquisas determinadas pela diretora acadêmica dentro do Sistema de Gestão da Qualidade; dar suporte às atividades didáticas quando requeridos.

- Mestrandos: desenvolver pesquisa que resulte em dissertação; publicar pelo menos um artigo, preferencialmente em revista internacional, para a defesa de dissertação. 
Tabela 2. Continuação...

- Doutorandos: desenvolver pesquisa que resulte em tese; publicar pelo menos dois artigos, preferencialmente em revista internacional, para a defesa de tese; auxiliar na orientação de alunos de IC e estagiários.

\section{Estagiários e IC}

OBJETIVOS DO CARGO

Participar de pesquisa junto ao LQA, cooperando com o Sistema de Gestão da Qualidade.

\section{DESCRIÇÃO DAS FUNÇÕES}

- Auxiliar nas atividades do laboratório, conforme orientação da gerente técnica; auxiliar nas atividades de pesquisa de pesquisadores de mestrado, doutorado ou pós-doutorado, conforme orientação da diretora acadêmica.

A estrutura do Sistema de Gestão da Qualidade baseia-se nos procedimentos operacionais padrão e no Manual da Qualidade. A seguir, são apresentados os procedimentos necessários para implementação e manutenção do Sistema de Gestão da Qualidade utilizado no LQA. 


\section{CAPÍTULO 2}

\section{Procedimentos \\ Necessários dentro do \\ Sistema de Gestão \\ da Qualidade}


Neste capítulo, apresentamos as responsabilidades dos membros do LQA e discutimos os procedimentos necessários ao Sistema de Gestão da Qualidade, ou seja, os registros que devem ser mandatoriamente observados para garantir a rastreabilidade dos resultados. Especial ênfase é dada à agenda mestra, assim como ao controle de documentos e ao registro dos dados brutos.

\title{
2.1 Agenda Mestra
}

\begin{abstract}
A Agenda Mestra - AM - é o documento de anotações do pesquisador. É na AM que os pesquisadores do LQA reportam a rotina da pesquisa, devendo ser preenchida antes do início do trabalho experimental. Para seu correto preenchimento, é necessário reunir, primeiramente, os formulários referentes a cada equipamento ou material. Cabe aqui ressaltarmos a diferença entre formulário e registro. Registro é um formulário completo, ou melhor, formulário é um registro em branco. Nos formulários, são registrados os dados brutos ou as informações referentes ao equipamento, procedimento ou método. No caderno do pesquisador, são registrados os dados brutos. Como caderno do pesquisador entende-se qualquer caderno/bloco/agenda etc. intitulado como caderno do pesquisador. Em nosso caso, aconselhamos fortemente a utilizar o 'Caderno de Anotações Experimentais' disponibilizado pelo IQSC (Figura 1). Como ilustração, segue o POP 003 - Agenda Mestra (Figura 5) e uma página do formulário da Agenda Mestra (Figura 6).

Podemos afirmar que a Agenda Mestra éo coração do nosso Sistema de Gestão da Qualidade. Com o seu correto preenchimento, estabelecemos a rastreabilidade dos resultados para uma futura auditoria.
\end{abstract}

\subsection{Controle de Documentos}

OLQA estabelece e mantém procedimentos para controlar todos os documentos que integram o Sistema de Gestão da Qualidade, quer sejam os gerados internamente, como POPs e formulários, quer sejam aqueles obtidos de fontes externas, como regulamentos, normas, métodos de ensaio, softwares, instruções e manuais.

Há no LQA um documento intitulado Lista Mestra de Procedimentos e outro intitulado Controle de Registros. Na Lista Mestra de Procedimentos, referenciam-se todos os POPs, o número de sua revisão, a data de criação e a data da possível revisão. Desse modo, evita-se o uso dos documentos inválidos ou obsoletos. O Controle de Registros referencia cada registro, a que POP se aplica, quem é o responsável (área técnica, área acadêmica ou área da gestão), o local em que se encontra e por quanto tempo deve ser retido após seu preenchimento.

Todos os documentos emitidos para o pessoal dolaboratório como parte do Sistema de Gestão da Qualidade (POPs, formulários, instruções operacionais e métodos de ensaio) são analisados criticamente e, após aprovados pela alta direção, assinados e datados, são disponibilizados. 
Os documentos do Sistema de Gestão da Qualidade gerados pelo laboratório são univocamente identificados. A identificação inclui a data da emissão e/ou identificação da revisão, a paginação, o número total de páginas e a(s) autoridade(s) emitente(s).

Sucintamente, temos queoLQA mantém procedimentos operacionais padrãopara processos críticos do laboratório definidos no POP 004 - Estrutura de POP e Formulários (Figura 2). Para a elaboração de POPs e formulários, segue-se um modelo preestabelecido (Figura 7). A Lista Mestra de Procedimentos traz a relação dos procedimentos operacionais padrão, assim como a revisão e o local de armazenamento dos documentos (Figura 8). O LQA mantém cópias impressas e revisadas dos procedimentos operacionais padrão prontamente disponíveis para todos os pesquisadores. O Mapa de Distribuição dos Procedimentos do Sistema de Qualidade (MDPSQ) contém a relação dos locais de armazenamento dos Procedimentos Operacionais Padrão, assim como a definição de responsáveis por cada documento da qualidade (Figura 9). O Controle de Registros descreve cada registro e a que POP se aplica (Figura 10).

Todos esses documentos - LMP, MDPSQ e CR - são importantes para as auditorias e devem ser afixados em local de fácil acesso e visível a todos.

Figura 5. Cópia ilustrativa do POP 003 - Agenda Mestra

AGENDA MESTRA
$\frac{\text { POP } 003}{\text { DATA_I_/20_ }}$

1 OBJETIVO

Estabelecer a sistemática para o registro e controle de observações originais e dados derivados.

\section{PROCEDIMENTO}

2.1 Durante a rotina laboratorial, as anotações devem fornecer informações suficientes para estabelecer uma linha de auditoria.

a) Na Agenda Mestra - AM (Anexo 1), são registradas as informações relacionadas à prática laboratorial, anterior ao início de cada atividade.

b) No caderno do pesquisador, são registrados os dados brutos.

c) Nos formulários, são registrados os dados brutos ou as informações referentes ao equipamento, procedimento ou método.

\section{RESPONSABILIDADE}

Diretor acadêmico, gerente técnico, alunos de IC, mestrandos, doutorandos e pós-doutorandos.

\section{ANEXOS}

ANEXO 1 - Agenda Mestra (AM).

\section{APROVAÇÕES}

\begin{tabular}{|l|l|l|}
\hline Autor & Aprovado / Assinatura & Data \\
\hline & & \\
\hline
\end{tabular}


Figura 6. Cópia ilustrativa de uma página da Agenda Mestra (ANEXO 1) do POP 003 - Agenda Mestra

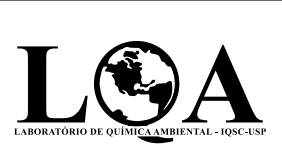
ANEXO 1- AGENDA MESTRA
(POP 003)

AM N ${ }^{\circ} 1$

REV: X PÁGINA 1 DE 100

DATA_I_/20

PESQUISA

RESPONSÁVEL

ID AMOSTRAS

MÉTODO (ME OU REFERÊNCIA)

ID EQUIPAMENTO

\section{ID REAGENTES}

\section{ID MATERIAL DE REFERÊNCIA}

\section{REGISTROS GERADOS}

Observações e informações complementares

Trabalho supervisionado? ( ) Não ( ) Sim, assinatura do supervisor: 
Figura 7. Cópia ilustrativa do Modelo de Procedimento Operacional Padrão (ANEXO 1) do POP 004 Estrutura de POP e Formulários

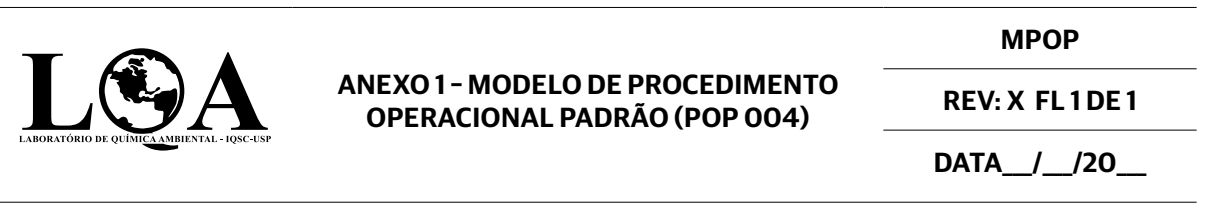

\section{OBJETIVO}

Estabelecer a sistemática para...

Obs.: Neste primeiro campo, você deverá descrever o objetivo do procedimento com base no requisito da norma.

\section{DOCUMENTOS COMPLEMENTARES}

Neste campo, o usuário deverá referenciar todos os procedimentos e, quando aplicáveis, os documentos: POPs, IOs e MEs.

Obs.: Normalmente são citados neste campo os procedimentos que iniciam ou encerram a rotina que está sendo trabalhada. Contudo, quando não houver documentos complementares, não incluir este item.

\section{PROCEDIMENTO}

Este campo serve para detalhar os procedimentos.

\section{RESPONSABILIDADES}

Este campo serve para detalhar as responsabilidades de cada função para a plena implementação do procedimento.

Obs.: Quando não houver a necessidade de discriminar as responsabilidades, não incluir este item.

\section{REGISTROS}

Neste campo, você deverá citar todos os "registros" que servirão de evidência do pleno atendimento do requisito do Manual da Qualidade.

\section{ANEXOS}

Este campo deverá ser usado para referenciar os formulários utilizados como registros, assim como os planos, as planilhas e as tabelas, quando aplicáveis.

\section{APROVAÇÕES}

\begin{tabular}{|l|l|l|}
\hline Autor (nome e função) & Aprovado/Assinatura & Data \\
\hline & & \\
\hline
\end{tabular}


Figura 8. Cópia ilustrativa da Lista Mestra de Procedimentos (ANEXO 3) do POP 004 - Estrutura de POP e Formulários

\begin{tabular}{|c|c|c|c|c|}
\hline CÓDIGO & TÍTULO DO POP & $\begin{array}{l}\text { DATA DA } \\
\text { CRIAÇÃO }\end{array}$ & $\begin{array}{l}\text { NÚMERO DA } \\
\text { REVISÃO }\end{array}$ & $\begin{array}{l}\text { DATA DA } \\
\text { REVISÃO }\end{array}$ \\
\hline POP 001 & EQUIPAMENTOS & & & \\
\hline POP 002 & $\begin{array}{l}\text { MANUSEIO DE MATERIAIS DE REFERÊNCIA } \\
\text { E PREPARO DE SOLUÇÕES ESTOQUE }\end{array}$ & & & \\
\hline POP 003 & AGENDA MESTRA & & & \\
\hline POP 004 & ESTRUTURA DE POPS E FORMULÁRIOS & & & \\
\hline POP 005 & LIMPEZA DO LQA & & & \\
\hline POP 006 & DESCARTE DE RESÍDUOS QUÍMICOS & & & \\
\hline POP 007 & VERIFICAÇÃO DE BALANÇAS & & & \\
\hline POP 008 & VALIDAÇÃO & & & \\
\hline POP 009 & LIMPEZA DE VIDRARIA & & & \\
\hline POP 010 & $\begin{array}{l}\text { AQUISIÇÃO DE SERVIÇOS E DE } \\
\text { SUPRIMENTOS }\end{array}$ & & & \\
\hline POP 011 & INSUMOS & & & \\
\hline POP 012 & AUDITORIA & & & \\
\hline POP 013 & CADASTRO DE FORNECEDORES & & & \\
\hline POP 014 & CONTROLE DAS NÃO CONFORMIDADES & & & \\
\hline POP 015 & PESQUISA EXTERNA & & & \\
\hline POP 016 & MÉTODOS DE ENSAIO & & & \\
\hline POP 017 & PRESTAÇÃO DE SERVIÇO & & & \\
\hline POP 018 & CARTAS CONTROLE & & & \\
\hline POP 019 & RESPONSABILIDADES & & & \\
\hline POP 020 & PLANEJAMENTO DA PESQUISA & & & \\
\hline
\end{tabular}

\begin{tabular}{|l|l|l|}
\hline Autor & Aprovado / Assinatura & Data \\
\hline & & \\
\hline
\end{tabular}


Figura 9. Cópia ilustrativa do Mapa de Distribuição dos Procedimentos do Sistema de Qualidade (ANEXO 4) do POP 004 - Estrutura de POP e Formulários

\begin{tabular}{|c|c|c|c|}
\hline & \multicolumn{2}{|c|}{$\begin{array}{c}\text { MAPA DE DISTRIBUIÇÃO } \\
\text { DOS PROCEDIMENTOS DO SISTEMA } \\
\text { DE QUALIDADE }\end{array}$} & \multirow{2}{*}{$\begin{array}{c}\text { MDPSQ } \\
\text { REV: X FL } 1 \text { DE } 1 \\
\text { DATA_/_/20__ }\end{array}$} \\
\hline & & & \\
\hline Procedimento & Responsável & \multicolumn{2}{|c|}{ Localização } \\
\hline POP 001 & $x x x x$ & \multicolumn{2}{|c|}{$\begin{array}{l}\text { Laboratório 1; Bancada de Apoio 1; } \\
\text { Gaveta 1.C (por exemplo) }\end{array}$} \\
\hline POP 002 & $x x x x$ & \multicolumn{2}{|l|}{$x x x x$} \\
\hline POP 003 & $x x x x$ & \multicolumn{2}{|l|}{$x x x x$} \\
\hline POP 004 & $x x x x$ & \multicolumn{2}{|l|}{$x x x x$} \\
\hline POP 005 & $x x x x$ & \multicolumn{2}{|l|}{$x x x x$} \\
\hline POP 006 & $x X X X$ & \multicolumn{2}{|l|}{$x X X X$} \\
\hline POP 007 & $x X X X$ & \multicolumn{2}{|l|}{$x X X X$} \\
\hline POP 008 & $x X X X$ & \multicolumn{2}{|l|}{$x x x x$} \\
\hline POP 009 & $x x x x$ & \multicolumn{2}{|l|}{$x x x x$} \\
\hline POP 010 & $x x x x$ & \multicolumn{2}{|l|}{$x x x x$} \\
\hline POP 011 & $x x x x$ & \multicolumn{2}{|l|}{$x x x x$} \\
\hline POP 012 & $x x x x$ & \multicolumn{2}{|l|}{$x x x x$} \\
\hline POP 013 & $x x x x$ & \multicolumn{2}{|l|}{$x x x x$} \\
\hline POP 014 & $x x x x$ & \multicolumn{2}{|l|}{$x x x x$} \\
\hline POP 015 & $x x x x$ & \multicolumn{2}{|l|}{$x x x x$} \\
\hline POP 016 & $x x x x$ & \multicolumn{2}{|l|}{$x x x x$} \\
\hline POP 017 & $x x x x$ & \multicolumn{2}{|l|}{$x x x x$} \\
\hline POP 018 & $x x x x$ & \multicolumn{2}{|l|}{$x x x x$} \\
\hline POP 019 & $x x x x$ & \multicolumn{2}{|l|}{$x x x x$} \\
\hline POP 020 & $x x x x$ & \multicolumn{2}{|l|}{$x x x x$} \\
\hline
\end{tabular}

\begin{tabular}{|l|l|l|}
\hline Autor & Aprovado/ Assinatura & Data \\
\hline & & \\
\hline
\end{tabular}


Figura 10. Cópia ilustrativa do Controle de Registros (ANEXO 6) do POP 004 - Estrutura de POP e Formulários

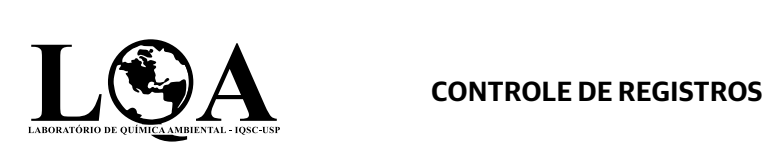

CR

\begin{tabular}{lllll} 
& & & DATA_l_L__- \\
\hline Registro & Aplicação & Responsável & Armazenamento & Retenção \\
\hline $\begin{array}{l}\text { Registro de Controle de } \\
\text { Gases }\end{array}$ & POP 011 & Lab 1. Banc 1. Gaveta 1.A & 1 ano \\
\hline $\begin{array}{l}\text { Registro de Controle } \\
\text { de Reagentes }\end{array}$ & POP 011 & Lab 1. Banc 1. Gaveta 1.A & 1 ano \\
\hline $\begin{array}{l}\text { Agenda Mestra } \\
\text { Solicitação de Compra }\end{array}$ & POP 010 & Lab 1. Banc 1. Gaveta 1.B & 6 meses \\
\hline $\begin{array}{l}\text { Relatório de Inspeção } \\
\text { de Serviços }\end{array}$ & POP 011 & Lab 1. Banc 1. Gaveta 1.C & 6 meses \\
\hline $\begin{array}{l}\text { Relatório de Inspeção } \\
\text { de Produtos }\end{array}$ & POP 011 & Lab 1. Banc 1. Gaveta 1.C & 6 meses \\
\hline
\end{tabular}

\begin{tabular}{lll}
\hline Lista de Verificação & & \\
de Recursos e & POP 017 & Lab 1. Banc 1. Gaveta 1.D \\
Documentação & & \\
\hline
\end{tabular}

\begin{tabular}{|c|c|c|c|}
\hline $\begin{array}{l}\text { Lista de Verificação } \\
\text { Técnica de Resultados }\end{array}$ & POP 017 & Lab 1. Banc 1. Gaveta 1.D & 6 meses \\
\hline $\begin{array}{l}\text { Certificado de } \\
\text { Treinamento Prático }\end{array}$ & POP 020 & Lab 1. Banc 1.Gaveta 1.E & 6 meses \\
\hline $\begin{array}{l}\text { Relatório de Não } \\
\text { Conformidade }\end{array}$ & POP 014 & Lab 1. Banc 1. Gaveta 1.E & 6 meses \\
\hline $\begin{array}{l}\text { Cadastro de } \\
\text { Fornecedores }\end{array}$ & POP 013 & Lab 1. Banc 1. Gaveta 1.F & 6 meses \\
\hline $\begin{array}{l}\text { Registro de } \\
\text { Gerenciamento do } \\
\text { pHmetro } 01\end{array}$ & 1010 & Lab 1. Banc 6 & 6 meses \\
\hline $\begin{array}{l}\text { Registro de } \\
\text { Gerenciamento do } \\
\text { pHmetro } 02\end{array}$ & IO 11 & Lab 1. Banc 6 & 6 meses \\
\hline $\begin{array}{l}\text { Registro de } \\
\text { Gerenciamento do } \\
\text { Condutivímetro } \\
\text { Portátil } 01\end{array}$ & 1039 & Lab 1. Banc 6 & 6 meses \\
\hline $\begin{array}{l}\text { Registro de } \\
\text { Gerenciamento do } \\
\text { Liofilizador } 01\end{array}$ & 1014 & Lab 1. Banc 5 & 6 meses \\
\hline
\end{tabular}


Figura 10. Continuação...

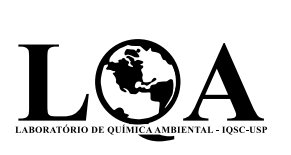

CR

CONTROLE DE REGISTROS

\begin{tabular}{c} 
CR \\
\hline REV: X FL 2 DE 4 \\
\hline DATA_/_/20__
\end{tabular}

\begin{tabular}{|c|c|c|c|c|}
\hline Registro & Aplicação & Responsável & Armazenamento & Retenção \\
\hline $\begin{array}{l}\text { Registro de } \\
\text { Gerenciamento da } \\
\text { Mesa Agitadora } 01\end{array}$ & 1009 & & Lab 1. Banc 5 & 6 meses \\
\hline $\begin{array}{l}\text { Registro de } \\
\text { Gerenciamento do } \\
\text { Banho de Ultrassom } 01\end{array}$ & IO 15 & & Lab 1. Banc 5 & 6 meses \\
\hline
\end{tabular}

\section{Registro de}

Gerenciamento do

1016

Lab 1. Banc 5

6 meses

02

Registro de

Gerenciamento da $\quad 1004$

Lab 1. Banc 3

6 meses

Balança 03

Registro de

Gerenciamento do

1025

Lab 1. Banc 9

6 meses

Forno de Micro-ondas

Registro de

Gerenciamento da

Câmara de Germinação

1005

Lab 1. Banc 9

6 meses

01

\section{Registro de}

Gerenciamento do

1023

Lab 1

6 meses

Refrigerador 01

\section{Registro de}

$\begin{array}{llll}\text { Gerenciamento do } & 1023 & \text { Lab } 1 & 6 \text { meses } \\ \text { Refrigerador } 02 & & \end{array}$

\begin{tabular}{|c|c|c|c|}
\hline $\begin{array}{l}\text { Registro de } \\
\text { gerenciamento do } \\
\text { Refrigerador } \mathrm{O3}\end{array}$ & 1023 & Lab 1 & 6 meses \\
\hline $\begin{array}{l}\text { Registro de } \\
\text { Gerenciamento do } \\
\text { Refrigerador } 06\end{array}$ & 1023 & Lab 1 & 6 meses \\
\hline $\begin{array}{l}\text { Registro de } \\
\text { Gerenciamento da } \\
\text { Centrífuga } 01\end{array}$ & 1013 & Lab 1. Banc 7. Gaveta 7.C & 6 meses \\
\hline $\begin{array}{l}\text { Registro de } \\
\text { Gerenciamento do } \\
\text { Destilador de Água } 01\end{array}$ & 1008 & Lab 1. Banc 7. Gaveta 7.C & 6 meses \\
\hline
\end{tabular}


Figura 10. Continuação...

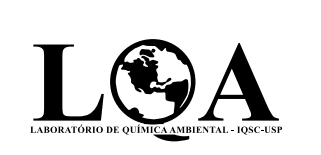

CR

CONTROLE DE REGISTROS

\begin{tabular}{c} 
CR \\
\hline REV: X FL 3 DE 4 \\
\hline DATA_/_/20__
\end{tabular}

\begin{tabular}{|c|c|c|c|c|}
\hline Registro & Aplicação & Responsável & Armazenamento & Retenção \\
\hline $\begin{array}{l}\text { Registro de } \\
\text { Gerenciamento do } \\
\text { Ar-Condicionado } 01\end{array}$ & 1026 & & Lab 1. Banc 7. Gaveta 7.C & 6 meses \\
\hline $\begin{array}{l}\text { Registro de } \\
\text { Gerenciamento do } \\
\text { Rotoevaporador } 01\end{array}$ & 1006 & & Lab 1. Banc 7. Gaveta 7.C & 6 meses \\
\hline
\end{tabular}

\section{Registro de}

Gerenciamento

do Mini agitador

1031

Lab 1. Banc 7. Gaveta 7.D 6 meses

Mecânico

Registro de

Gerenciamento da $\quad 1034 \quad$ Lab 1. Banc 7. Gaveta 7.C 6 meses

Estufa 01

Registro de

Gerenciamento da $\quad 1007 \quad$ Lab 1. Banc 7. Gaveta 7.C 6 meses

Estufa 02

Registro de

Gerenciamento da $\quad 1033$

Lab 1. Banc 7. Gaveta 7.C 6 meses

Mufla 01

Registro de

Gerenciamento do

Agitador Magnético 03

Registro de

$\begin{array}{llll}\text { Gerenciamento da } & 1022 & \text { Lab 1. Banc 7. Porta 7.3 } & 6 \text { meses } \\ \text { Mini sonda } 01 & & \end{array}$

Mini sonda 01

Registro de

Gerenciamento do $\quad$ IO 28

Lab 1. Banc 7. Porta $7.3 \quad 6$ meses

Eletroflotador

Registro de

$\begin{array}{llll}\text { Gerenciamento do } & 1024 & \text { Lab 1. Banc 7. Porta 7.3 } & 6 \text { meses } \\ \text { Extrator } 01 & \end{array}$

\section{Registro de}

Gerenciamento do $\quad 1024$

Lab 1. Banc 7. Porta 7.3 6 meses

Extrator 02

Registro de

Gerenciamento do

1012

Lab 1. Banc 7. Porta $7.3 \quad 6$ meses

$\mathrm{HACH} O 1$ 
Figura 10. Continuação...

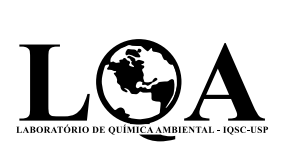

CR

CONTROLE DE REGISTROS

\begin{tabular}{c} 
CR \\
REV:X FL 4 DE 4 \\
\hline DATA_I_/20__
\end{tabular}

\begin{tabular}{lllll}
\hline Registro & Aplicação & Responsável & Armazenamento & Retenção \\
\hline $\begin{array}{l}\text { Registro de } \\
\text { Gerenciamento do }\end{array}$ & 1037 & Lab 2. Banc 10. & 6 meses \\
HACH 02 & & & \\
\hline
\end{tabular}

Registro de

Gerenciamento do

1026

Lab 2. Banc 10.

6 meses

Ar-Condicionado 02

Registro de

Gerenciamento do IO $\quad$ IO

Lab 2. Banc 10.

6 meses

TOC 01

\section{Registro de}

Gerenciamento do $\quad$ IO 21

Cromatógrafo 04

Registro de Controle

de Materiais de POP 011

Lab 2. Banc 11. Porta $11.1 \quad 6$ meses

Referência

Registro de

Gerenciamento do

1018

Lab 3. Banc 13. Gaveta

13.C

6 meses

Cromatógrafo 01

Registro de

Gerenciamento do

IO 26

Lab 3. Banc 13. Gaveta

13.C

6 meses

Ar-Condicionado 03

Registro de Controle

Estatístico

POP 018

Lab 3. Banc 12

6 meses

Registro de

Gerenciamento do

1020

Lab 3. Banc 13. Porta

13.8

6 meses

Cromatógrafo 03

Registro de

Gerenciamento do

1019

Cromatógrafo 02

Lab 3. Banc 13. Porta

13.6

6 meses

*Todos documentos obsoletos são alocados no Armário 17 da Sala de Estudos.

\begin{tabular}{|l|l|l|}
\hline Autor & Aprovado/ Assinatura & Data \\
\hline & & \\
\hline
\end{tabular}




\subsubsection{Alteração em Documentos}

As alterações nos documentos são, a exemplo dos documentos originais, analisadas criticamente, aprovadas, assinadas e datadas pela mesma função (acadêmica, técnica ou de gestão) que realizou a análise crítica original, salvo prescrição contrária. Onde praticável, o texto alterado ou o novo texto éidentificado no documento ou em anexos apropriados. O sistema de controle da documentação do laboratório permite emendas manuscritas dos documentos, até sua remissão, as quais estão definidas nos procedimentos, assim como as pessoas autorizadas para fazê-las. As emendas são claramente marcadas, rubricadas e datadas. O documento revisado é reemitido formalmente dentro da maior brevidade possível.

O procedimento para emissão, alteração, aprovação de documentos e controle de registros está descrito no POP 004 - Estrutura de POP e Formulários (Figura 2).

\subsubsection{Ensaios}

Todos os documentos destinados ao pessoal do laboratório como parte do Sistema de Gestão da Qualidade são analisados criticamente e aprovados por pessoal autorizado antes de serem emitidos. A relação de todos os documentos do Sistema de Gestão da Qualidade consta em uma lista mestra e refere-se aos documentos externos ao laboratório, tais como normas, artigos, manuais etc., e identifica o status da revisão atual, sua distribuição e localização no LQA, para que se evite o uso dos documentos inválidos ou obsoletos.

Para a execução dos métodos de ensaio, utiliza-se um procedimento operacional padrão específico para o método em foco. No caso de adaptações ou desenvolvimento de método por pesquisadores do LQA, é mandatório que, após sua finalização, o método seja escrito para posterior consulta. Para elaborar a escrita de um método de ensaio, emprega-se o POP 016 - Métodos de ensaio (Figura 11).

\subsection{Equipamentos}

O LQA dispõe de equipamentos necessários ao bom desenvolvimento dos ensaios. Possui instruções sobre o uso e operação de todos os equipamentos relevantes, sobre o seu manuseio ea sua preparação dos itens para ensaio. Todas as instruções, as normas e os dados de referência relevantes para o trabalho do LQA são mantidos atualizados e prontamente disponíveis para o pesquisador. Há um procedimento operacional padrão, o POP 001 - Equipamentos, que traz instruções sobre manutenção, identificação, elaboração de registros e instruções operacionais para os equipamentos do LQA. Na Figura 12, apresenta-se uma cópia desse POP. Já nas Figuras 13 a 17, apresentam-se as cópias dos respectivos anexos.

Nos casos em que o LQA precisa usar equipamentos que estejam fora de seu controle permanente, procuram-se laboratórios de reconhecida qualidade que atendam às normas de um Sistema de Gestão da Qualidade ou cujo responsável seja pesquisador de notória expertise.

Os equipamentos são operados por pessoal treinado. Instruções atualizadas sobre o uso e a manutenção do equipamento (incluindo quaisquer manuais pertinentes fornecidos pelo fabricante) encontram-se prontamente disponíveis para uso dos pesquisadores do LQA, conforme POP 001.

Cada item do equipamento usado para ensaio que seja significativo para o resultado é identificado. Na Instrução Operacional, deve ser mantida uma lista (Figura 12) contendo todos os itens de uso do equipamento (Figuras 13 a 17). 
Figura 11. Cópia ilustrativa do POP 016 - Métodos de Ensaio

MÉTODOS DE ENSAIO $\frac{\text { POP } 016}{\text { REV: X FL 1DE } 1}$

\section{OBJETIVO}

Estabelecer a sistemática para a estruturação e formatação dos métodos de ensaio.

\section{CONDIÇÕES}

A necessidade de adoção ou criação de um método é originada a partir da necessidade da pesquisa. Este documento trata da estruturação e formatação de formulários dos métodos de ensaio.

2.1 Métodos de Ensaio (MEs)

2.1.1. Os MEs descrevem os procedimentos de ensaio e atendem ao requisito 4.3 do Manual da Qualidade do Laboratório de Química Ambiental.

2.1.2 Adota-se o Modelo de Método de Ensaio - MME (Anexo 1) para a estruturação e formatação dos MEs.

2.1.3 Os MEs se referem a um único método de ensaio.

2.1.4 A Lista Mestra de Métodos de Ensaio é uma relação dos MEs do laboratório e o status de sua revisão, necessária para controle e para evitar o uso de MEs obsoletos (Anexo2).

\section{REGISTROS}

Anexo 1 - Modelo de Método de Ensaio (MME).

Anexo 2 - Lista Mestra de MEs (LMMEs).

\section{RESPONSABILIDADES}

4.1 Diretor acadêmico: seleciona o método com base no planejamento da pesquisa. Mestrandos, doutorandos e pós-doutorandos: podem ser escolhidos pelo DA para emissão do ME.

\section{APROVAÇÕES}

\begin{tabular}{|l|l|l|}
\hline Autor & Aprovado / Assinatura & Data \\
\hline & & \\
\hline
\end{tabular}

Todos os dados referentes a ensaios são registrados e reportados no Anexo 1 do POPOO3 Agenda Mestra (Figura 6). 
Figura 12. Cópia ilustrativa do POP 001 - Equipamentos

EQUIPAMENTOS $\frac{\text { POP } 001}{\text { REV:X FL } 1 \text { DE } 1}$

\section{OBJETIVO}

Estabelecer a sistemática para manutenção, identificação, elaboração de registros e instruções operacionais para equipamentos do LQA.

\section{PROCEDIMENTO}

2.1 Manutenção

2.1.1 A manutenção dos equipamentos está descrita no IO de cada equipamento e é registrada na Ficha do Equipamento (Anexo 5).

Nota: qualquer observação a respeito do equipamento será anotada na Ficha do Equipamento (Anexo 5).

2.2 Instrução Operacional

2.2.1 A instrução operacional (IO) contém informações detalhadas do equipamento, do manuseio e da manutenção e encontra-se próximo ao equipamento. Adota-se o Modelo de IO - MIO (Anexo 1) para a estruturação e formatação das Instruções Operacionais.

2.2.2 A Listra Mestra de IOs - LMIO (Anexo 4) contém o registro dos IOs disponíveis no LQA.

2.3 Registro

2.3.1 O Registro de Gerenciamento de Equipamento (RGE) contém informações sobre o uso do equipamento, o responsável e a data e encontra-se próximo ao equipamento. Adota-se o Modelo de Registro de Gerenciamento de Equipamento - MRGE (Anexo 2) para a estruturação e formatação dos registros de equipamentos.

2.4 Identificação de Equipamentos

2.4.1 Adota-se o Modelo de Etiqueta de Identificação de Equipamento - MEIE (Anexo 3) para identificar os equipamentos.

\section{ANEXOS}

- Anexo 1 - Modelo de Instrução Operacional (MIO).

- $\quad$ Anexo 2 - Modelo de Registro de Gerenciamento de Equipamento (MRGE).

- $\quad$ Anexo 3 - Modelo de Etiqueta de Identificação de Equipamento (MEIE).

- $\quad$ Anexo 4 - Lista Mestra de IOs (LMIO).

- $\quad$ Anexo 5 - Ficha do Equipamento (FE).

\section{APROVAÇÕES}

\begin{tabular}{|l|l|l|}
\hline Autor & Aprovado / Assinatura & Data \\
\hline & & \\
\hline
\end{tabular}


Figura 13. Cópia ilustrativa do Modelo de Instrução Operacional (ANEXO 1) do POP 001 - Equipamentos

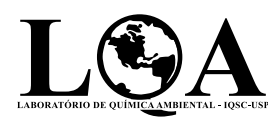 \\ ANEXO 1 - MODELO DE INSTRUÇÃO OPERACIONAL*}

MIO

"Mudar o nome do documento. Ex:" IO - Balança 01 - Balança Analítica Gehaka AG 200"

REV: X FL 1 DE 2

DATA $I+120$

\section{OBJETIVO}

Estabelecer a sistemática para o uso, transporte, manutenção, limpeza e verificação do (... equipamento...), bem como identificá-lo(a) e localizá-lo(a) dentro do LQA.

Observações: equipamento: "nossa identificação - identificação completa do fabricante". Por exemplo: ... da "Balança 01 - Balança Analítica Gehaka AG 200".

\section{PROCEDIMENTOS}

2.1 Identificação de equipamentos

\begin{tabular}{|l|l|l|}
\hline Identificação & \multicolumn{2}{|c|}{ Nome do equipamento, fabricante e modelo } \\
\hline$N^{\circ}$ série & Patrimônio & Origem da verba \\
\hline$\square$ Manutenção Preventiva & $\square$ Calibração & $\square$ Manual Técnico \\
\hline Local de arquivamento do IO, Registro e Manuais: \\
\hline Número de supervisões requeridas após treinamento:
\end{tabular}

2.2 Relação de itens e/ou softwares e manuais

Observações: listar e descrever todos os itens/softwares e manuais do equipamento.

2.3 Especificações técnicas

Observações: incerteza, tolerância, faixa de medição, precisão, alimentação e informações técnicas fornecidas pelo fabricante.

2.4 Especificações técnicas de instalação

Observações: descrever condições ambientais e especificações requeridas para a instalação do equipamento, quando apresentadas pelo fabricante.

2.5 Localização e Transporte

Observações: especificar o laboratório, bancada e, quando pertinente, a porta em que o equipamento se encontra instalado ou armazenado. Quando o uso do equipamento prever o transporte, incluir o modo adequado de fazê-lo.

2.6 Manuseio e Uso

Observações: descrever o passo a passo da utilização do equipamento, incluindo, quando aplicável, verificação, calibração, limpeza e registro das informações. Incluir o passo a passo de variações rotineiras do uso.

Por exemplo: o uso da balança inclui: a) ligar; b) verificar; c) registrar a verificação; d) uso (amostra); e) registrar o uso; $f$ ) limpeza; $g$ ) registrar a limpeza não rotineira. O uso do cromatógrafo inclui as mesmas operações mais, por exemplo, acertar a programação da temperatura do forno.

2.7 Limpeza

Observações: descrever o passo a passo da limpeza do equipamento e com qual periodicidade. Evidenciar recomendações específicas, como quais produtos devem ser usados e quais não devem, de forma alguma, ser usados na limpeza. Evidenciar as situações que exigem limpeza imediata. Quando houver necessidade de desmontar o equipamento para a limpeza, descrever também o passo a passo da desmontagem e montagem. 
Figura 13. Continuação...

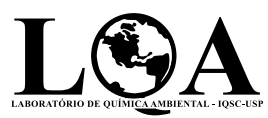

\section{ANEXO 1- MODELO DE INSTRUÇÃO OPERACIONAL*}

MIO

REV: X FL 2 DE 2

DATA $/ \_/ 20$

"Mudar o nome do documento. Ex:" IO - Balança O1 - Balança Analítica Gehaka AG 200"

2.8 Verificação ou Monitoramento Observações: verificar se é aplicável a todos os equipamentos calibrados. O monitoramento pode ou não ser aplicável aos equipamentos não calibrados.

Quando aplicável, descrever o passo a passo da verificação/monitoramento do equipamento e com qual periodicidade.

Quando do monitoramento, definir o critério de aceitação ("O critério de aceitação adotado pelo LQA corresponde a ..."). O critério de aceitação dos equipamentos calibrados é definido no POP 011 - Análise Crítica da Verificação de Equipamentos e padrões passíveis de calibração.

2.9 Manutenção preventiva

Observações: descrever conforme orientação do fabricante. Quando houver necessidade de desmontar o equipamento para a manutenção interna, descrever também o passo a passo da desmontagem e montagem.

\section{REGISTROS}

Registro do (equipamento).

Observações: equipamento: "nossa identificação - identificação completa do fabricante". Ex: ... da "Balança 01 - Balança Analítica Gehaka AG 200".

\section{ANEXOS}

Anexo 1 - Registro do (equipamento).

Anexo 2 - Manuais (especificar todos os volumes e a forma como ele se encontra, se disponível eletronicamente, se impresso pelo fabricante etc.).

Anexo 3 - Continuar conforme a necessidade.

\section{DOCUMENTOS COMPLEMENTARES}

Observações: se aplicável.

\section{APROVAÇÕES}

\begin{tabular}{|l|l|l|}
\hline Autor & Aprovado / Assinatura & Data \\
\hline & & \\
\hline
\end{tabular}


Figura 14. Cópia ilustrativa do Modelo de Registro de Gerenciamento de Equipamento (ANEXO 2) do POP 001 - Equipamentos

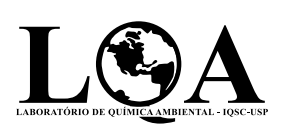

\section{ANEXO 2 - MODELO DE REGISTRO DE GERENCIAMENTO DE EQUIPAMENTO*}

\begin{tabular}{c} 
MRGE \\
\hline REV:X FL 1 DE 1 \\
\hline DATA_/_/20__
\end{tabular}

* Mudar o nome do documento. Ex:" Registro de Gerenciamento da Balança 01 - Balança Analítica Gehaka AG 200"

NOTA: Em todas as tabelas, obrigatoriamente incluir os campos de "Data" e "Responsável".

\section{USO}

Observações: ajustar o conteúdo das tabelas conforme a natureza do equipamento. Considerar o espaço para o registro de seis meses de utilização do equipamento. Obrigatoriamente incluir os campos de "Data" e "Responsável".

\section{LIMPEZA}

Observações: ajustar o conteúdo das tabelas conforme a natureza do equipamento. Considerar o espaço para o registro de seis meses de limpeza do equipamento. Considera-se necessário apenas o registro da limpeza que afete a confiabilidade do resultado.

\section{MONITORAMENTO (PARA EQUIPAMENTOS NÃO CALIBRADOS - QUANDO APLICÁVEL)}

Observações: ajustar o conteúdo das tabelas conforme a natureza do equipamento. Recomenda-se que, quando o monitoramento for simultâneo ao uso, que essas tabelas estejam juntas.

\section{VERIFICAÇÃO (PARA EQUIPAMENTOS CALIBRADOS - QUANDO APLICÁVEL)}

Observações: ajustar o conteúdo das tabelas conforme a natureza do equipamento. Recomenda-se que, quando a verificação for simultânea ao uso, que essas tabelas estejam juntas. 
Figura 15. Cópia ilustrativa do Modelo de Etiqueta de Identificação de Equipamento (ANEXO 3) do POP 001 - Equipamentos

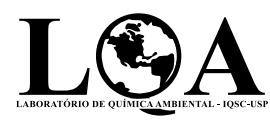

\section{ANEXO 3 - MODELO DE ETIQUETA DE IDENTIFICAÇÃO DE EQUIPAMENTO}

MEIE

REV: X FL 1 DE 1

DATA_I_/20

Modelo: trocar os campos grifados pelos dados do equipamento.

\section{LOGO}

\section{Tipo do Equipamento/Padrão - Número}

Equipamento/padrão: nome do equipamento/ padrão (incluindo nome do fabricante e modelo)

Calibração: ( ) SIM ( ) NÃO

Exemplo:

\section{LOGO}

\section{Balança 01}

Equipamento: Balança Analítica GEHAKA AG 200

Calibração: ( ) SIM ( ) NÃO 
Figura 16. Cópia ilustrativa da Lista Mestra de IOs (ANEXO 4) do POP 001 - Equipamentos

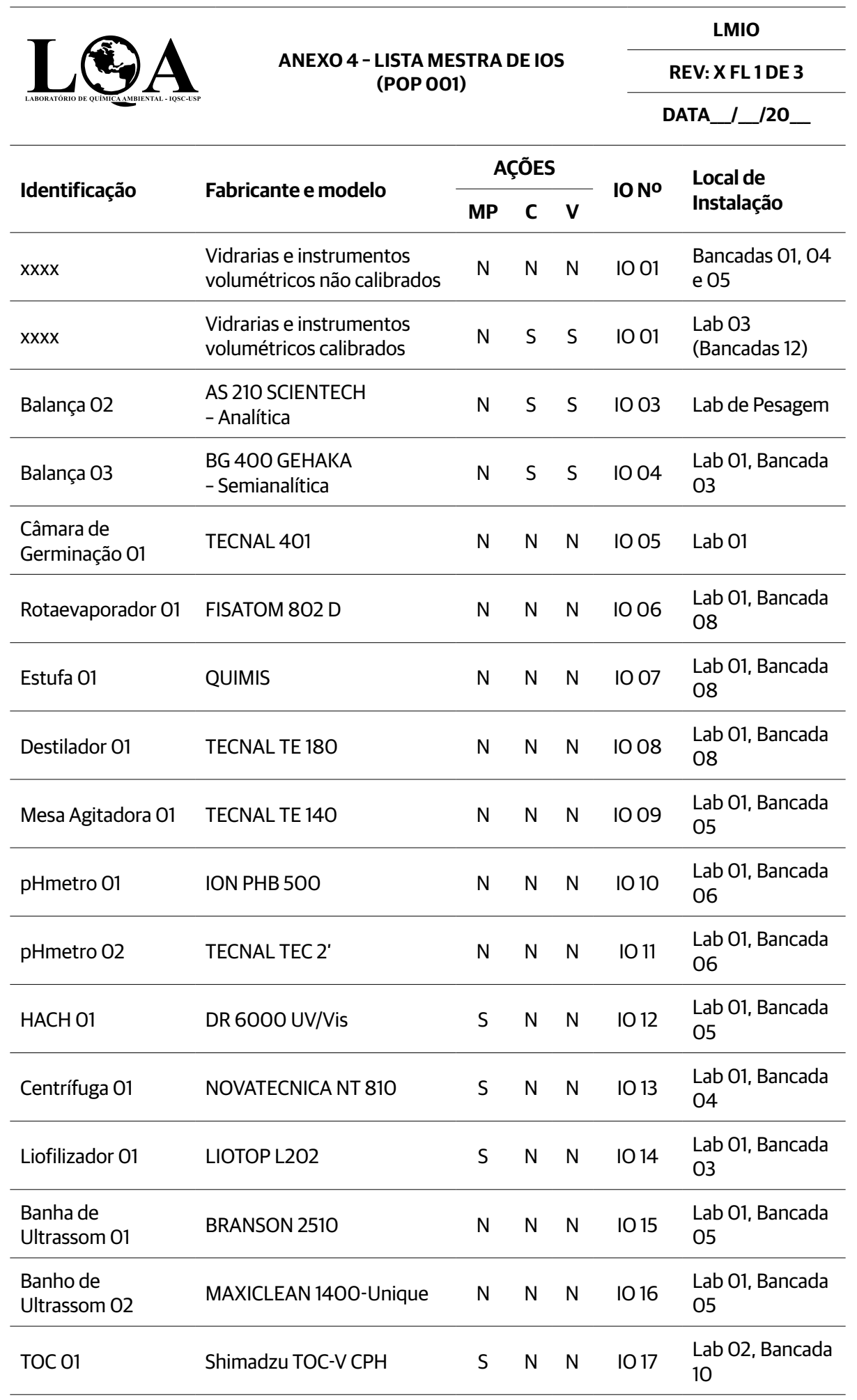


Figura 16. Continuação...

\begin{tabular}{|c|c|c|c|c|c|c|}
\hline \multirow{2}{*}{\multicolumn{5}{|c|}{ ANEXO 4- LISTA MESTRA DE IOS }} & \multirow{2}{*}{\multicolumn{2}{|c|}{$\frac{\text { LMIO }}{\text { REV: X FL } 2 \text { DE } 3}$}} \\
\hline & & & & & & \\
\hline & & & & & \multicolumn{2}{|c|}{ DATA_I_/20_ } \\
\hline \multirow{2}{*}{ Identificação } & \multirow{2}{*}{ Fabricante e modelo } & \multicolumn{3}{|c|}{ AÇÕES } & \multirow{2}{*}{ IO NO } & \multirow{2}{*}{$\begin{array}{l}\text { Local de } \\
\text { Instalação }\end{array}$} \\
\hline & & MP & C & $\mathbf{V}$ & & \\
\hline Cromatógrafo 01 & $\begin{array}{l}\text { Shimadzu GCMS-QP } 210 \\
\text { PLUS }\end{array}$ & $\mathrm{S}$ & $\mathrm{S}$ & $\mathrm{N}$ & 1018 & $\begin{array}{l}\text { Lab 03, Bancada } \\
13\end{array}$ \\
\hline Cromatógrafo 02 & Shimadzu GC-210 FID ECD & $\mathrm{S}$ & $\mathrm{N}$ & $\mathrm{N}$ & 1019 & $\begin{array}{l}\text { Lab 03, Bancada } \\
13\end{array}$ \\
\hline Cromatógrafo 03 & Shimadzu HPLC & $\mathrm{S}$ & $\mathrm{N}$ & $\mathrm{N}$ & 1020 & $\begin{array}{l}\text { Lab 03, Bancada } \\
13\end{array}$ \\
\hline Cromatógrafo 04 & Shimadzu HPLC & $\mathrm{S}$ & $\mathrm{N}$ & $\mathrm{N}$ & IO 21 & $\begin{array}{l}\text { Lab 02, Bancada } \\
11\end{array}$ \\
\hline Minissonda 01 & $\begin{array}{l}\text { Mini Sonda Termo- } \\
\text { Scientific/ Orion } 5 \text { Star }\end{array}$ & $\mathrm{N}$ & $\mathrm{N}$ & $\mathrm{N}$ & 1022 & Lab 01 \\
\hline Refrigerador 01 & ELETROLUX RE 26 & $\mathrm{~S}$ & $\mathrm{~N}$ & $\mathrm{~N}$ & 1023 & Lab 01 \\
\hline Refrigerador $\mathrm{O} 2$ & CONSUL 280 & $\mathrm{~S}$ & $\mathrm{~N}$ & $\mathrm{~N}$ & 1023 & Lab 01 \\
\hline Refrigerador $\mathrm{O3}$ & ELETROLUX RDE 30 & $\mathrm{~S}$ & $\mathrm{~N}$ & $\mathrm{~N}$ & 1023 & Lab 02 \\
\hline Refrigerador 04 & WHITE-WESTING HOUSE & $\mathrm{S}$ & $\mathrm{N}$ & $\mathrm{N}$ & 1023 & Área Externa \\
\hline Refrigerador 05 & CONSUL Super Luxo & $\mathrm{S}$ & $\mathrm{N}$ & $\mathrm{N}$ & 1023 & Área Externa \\
\hline Refrigerador 06 & BRASTEMP Clean BRB39 & $\mathrm{S}$ & $\mathrm{N}$ & $\mathrm{N}$ & 1023 & Lab 01 \\
\hline Extrator 01 & Extrator fase líquida & $\mathrm{N}$ & $\mathrm{N}$ & $\mathrm{N}$ & 1024 & Lab 01 \\
\hline Extrator $\mathrm{O} 2$ & Extrator fase líquida & $\mathrm{N}$ & $\mathrm{N}$ & $\mathrm{N}$ & 1024 & Lab 01 \\
\hline $\begin{array}{l}\text { Forno de Micro- } \\
\text { ondas } 01\end{array}$ & BERGHOF SpeedWave Four & $\mathrm{N}$ & $\mathrm{N}$ & $\mathrm{N}$ & 1025 & Lab 01 \\
\hline $\begin{array}{l}\text { Ar-Condicionado } \\
01\end{array}$ & CARRIER Split Space & $\mathrm{S}$ & $\mathrm{N}$ & $\mathrm{N}$ & 1026 & Lab 01 \\
\hline $\begin{array}{l}\text { Ar-Condicionado } \\
\mathrm{O} 2\end{array}$ & CONSUL 7500 Air Master & $\mathrm{S}$ & $\mathrm{N}$ & $\mathrm{N}$ & 1026 & Lab 02 \\
\hline $\begin{array}{l}\text { Ar-Condicionado } \\
03\end{array}$ & SPRINGER 7500 Mundial & $\mathrm{S}$ & $\mathrm{N}$ & $\mathrm{N}$ & 1026 & Lab 03 \\
\hline Nobreak 01 & $\begin{array}{l}\text { EMERSON LIEBERT } \\
\text { GXT3RT230 }\end{array}$ & $\mathrm{N}$ & $\mathrm{N}$ & $\mathrm{N}$ & 1027 & Lab 01 \\
\hline Eletroflotador 01 & Eletroflotador 01 & $\mathrm{~N}$ & $\mathrm{~N}$ & $\mathrm{~N}$ & 1028 & Lab 01 \\
\hline Computador 01 & $\begin{array}{l}\text { Intel Core i5 @ 2,67GHz } \\
\text { 2,00 GB RAM }\end{array}$ & $\mathrm{S}$ & $\mathrm{N}$ & $\mathrm{N}$ & 1029 & Lab 01 \\
\hline
\end{tabular}


Figura 16. Continuação...

\begin{tabular}{|c|c|c|c|c|c|c|c|}
\hline \multirow{2}{*}{\multicolumn{6}{|c|}{ ANEXO 4 - LISTA MESTRA DE IOS }} & \multirow{2}{*}{\multicolumn{2}{|c|}{$\frac{\text { LMIO }}{\text { REV: X FL } 3 \text { DE } 3}$}} \\
\hline & & & & & & & \\
\hline & & & & & & & TA_I_/20_ \\
\hline \multirow{2}{*}{ Identificação } & \multirow{2}{*}{\multicolumn{2}{|c|}{ Fabricante e modelo }} & & ÕES & & I & Local de \\
\hline & & & MP & C & V & (1) & Instalação \\
\hline Computador $\mathrm{O} 2$ & \multicolumn{2}{|c|}{$\begin{array}{l}\text { Intel Pentium } 4 \text { @ 3,00 GHz } \\
\text { 1,00 GB RAM }\end{array}$} & $\mathrm{S}$ & $\mathrm{N}$ & $\mathrm{N}$ & 1029 & Sala de Estudos \\
\hline Computador $\mathrm{O3}$ & \multicolumn{2}{|c|}{$\begin{array}{l}\text { Pentium } 4 @ 2,8 \text { GHz } 512 \\
\text { MB RAM }\end{array}$} & $\mathrm{S}$ & $\mathrm{N}$ & $\mathrm{N}$ & 1029 & Lab 02 \\
\hline Computador 04 & \multicolumn{2}{|c|}{$\begin{array}{l}\text { Pentium Dual Core @ 2,5 } \\
\text { GHz 2,00 GB RAM }\end{array}$} & $\mathrm{S}$ & $\mathrm{N}$ & $\mathrm{N}$ & 1029 & Lab 02 \\
\hline Computador 05 & \multicolumn{2}{|c|}{$\begin{array}{l}\text { Intel Celeron @ 2,8GHz } \\
\text { 2,00 GB RAM }\end{array}$} & $\mathrm{S}$ & $\mathrm{N}$ & $\mathrm{N}$ & 1029 & Lab 03 \\
\hline Computador 06 & \multicolumn{2}{|c|}{$\begin{array}{l}\text { AMD Athlon XP2600+ } \\
\text { @1917 MHz } 785 \text { MB RAM }\end{array}$} & $\mathrm{S}$ & $\mathrm{N}$ & $\mathrm{N}$ & 1029 & Lab 03 \\
\hline Computador 07 & \multicolumn{2}{|c|}{$\begin{array}{l}\text { Intel Core 2 Duo @ 2,2 GHz } \\
\text { 1,99 GB RAM }\end{array}$} & $\mathrm{S}$ & $\mathrm{N}$ & $\mathrm{N}$ & 1029 & Lab 03 \\
\hline $\begin{array}{l}\text { Agitador } \\
\text { Magnético } 01\end{array}$ & \multicolumn{2}{|c|}{ SOLAB SL-91 } & $\mathrm{N}$ & $\mathrm{N}$ & $\mathrm{N}$ & 1030 & Lab 01 \\
\hline $\begin{array}{l}\text { Miniagitador } \\
\text { Mecânico }\end{array}$ & \multicolumn{2}{|c|}{ QUIMIS Q-235-2 } & $\mathrm{N}$ & $\mathrm{N}$ & $\mathrm{N}$ & IO 31 & Lab 01 \\
\hline $\begin{array}{l}\text { Agitador } \\
\text { Magnético } 02\end{array}$ & \multicolumn{2}{|c|}{ CORNING PC 410} & $\mathrm{~N}$ & $\mathrm{~N}$ & $\mathrm{~N}$ & 1032 & Lab 01 \\
\hline Mufla 01 & \multicolumn{2}{|c|}{ EDG 1800} & $\mathrm{~N}$ & $\mathrm{~N}$ & $\mathrm{~N}$ & 1033 & Lab 01 \\
\hline Estufa 02 & \multicolumn{2}{|c|}{ ETHIK TECHNOLOGY 42O/D } & $\mathrm{N}$ & $\mathrm{N}$ & $\mathrm{N}$ & 1034 & Lab 01 \\
\hline $\begin{array}{l}\text { Agitador } \\
\text { Magnético } 03\end{array}$ & \multicolumn{2}{|c|}{ FISATOM 752A } & $\mathrm{N}$ & $\mathrm{N}$ & $\mathrm{N}$ & 1035 & Lab 01 \\
\hline $\begin{array}{l}\text { Termômetros } \\
\text { Calibrados }\end{array}$ & \multicolumn{2}{|c|}{ Modelos e marcas variados } & $\mathrm{N}$ & $\mathrm{S}$ & $S$ & 1036 & Lab 01 \\
\hline $\mathrm{HACHO} O 2$ & \multicolumn{2}{|c|}{ HACH - DR 2500} & $\mathrm{~S}$ & $\mathrm{~N}$ & $\mathrm{~N}$ & 1037 & Lab 02 \\
\hline Pesos Padrão & \multicolumn{2}{|c|}{ Modelos e marcas variados } & $\mathrm{N}$ & $\mathrm{S}$ & $S$ & 1038 & Lab 01 e Lab 02 \\
\hline $\begin{array}{l}\text { Condutivímetro } \\
\text { Portátil }\end{array}$ & \multicolumn{2}{|c|}{$\begin{array}{l}\text { GEHAKA Microprocessado } \\
\text { CG } 220\end{array}$} & $\mathrm{~N}$ & $\mathrm{~N}$ & $\mathrm{~N}$ & 1039 & Lab 01 \\
\hline \multicolumn{8}{|l|}{ Legenda: } \\
\hline \multicolumn{2}{|c|}{ MP - manutenção preventiva } & \multicolumn{3}{|l|}{ C - calibração } & \multicolumn{3}{|c|}{ V- verificação } \\
\hline \multicolumn{2}{|l|}{$\mathrm{DA}$} & \multicolumn{2}{|l|}{$\mathrm{GT}$} & & & \multicolumn{2}{|r|}{ GQ } \\
\hline Data & & Data & 1 & & & Dat & 11 \\
\hline
\end{tabular}


Figura 17. Cópia ilustrativa de uma página da Ficha do Equipamento (ANEXO 5) do POP 001 - Equipamentos

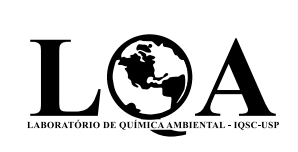

\section{ANEXO 5 - FICHA DO EQUIPAMENTO (POP 001)}

FE No 1

\begin{tabular}{|c|c|c|}
\hline \multicolumn{3}{|c|}{ DADOS TÉCNICOS - IO no 01} \\
\hline $\begin{array}{l}\text { Identificação: } \\
\text { xxxx }\end{array}$ & \multicolumn{2}{|c|}{$\begin{array}{l}\text { Nome do equipamento, fabricante e modelo: } \\
\text { xxxx }\end{array}$} \\
\hline \multicolumn{3}{|c|}{$\begin{array}{l}N^{\circ} \text { série, Patrimônio e Origem da Verba: } \\
\text { xxxx }\end{array}$} \\
\hline$\square$ Manutenção Preventiva & $\square$ Calibração & $\square$ Manual Técnico \\
\hline \multicolumn{3}{|c|}{ Local de arquivamento do IO, Registro e Manuais: xxxx } \\
\hline \multicolumn{3}{|c|}{ Número de supervisões requeridas após o treinamento: $x x x x$} \\
\hline \multicolumn{3}{|c|}{ DADOS OPERACIONAIS } \\
\hline \multicolumn{3}{|c|}{$\begin{array}{l}\text { Autorizados a manusear o equipamento (após treinamento): } \\
\square \text { DA } \square \text { GT } \square \text { GQ } \square \text { Pós-doutorandos } \square \text { Doutorandos } \square \text { Mestrandos } \square \text { IC }\end{array}$} \\
\hline \multicolumn{3}{|l|}{$\begin{array}{l}\text { Fornecedores Manutenção: } \\
\text { xxxx }\end{array}$} \\
\hline \multicolumn{3}{|l|}{$\begin{array}{l}\text { Fornecedores Calibração: } \\
\text { xxxx }\end{array}$} \\
\hline \multicolumn{3}{|c|}{ Tolerância do equipamento (dada no manual): xxxx } \\
\hline Critério de aceitação (um te & ncia): xxxx & \\
\hline
\end{tabular}

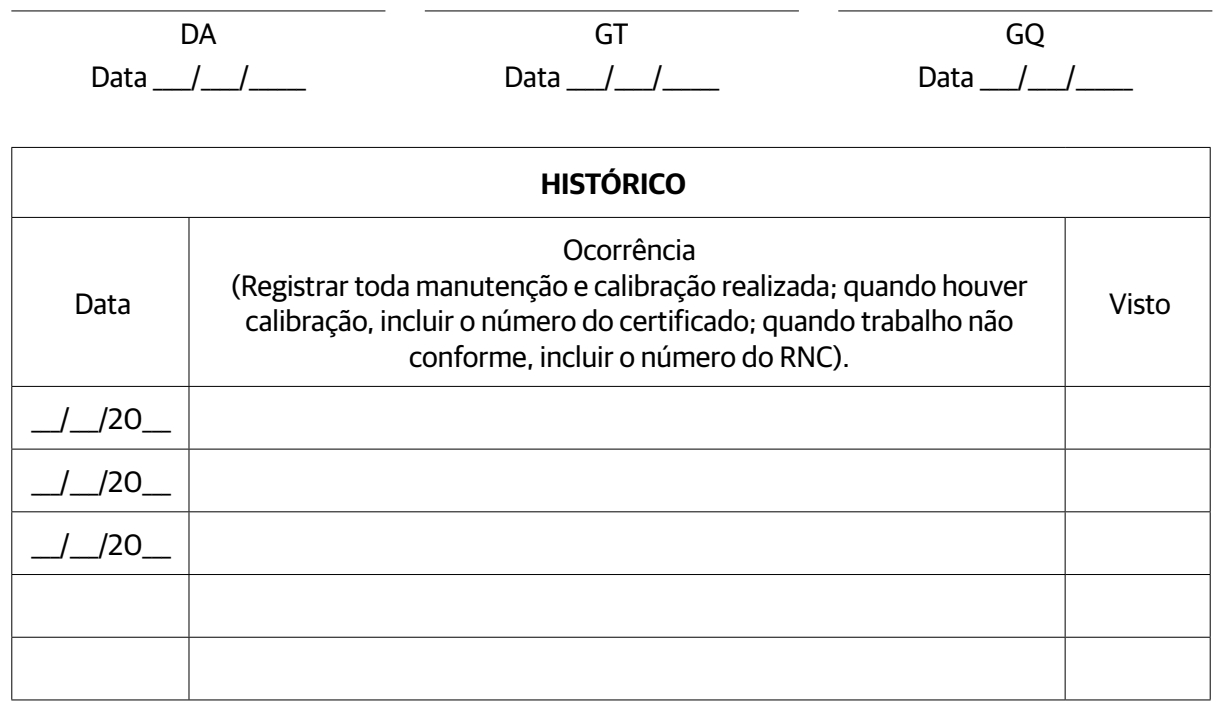




\subsection{Treinamentos}

O LQA provê treinamento e supervisão adequada, conforme cada Instrução Operacional dos equipamentos.

Agerência do LQA controla a competência de todos os queoperamequipamentos, fornecendo treinamento adequadoe supervisões, conforme POP020-Planejamento da Pesquisa (Figura 18).

Figura 18. Cópia ilustrativa do POP 020 - Planejamento da Pesquisa

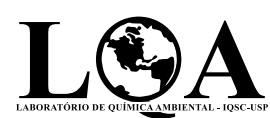

PLANEJAMENTO DA PESQUISA

POP 020

REV: X FL 1 DE 2

DATA $/ 20$

\section{OBJETIVO}

1.1 Dar condições para o desenvolvimento de um projeto de pesquisa que possa ser divulgado cientificamente e que promova a formação de pessoas.

\section{APLICAÇÃO}

2.1 Este procedimento se aplica ao planejamento da pesquisa de todos os pesquisadores que compõem o quadro do LQA e atende aos requisitos 4.1.5g e 4.1.6 do Manual da Qualidade do Laboratório de Química Ambiental.

\section{CONDIÇÕES GERAIS}

3.1 O planejamento das pesquisas e as responsabilidades dos pesquisadores e da diretora acadêmica, entre outros, estão definidos no Manual da Qualidade do Laboratório de Química Ambiental. Os formulários e termos de conhecimento relacionados aos requisitos do Manual da Qualidade estão listados nesse documento.

\section{CONDIÇÕES ESPECÍFICAS}

4.1 Antes do início do trabalho, o pesquisador interno deve assinar os documentos Termo de Conhecimento e Termo de Conduta Profissional, que atestam que ele tomou conhecimento da descrição de seu cargo, e Treinamento de Pessoas Externas e Cartilha do Ingressante. Quando de sua saída, o pesquisador assina o Termo de Desligamento. Todos esses documentos fazem parte do POP 019 - Responsabilidades.

\subsubsection{Projeto de pesquisa}

O planejamento da pesquisa inicia-se com a elaboração de um projeto de pesquisa embasado na literatura. Esse projeto deve compreender, em linhas gerais, um resumo, introdução e justificativa, objetivos, plano de trabalho e cronograma, material e métodos e forma de análise dos resultados. O LQA espera que o candidato participe intensamente na redação do projeto. A responsabilidade pelo projeto é de ambos, mas o candidato deve estar preparado para discuti-lo e para analisar os resultados.

4.1.2 Desenvolvimento da pesquisa

A pesquisa deve ser desenvolvida dentro do cronograma proposto no projeto de pesquisa, com acompanhamento periódico e constante, de acordo com cada necessidade. Espera-se que o pesquisador execute seu projeto específico de maneira ética, participe proativamente de todas as atividades do LQA, incluindo outras pesquisas, coopere com o sistema de qualidade e preserve a boa imagem do LQA. Todos os pesquisadores devem preencher a Agenda Mestra, que reporta a rotina da pesquisa, para estabelecer uma linha de auditoria (ver POP 003 - Agenda Mestra).

4.1.3 Apresentação dos resultados

Os resultados da pesquisa devem ser relatados na forma de tese, dissertação, monografia, artigos, livros, capítulos de livro, relatórios, resumos, palestras em congressos etc. Recomenda-se também que sejam divulgados na forma de atividades de extensão, com vistas a aproximar a universidade da comunidade. 
Figura 18. Continuação...

\section{LQA \\ POP 020 \\ PLANEJAMENTO DA PESQUISA \\ REV: X FL 2 DE 2 \\ DATA_I_/20}

\section{RESPONSABILIDADES}

5.1 IQSC

Aprova pesquisadores de iniciação científica, mestrado, doutorado e pós-doutorado (Lab.

Pesquisa níveis 1, 2, 3 e 4, respectivamente).

5.2 Pesquisador

Disponibiliza currículo e horários disponíveis para a realização do trabalho.

5.3 DA

Avalia currículo, desempenho acadêmico e horários disponíveis dos pesquisadores níveis 1, 2,3 e 4 . A diretora acadêmica pode aprovar alunos estagiários. Identifica a necessidade de treinamento ao realizar o planejamento de pesquisa.

5.4 Pesquisador

Confirma conhecimento do POP 019 - Responsabilidades e do Anexo 1 - Certificado de Treinamento Prático.

\section{ANEXOS}

Anexo 1 - Certificado de Treinamento Prático (CTP).

\section{APROVAÇÃO}

\begin{tabular}{|l|l|l|l|}
\hline Autor & Aprovado por & Assinatura & Data \\
\hline & & & \\
\hline
\end{tabular}

Para o bom uso dos equipamentos, é mandatório que eles se encontrem em condições ambientais adequadas, conforme já destacado no POP 001 - Equipamentos, e em local apropriado, conforme cada IO. Há um procedimento específico para limpeza do LQA (Figura 19). 
Figura 19. Cópia ilustrativa do POP 005 - Limpeza do Laboratório

LIMPEZA DO LQA $\frac{\text { POP } 005}{\text { REV:X FL 1DE } 1}$

\section{OBJETIVO}

Estabelecer a sistemática para limpeza das instalações do LQA.

\section{DOCUMENTOS COMPLEMENTARES}

POP 020 - Responsabilidades.

POP 006 - Descarte de Resíduos.

\section{PROCEDIMENTO}

A limpeza da estrutura física do LQA ajuda a promover um ambiente confortável e seguro para a execução dos trabalhos.

O lixo comum é descartado no lixo. Os resíduos são descartados conforme o POP 008 - Descarte de Resíduos.

Para evitar contaminação cruzada, a limpeza das bancadas, dos armários e das capelas é feita com material descartável.
3.1 Piso
O piso é limpo pelo pessoal da limpeza. Os procedimentos devem obedecer aos descritos no PT 001 - Responsabilidades.

\subsection{Bancadas, capelas e armários}

As bancadas e capelas devem ser limpas após o uso, enquanto os armários devem ser limpos quando necessário.

Para a limpeza, o pesquisador responsável deverá:

a) Retirar os materiais e colocá-los em local adequado, prevenindo danos e/ou acidentes.

b) Retirar a sujeira com cuidado para não sujar o chão.

c) Esfregar com esponja úmida com detergente.

d) Retirar o excesso de espuma.

e) Enxaguar com esponja úmida.

f) Secar o local.

g) Finalizar a limpeza com etanol comercial.

Quando houver derramamento de materiais de referência, reagentes ou amostras, secar o local com papel descartável ou juntar o material com auxílio de espátulas e papel absorvente. Descartar o papel conforme POP 008. A limpeza da área deverá seguir os procedimentos normais de limpeza.

Quando necessário, utilizar os EPIs adicionais para a limpeza.

\section{RESPONSABILIDADES}

4.1 Pesquisador (que utilizou o local): limpar bancadas e capelas após o uso.

4.2 Gerente técnico: supervisionar a limpeza dos armários em dia preestabelecido.

4.3 Pesquisadores: limpar os armários em dia preestabelecido.

\section{APROVAÇÕES}

\begin{tabular}{|l|l|l|}
\hline Autor & Aprovado/ Assinatura & Data \\
\hline & & \\
\hline
\end{tabular}


Os resultados dos ensaios são supervisionados pela alta direção e avaliados criticamente. $\mathrm{O}$ pessoal querealiza tarefas específicaséqualificadocombasenaformação, treinamento, experiência apropriada e/ou habilidades demonstradas, conforme descrito no POP 019-Responsabilidades (Tabela 2) e no POP 020 - Planejamento da Pesquisa (Figura 18). O POP 019 - Responsabilidades discrimina, como mencionado, as responsabilidades dos membros do LQA e dá providências acerca dessas responsabilidades, a saber: $(i)$ o Treinamento de Pessoas Externas - TPE (Anexo 1) apresenta as obrigações dos pesquisadores internos doLQA com respeito ao pessoal da limpeza, aos prestadores de serviços eaos pesquisadores externos ao LQA, poisé dever de todos conhecer eatentar para a segurança de terceiros; (ii) a Cartilha do Ingressante-CI(Anexo 2) apresenta alguns procedimentos simples de segurança e prática laboratorial, pois é dever de todos conhecerem e adotarem esses procedimentos; (iii) o Termo de Conhecimento - TC (Anexo 3), que deve ser preenchido por todos os pesquisadores internos, atestando conhecimento nos documentos anteriormente exigidos; (iv) o Termo de Conduta Profissional-TCP(Anexo 4), que também deve ser preenchido por todos os pesquisadores internos, atestando, principalmente, conhecimento do Manual da Qualidade doLaboratório deQuímica Ambiental; (v)o Termo de Desligamento-TD (Anexo 5), que deve ser preenchido quando da saída do pesquisador (Figuras 20 a 24).

Cada pesquisador, quando da entrada no LQA, toma conhecimento de todos os documentos reportados no POP 019.

Figura 20. Cópia ilustrativa do Treinamento de Pessoas Externas (ANEXO 1) do POP 019 - Responsabilidades

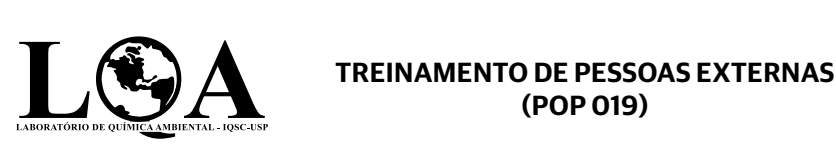

TPE

$\frac{\text { TPE }}{\frac{\text { REV: X FL 1 DE } 1}{\text { DATA___/20__ }}}$

É dever de todos os pesquisadores, quando estiverem dentro dos limites do LQA, cuidar da segurança de terceiros.

Todos os prestadores de serviço e pesquisadores externos devem ser orientados quanto aos procedimentos de segurança descritos a seguir:

\begin{tabular}{|l|l|}
\hline Pessoal da limpeza & $\begin{array}{l}\text { Devem ser acompanhados durante todo o período de limpeza em } \\
\text { que permanecerem no laboratório. } \\
\text { Não podem limpar bancadas nem equipamentos. A limpeza } \\
\text { restringe-se ao esvaziamento das lixeiras, às mesas na Sala de } \\
\text { Estudos e na sala da Profa. Maria Olímpia e ao piso de toda a área } \\
\text { do Laboratório. }\end{array}$ \\
\hline $\begin{array}{l}\text { Pessoal de manutenção / } \\
\text { Frestadores de Serviços / }\end{array}$ & $\begin{array}{l}\text { Devem ser acompanhados durante todo o período de } \\
\text { permanência no Laboratório. }\end{array}$ \\
\hline $\begin{array}{l}\text { Alunos / Professores / } \\
\text { Técnicos }\end{array}$ & $\begin{array}{l}\text { Devem ser acompanhados durante todo o período de } \\
\text { permanência no Laboratório. } \\
\text { Quando forem acompanhar algum ensaio, devem estar } \\
\text { devidamente vestidos com jalecos. }\end{array}$ \\
\hline
\end{tabular}

Eventuais usuários de equipamentos

Devem ser acompanhados durante todo o período de permanência no Laboratório.

Poderão acompanhar a realização dos ensaios realizados por pesquisador interno, mas jamais manusear um equipamento do LQA. Quando acompanharem a realização de um ensaio, devem estar devidamente vestidos com jalecos. 
Figura 21. Cópia ilustrativa da Cartilha do Ingressante (ANEXO 2) do POP 019 - Responsabilidades

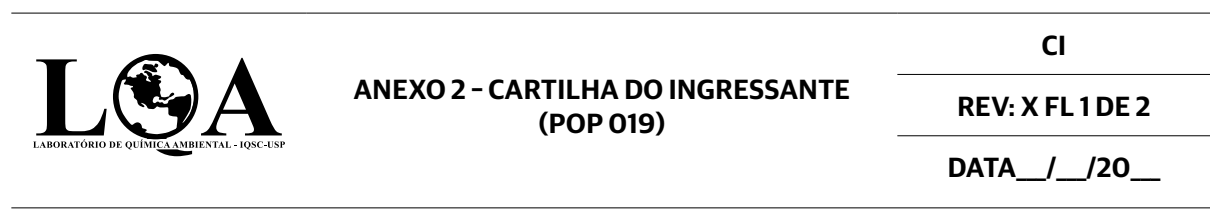

\section{SEGURANÇA}

Segurança é um assunto de máxima importância, por isso especial atenção deve ser dada às medidas de segurança pessoal e coletiva em um laboratório químico. Embora não seja possível enumerar aqui todas as normas de segurança, existem certos cuidados básicos decorrentes do uso do bom senso e de conhecimentos científicos que devem ser observados, por exemplo:

\begin{tabular}{|c|c|}
\hline 1.1 & $\begin{array}{l}\text { O laboratório é lugar de trabalho sério. Trabalhe com atenção, método e calma. Conheça } \\
\text { a localização e saiba usar o chuveiro de emergência e o lava-olhos. }\end{array}$ \\
\hline 1.2 & Para pipetar, use pera de borracha; para aspirar o líquido, use seringa, e nunca a boca. \\
\hline 1.3 & Nunca deixe frascos contendo solventes inflamáveis abertos ou expostos ao sol. \\
\hline 1.4 & $\begin{array}{l}\text { Água e outros produtos derramados no chão podem tornar o piso escorregadio, por isso } \\
\text { providencie imediatamente a limpeza. }\end{array}$ \\
\hline 1.5 & $\begin{array}{l}\text { Vidros quebrados devem ser descartados, depois de limpos, em depósito de lixo para } \\
\text { vidros. }\end{array}$ \\
\hline 1.6 & Nunca retorne ao frasco um reagente retirado em excesso. \\
\hline 1.7 & $\begin{array}{l}\text { Uso obrigatório de jaleco, sapato fechado e calça comprida para manusear qualquer } \\
\text { produto/equipamento. }\end{array}$ \\
\hline 1.8 & $\begin{array}{l}\text { Uso obrigatório de capelas, luvas e óculos quando manusear reagentes perigosos e } \\
\text { tóxicos. }\end{array}$ \\
\hline 1.9 & Ler sempre o rótulo antes de manusear reagentes. \\
\hline 1.10 & $\begin{array}{l}\text { Descartar os resíduos gerados em frascos devidamente rotulados e identificados quanto } \\
\text { à origem do resíduo, conforme POP } 006 \text { - Descarte de Resíduos Químicos. }\end{array}$ \\
\hline 1.11 & $\begin{array}{l}\text { Ao manusear frascos de reagentes corrosivos, fazê-lo em cima da bancada e a uma } \\
\text { distância segura do corpo, isto é, deixar o frasco afastado da beirada para evitar acidentes } \\
\text { em caso de quebra acidental. }\end{array}$ \\
\hline 1.12 & Manusear vidraria de precisão, como seringas, sempre em cima da bancada. \\
\hline 1.13 & $\begin{array}{l}\text { Estagiários e alunos de IC só poderão permanecer no laboratório supervisionados pelo } \\
\text { gerente técnico, pela diretora acadêmica ou por pós-graduandos. }\end{array}$ \\
\hline 1.14 & $\begin{array}{l}\text { Qualquer trabalho experimental só poderá ser executado após treinamento prévio nos } \\
\text { IOs dos equipamentos que serão usados e no método aplicado. }\end{array}$ \\
\hline
\end{tabular}

\section{ORGANIZAÇÃO}

Organização e planejamento do trabalho são de fundamental importância para o bom desenvolvimento e resultado das pesquisas.

\footnotetext{
2.1 Usar materiais de referência, reagentes e soluções após o treinamento no POP 002 Manuseio de Materiais de Referência e preparo de Soluções Estoque.

2.2 Lavar os frascos e devolver a vidraria limpa e seca no armário (lugar certo) após o uso.
} 
Figura 21. Continuação...

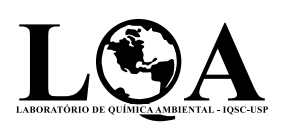

\section{ANEXO 2 - CARTILHA DO INGRESSANTE (POP 019)}

Cl

REV: X FL 2 DE 2

DATA_I_/20_

\begin{tabular}{|c|c|}
\hline 2.3 & $\begin{array}{l}\text { Devolver materiais de suporte, como tesoura, grampeador, etiquetas, fitas adesivas e } \\
\text { canetas, ao lugar de origem após o uso. }\end{array}$ \\
\hline 2.4 & Identificar o material ao colocá-lo para lavar ou deixar de molho. \\
\hline 2.5 & Deixar a vidraria de molho por, no máximo, três dias. \\
\hline 2.6 & Guardar o material de trabalho na geladeira em caixas identificadas. \\
\hline 2.7 & Manter a bancada limpa e organizada. \\
\hline 2.8 & $\begin{array}{l}\text { Solicitar reagente ou vidraria com antecedência conforme POP } 010 \text { - Aquisição de } \\
\text { Serviços e de Suprimentos. }\end{array}$ \\
\hline 2.9 & Colocar o papel de rascunho sempre da mesma forma na caixa de mesmo nome. \\
\hline 2.10 & Manter o jaleco limpo. \\
\hline 2.11 & Rotular as soluções e amostras com rótulos apropriados (conforme POP 011 - Insumos). \\
\hline 2.12 & Rotular soluções de trabalho com rótulos apropriados (conforme POP 011 - Insumos). \\
\hline 2.13 & Conferir o fechamento da porta de emergência ao trancar o laboratório. \\
\hline 2.14 & $\begin{array}{l}\text { Conferir se as luzes e o ar-condicionado estão desligados, e as torneiras, fechadas ao } \\
\text { trancar o laboratório. } \\
\text { Cuidado ao desligar o ar-condicionado - alguns equipamentos requerem o } \\
\text { ar-condicionado ligado quando em uso. }\end{array}$ \\
\hline
\end{tabular}

\section{ADICIONAIS}

\begin{tabular}{|l|l|}
\hline 3.1 & $\begin{array}{l}\text { Nunca colocar pipetas (graduadas ou volumétricas), balões volumétricos ou qualquer } \\
\text { material volumétrico em estufa ou refrigeradores para evitar perda da aferição. }\end{array}$ \\
\hline 3.2 & Nunca comer ou beber na área do laboratório. \\
\hline 3.3 & Cumprir os horários preestabelecidos de trabalho. \\
\hline 3.4 & Manter sempre fechada a porta das salas climatizadas. \\
\hline 3.5 & Manter a bancada do café limpa. \\
\hline 3.6 & Lavar e guardar xícaras, copos e talheres após o uso. \\
\hline 3.7 & Guardar os alimentos no frigobar. \\
\hline
\end{tabular}


Figura 22. Cópia ilustrativa do Termo de Conhecimento (ANEXO 3) do POP O19 - Responsabilidades

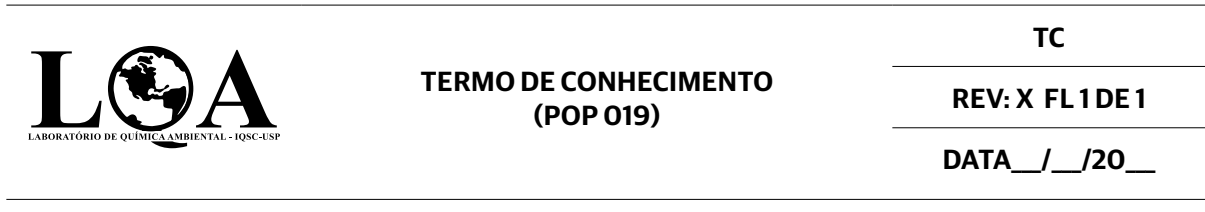

Eu, portador(a) do

documento de identidade $n^{0}$ declaro ter conhecimento da

Descrição de Cargos (DC), referente à função a mim atribuída.

Declaro ainda ter conhecimento da Cartilha do Ingressante $(\mathrm{Cl})$ e realizar as minhas atividades seguindo a Cartilha.

Declaro também ter conhecimento do Treinamento de Pessoas Externas (TPE) e auxiliar na segurança de terceiros quando estes permanecerem no LQA.

Declaro ainda ter conhecimento do Termo de Desligamento (TD).

\section{Assinatura do pesquisador}

São Carlos, de de 20.

\section{Se for o caso:}

Declaro ter uma cópia da chave do Laboratório de Química Ambiental (LQA) e estar ciente desta responsabilidade: NUNCA emprestar essa chave a qualquer pessoa e SEMPRE devolvê-la quando de minha saída do LQA. 
Figura 23. Cópia ilustrativa do Termo de Conduta Profissional (ANEXO 4) do POP 019 Responsabilidades

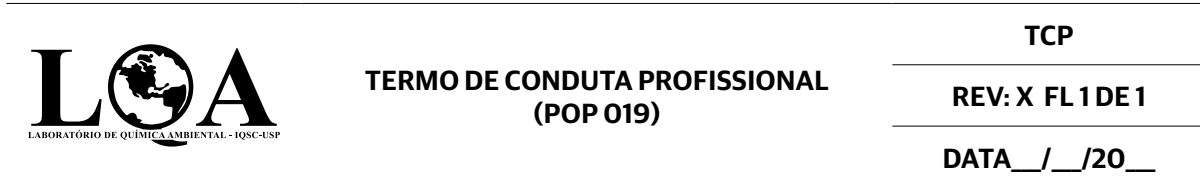

Declaro estar ciente da política, da missão e dos valores do LQA e desenvolver meu trabalho de acordo com essas condutas.

Estou ciente da forma como devo conduzir os meus relacionamentos com os pesquisadores internos e externos, fornecedores, órgãos governamentais e comunidade.

Estou ciente das minhas obrigações como pesquisador do LQA e como evitar conflitos de interesse.

Tenho pleno conhecimento do POP 020 - Responsabilidades.

Tenho pleno conhecimento do Manual da Qualidade do Laboratório de Química Ambiental.

Nome:

Assinatura:

Local e data: 
Figura 24. Cópia ilustrativa do Termo de Desligamento (ANEXO 5) do POP 019 - Responsabilidades

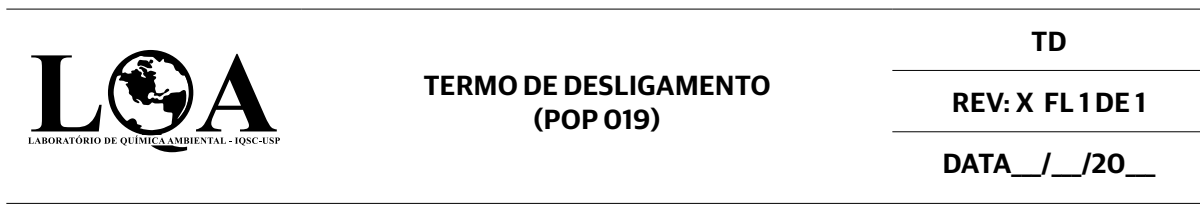

Eu, portador(a) do

documento de identidade no ao término de minha pesquisa no LQA, declaro que desocupei os armários por mim ocupados, descartei adequadamente os resíduos gerados e devolvi a chave do laboratório.

Assinatura do Pesquisador

São Carlos, de . de 20 .

Ciente: DA

\subsection{Pesquisa externa}

O LQA estabeleceu um procedimento para registro de pesquisas externas desenvolvidas no laboratório, conforme POP 015 - Pesquisa Externa ePOP 017-Prestação de Serviço. Compreende-se por pesquisa externa qualquer pesquisa desenvolvida por pesquisador que não pertença ao quadro do LQA. Prestação de serviço refere-se a serviços prestados à sociedade, solicitados por meio de pessoas física ou jurídica, que requeiram algum trabalho específico doLQA. Todos os ensaios são realizados por pessoal que compõe o quadro de pesquisadores do LQA. O POP 015 - Pesquisa Externa (Figura 25) e o respectivo anexo (Figura 26) auxiliam na compreensão da conduta para utilização do laboratório.

Com esse procedimento, registram-se todos os usuários externos que se utilizam das facilidades do LQA. 
Figura 25. Cópia ilustrativa do POP 015 - Pesquisa Externa

PESQUISA EXTERNA $\frac{\text { POP } 015}{\text { RATA_I_/20_ }}$

\section{OBJETIVO}

1.1 Estabelecer a sistemática para planejamento da pesquisa externa.

\section{APLICAÇÃO}

2.1 Este procedimento se aplica ao planejamento da pesquisa externa e atende ao requisito 4.4.2 do Manual da Qualidade do Laboratório de Química Ambiental.

\section{CONDIÇÕES GERAIS}

3.1 Toda pesquisa externa realizada nas dependências do LQA passa por um planejamento para garantir que os requisitos estejam documentados.

\section{CONDIÇÕES ESPECÍFICAS}

4.1 O pesquisador externo que deseja utilizar as instalações e os equipamentos do LQA deve preencher o APE.

\section{RESPONSABILIDADES}

5.1 DA

No ingresso de pesquisadores externos, a DA preenche a APE.

\section{FORMULÁRIOS}

Análise de Pesquisa Externa (APE).

\section{APROVAÇÕES}

\begin{tabular}{|l|l|l|}
\hline Autor & Aprovado / Assinatura & Data \\
\hline & & \\
\hline
\end{tabular}


Figura 26. Cópia ilustrativa de uma página da Análise de Pesquisa Externa (ANEXO 1) do POP 015 Pesquisa Externa

\begin{tabular}{|l}
\hline PESQUISADOR: \\
\hline LABORATÓRIO / ORIENTADOR:
\end{tabular}

DESCRIÇÃO DA PESQUISA:

Especificar os equipamentos do LQA que serão usados:

METODOLOGIAS - especificar:

OBSERVAÇÕES

\begin{tabular}{|l|l}
\hline VISTO DA: & DATA: \\
\hline
\end{tabular}




\subsubsection{Prestação de serviço}

No caso de prestação de serviço à sociedade, o serviço solicitado é executado integralmente por um pesquisador do LQA. A prestação de serviço pode compreender a cooperação técnica com outros pesquisadores. OPOP 017- Prestação de serviço (Figura 27) e os respectivos anexos (Figuras 28 a 40) auxiliam na compreensão da conduta para utilização do laboratório.

Com esse procedimento (POP 017), temos as bases para avaliar se o LQA tem competência quanto aos materiais, aos equipamentos e ao pessoal treinado para analisar as amostras trazidas por clientes ou por pesquisadores externos e desenvolver os projetos de pesquisa dos pesquisadores internos ao LQA. 
Figura 27. Cópia ilustrativa do POP 017 - Prestação de Serviço

PRESTAÇÃO DE SERVIÇO $\frac{\text { POP } 017}{\text { REV: X FL 1DE 5 }}$

\section{OBJETIVO}

Estabelecer a sistemática para análise crítica das propostas, dos pedidos e dos contratos de prestação de serviço e pesquisa de outros laboratórios.

\section{APLICAÇÃO}

Este procedimento se aplica à análise crítica de ensaios de prestação de serviço e atende aos requisitos 4.4.1 do Manual da Qualidade do Laboratório de Química Ambiental.

\section{CONDIÇÕES GERAIS}

3.1 Todos os ensaios realizados no LQA passam por uma análise crítica para garantir que os requisitos estão definidos, documentados e entendidos, que o LQA tem capacidade e recursos para atender aos requisitos e que um método adequado foi selecionado. Entende-se por análise crítica a definição apresentada no DOQ-CGCRE-035, item 7. Pela natureza dos ensaios, as análises críticas para a prestação de serviços e para a pesquisa diferem entre si.

3.2 Para facilitar a identificação, as amostras recebem uma etiqueta de cor: as de prestação de serviço recebem etiquetas verdes e, se conveniente, as de pesquisa recebem etiquetas amarelas.

3.3 Quaisquer modificações significativas, desvios das condições normais e discussões pertinentes relacionados aos requisitos ou resultados durante o período de execução do contrato ou da pesquisa são registrados no Relatório de Amostras, Identificação e Planejamento de Ensaios - RAIPE (Anexo 9). A inspeção das amostras no recebimento é registrada na Inspeção de Amostras - IA (Anexo 6).

\section{CONDIÇÕES ESPECÍFICAS}

\subsection{Análise crítica}

4.1.1 A análise crítica pode se referir a um conjunto de ensaios realizados de uma única vez (um único recebimento) ou em etapas (vários recebimentos de amostras). Desde que os requisitos sejam mantidos, a análise crítica não precisa ser repetida.

4.1.2 Todas as diferenças são resolvidas antes da aprovação do pedido.

4.1.3 Se houver necessidade de subcontratação de um laboratório, é necessário que este atenda aos requisitos da qualidade.

4.2 Análise crítica da prestação de serviço

4.2.1 A análise crítica pode ser realizada perante solicitação de proposta pelo cliente ou no recebimento de amostras.

NOTA: 'Cliente' pode se referir a pesquisador de outro laboratório.

4.2.2 A análise crítica é registrada no documento Análise Crítica de Contrato - ACC (Anexo 1).

4.2.3 Quando o pedido é aprovado, um Contrato de Prestação de Serviço - CPS (Anexo 2) é emitido. Para aceitar, o cliente é instruído a preencher a Autorização de Serviço, última página do CPS.

4.3 Escolha dos métodos

4.3.1 O método é escolhido em função do estudo.

4.4 Amostragem

4.4.1 A amostragem é um "procedimento definido, pelo qual uma parte de uma substância, material ou produto, é retirado para produzir uma amostra representativa do todo, para ensaio ou calibração." (NIT-DICLA-057, item 6.1). Sempre que viável, as orientações do Guia Nacional de Coleta e Preservação de Amostras devem ser seguidas. 
Figura 27. Continuação...

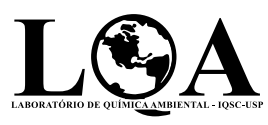

POP 017

PRESTAÇÃO DE SERVIÇO

REV: X FL 2 DE 5

DATA $/ Z / 20$

4.4.2 O Plano de Amostragem - PA (Anexo 3) é emitido pelo LQA, quando a responsabilidade for do laboratório, e com os procedimentos de amostragem adequados para cada caso. Quando realizada por terceiros, recomenda-se que a amostragem seja feita por pessoa competente.

4.4.3 As amostras enviadas pelo cliente têm sua identificação alterada para preservar o sigilo. As amostras são identificadas pelo número do Contrato de Prestação de Serviço - CPS (Anexo 2), seguido do ano e de um número em ordem crescente. No RAIPE, na aba 'Identificação', pode-se alterar a identificação da amostra.

4.5 Conservação de amostras

4.5.1 O documento Conservação de Amostras - CA (Anexo 4) é elaborado com base no Guia Nacional de Coleta e Preservação de Amostras e sempre emitido. As informações do CA são transmitidas ao cliente no Contrato de Prestação de Serviço - CPS.

4.5.2 Os frascos são limpos conforme procedimentos descritos no POP O09 - Limpeza de Vidraria.

4.6 Registro de Amostragem

4.6.1 As condições da amostragem são registradas na Cadeia de Custódia - CC (Anexo 5) ou documento equivalente.

4.7 Inspeção e Avaliação de Amostras Recebidas

4.7.1 As amostras são inspecionadas e avaliadas assim que recebidas no LQA.

4.7.2 A inspeção consiste em avaliar e registrar as condições de recebimento das amostras.

4.7.3 A avaliação é feita comparando-se os requisitos exigidos para os ensaios e as condições de recebimento das amostras.

4.7.4 Prestação de serviço: consultam-se os ensaios acordados no Contrato de Prestação de Serviço - CPS (Anexo 2), os ensaios solicitados na Cadeia de Custódia - CC (Anexo 5) e os requisitos de conservação de amostras descritos no Conservação de Amostras - CA (Anexo 4).

4.7.5 A conferência, a avaliação das condições de recebimento das amostras e as ações sobre amostras não conformes são registradas na Inspeção de Amostras - IA (Anexo 6).

4.8 Dúvidas sobre as Amostras ou Ensaios

4.8.1 Para amostras diferentes da descrição, ensaios não especificados ou quaisquer dúvidas, consulta-se o cliente antes de prosseguir com os ensaios.

4.9 Amostras Não Conformes

4.9.1 As amostras são consideradas não conformes quando os requisitos exigidos para os ensaios e as características de recebimento forem divergentes.

4.9.2 A ação sobre prosseguir ou não com os ensaios é registrada na Inspeção de Amostra - IA (Anexo 6). Discussões com o cliente ou com a Diretora Acadêmica e ação sobre prosseguir ou não com os ensaios são registradas no Relatório de Amostras, Identificação e Planejamento de Ensaios - RAIPE (Anexo 9).

4.9.3 Os impactos dos requisitos não conformes do recebimento são explicados ao cliente. O cliente é consultado sobre a decisão de prosseguir ou não com os ensaios. As discussões e a decisão do cliente são registradas na IA e no RAIPE e, preferencialmente, documentadas por e-mail com o cliente.

Quando da decisão de não prosseguir com os ensaios, as amostras podem ser devolvidas ao cliente ou descartadas conforme POP 006 - Descarte de Resíduos Químicos.

4.10 Alterações dos ensaios

4.10.1 Trabalhos alterados após a aprovação da análise crítica passam por nova análise crítica e todo pessoal afetado é comunicado.

4.11 Contato do LQA com o cliente 
Figura 27. Continuação...

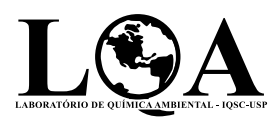

PRESTAÇÃO DE SERVIÇO

POP 017

REV: X FL 3 DE 5

DATA $/ Z / 20$

4.11.1 O LQA valoriza a comunicação com o cliente ao longo de todo o trabalho.

4.11.2 O cliente é notificado quando houver um recebimento de amostras não conforme.

4.11.3 O cliente é informado de qualquer desvio no contrato. Os desvios são justificados e precisam de aceitação do cliente.

4.11.4 As opiniões e interpretações dos resultados podem ser transmitidas nos Relatórios de Ensaio, mas são, preferencialmente, discutidas diretamente com o cliente, ocorrendo o registro do diálogo no Relatório de Amostras, Identificação e Planejamento de Ensaios - RAIPE (Anexo 9).

4.11.5 Após o envio dos relatórios de ensaio ao cliente, se detectada que uma não conformidade pode ter afetado os resultados enviados, o cliente é notificado.

4.11.6 O cliente recebe um feedback de toda opinião que possa ser interpretada como uma reclamação.

4.11.7 Reclamações ou elogios podem ser registrados no Relatório de Satisfação do Cliente RSC (Anexo 8) e podem gerar ações corretivas.

4.11.8 Todo contato, diálogos e discussões com o cliente são registrados no Relatório de Amostras, Identificação e Planejamento de Ensaios - RAIPE (Anexo 9) e, preferencialmente, retransmitidos ao cliente por e-mail.

4.11.9 O LQA se dispõe a cooperar com o cliente, desde que possa assegurar a confidencialidade dos outros clientes.

4.12 Relatórios

4.12.1 Apresentação de resultados de ensaio

4.12.1.1 Os resultados dos ensaios de prestação de serviço são apresentados aos clientes na forma de um Relatório de Ensaio - RE (Anexo 10). As informações para o preenchimento do RE são transcritas de vários documentos listados no quadro a seguir.

\begin{tabular}{|l|l|}
\hline RELATÓRIO DE ENSAIO & ORIGEM DAS ANOTAÇÕES \\
\hline Dados do cliente & Contrato de Prestação de Serviço - CPS (Anexo 2). \\
\hline $\begin{array}{l}\text { Dados da amostra e } \\
\text { amostragem }\end{array}$ & $\begin{array}{l}\text { Cadeia de Custódia - CC (Anexo 5). } \\
\text { Conservação de Amostras - CA (Anexo 4). } \\
\text { Plano de Amostragem - PA (Anexo 3), quando o LQA for } \\
\text { responsável pela amostragem. } \\
\text { NOTA: Reportar claramente quando o cliente for o responsável } \\
\text { pela amostragem (NIT-DICLA-057, item 9.4). }\end{array}$ \\
\hline Dados dos ensaios & $\begin{array}{l}\text { Inspeção de Amostras - IA (Anexo 6). } \\
\text { Relatório de Amostras, Identificação e Planejamento dos Ensaios } \\
\text { - RAIPE (Anexo 9). }\end{array}$ \\
\hline Resultados & $\begin{array}{l}\text { Registros de gerenciamento dos equipamentos. } \\
\text { Agenda Mestra - AM (POP 003). }\end{array}$ \\
\hline $\begin{array}{l}\text { Informações adicionais } \\
\text { Metodções ou exclusões dos } \\
\text { métodos ou da amostragem }\end{array}$ & $\begin{array}{l}\text { Especificar as abreviaturas usadas no RE e outras que se fizerem } \\
\text { necessárias. }\end{array}$ \\
\hline
\end{tabular}


Figura 27. Continuação...

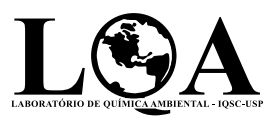

PRESTAÇÃO DE SERVIÇO

POP 017

REV: X FL 4 DE 5

DATA_I_ $/ 20$

\begin{tabular}{|l|l|}
\hline RELATÓRIO DE ENSAIO & ORIGEM DAS ANOTAÇÕES \\
\hline Opiniões e interpretações & $\begin{array}{l}\text { Expressas somente com bases documentadas. Preferencialmente } \\
\text { contatar o cliente e registrar a discussão no RAIPE (Anexo 9). }\end{array}$ \\
\hline Referência & Citar as legislações adotadas como referência. \\
\hline $\begin{array}{l}\text { Comparação com requisitos } \\
\text { e/ou especificações }\end{array}$ & $\begin{array}{l}\text { Se pertinente, declarar conformidade ou não conformidade com } \\
\text { a referência adotada. }\end{array}$ \\
\hline
\end{tabular}

4.12.1.2 Os resultados podem, quando acordados com o cliente, ser apresentados na forma reduzida de um Relatório de Ensaio - RE (Anexo 10), contemplando apenas os dados dos ensaios, resultados e informações adicionais.

Informações complementares estão prontamente disponíveis.

4.12.1.3 Com base no OGCOO2, item 7.2, o número de algarismos significativos é definido:

em coerência com a legislação e com o método de ensaio;

caso a incerteza não seja apresentada, apenas o último algarismo esteja afetado de dúvida;

caso a incerteza seja apresentada, o mesmo número de algarismos usado para a incerteza é usado para a apresentação dos resultados (no máximo dois).

4.12.1.4 Os resultados inferiores ao limite de quantificação são identificados como "<LQ".

4.12.1.5 Com base no OGCOO2, item 7.2, no caso de um resultado ser obtido pela soma de resultados individuais, em que um ou mais dos resultados individuais são inferiores ao LQ e um dos resultados é quantificável, o resultado pode ser expresso:

ignorando os resultados inferiores ao LQ;

sobre a forma de um intervalo (soma dos resultados quantificáveis $<x<$ soma de todos os resultados, incluindo os inferiores ao LQ, quando são somados os valores de LQ);

somando todos os resultados.

4.12.1.6 Com base no OGCOO2, item 7.2, no caso de um resultado ser obtido pela soma de resultados individuais, em que todos os resultados individuais são inferiores ao LQ, o resultado pode ser expresso:

pela soma dos limites de quantificação individuais ( $x<$ soma dos LQ); pela indicação do maior LQ $(x<L Q$ mais elevado).

4.13 Identificação de relatórios

4.13.1 Os Relatórios de Ensaio - RE (Anexo 10) são univocamente identificados com um número crescente formado por três dígitos, seguido de hífen e do ano (aaaa) da emissão do RE.

4.14 Controle de relatórios

4.14.1 O Controle de Relatórios de Ensaio - CRE (Anexo 11) é atualizado após a emissão de um RE.

4.15 Verificação dos Resultados

4.15.1 Após o término dos ensaios de prestação de serviço, os resultados, recursos e documentos utilizados são verificados, e os RE, verificados. 
Figura 27. Continuação...

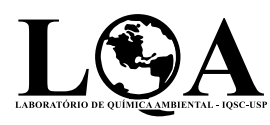

PRESTAÇÃO DE SERVIÇO

POP 017

REV: X FL 5 DE 5

DATA $\_/ 20$

4.15.2 Os resultados são tecnicamente verificados e a verificação é registrada na Lista de Verificação Técnica dos Resultados - LVTR (Anexo 12).

4.15.3 A documentação e os recursos utilizados são verificados e a verificação é registrada na Lista de Verificação de Recursos e Documentação utilizados durante os ensaios - LVRD (Anexo 13).

4.15.4 Erros diferem de não conformidades, pois os erros não infringem o sistema da qualidade. Os erros detectados na LVTR são corrigidos. Quando detectada uma não conformidade na LVTR ou LVRD, preenche-se um Relatório de Não Conformidade RNC (POP 014). Aguarda-se o parecer no RNC para considerar o resultado conforme (ou confiável) ou não conforme (ou não confiável).

4.16 Confidencialidade dos Resultados

4.16.1 Os resultados dos ensaios são mantidos seguros por meio de senhas. Os resultados são enviados ao cliente pela FAFQ, a qual procede à cobrança dos custos.

4.16.2 Apenas a Alta Direção tem acesso aos resultados dos ensaios, mantidos seguros por meio de senhas.

\section{RESPONSABILIDADES}

5.1 Todos do LQA

No recebimento da amostra, preenche-se a Inspeção de Amostras - IA (Anexo 6).

$5.2 \mathrm{GT}$

No recebimento de amostras ou pedido do cliente, realiza-se a Análise Crítica de Contrato

(ACC). Se necessário subcontratar o serviço, informa-se o cliente e anota-se no RAIPE

(Anexo 9).

Se ACC for aprovada, emite-se CPS e atualiza-se ACC. Se CPS for aprovado pelo cliente, atualiza-se ACC. Se ACC não for aprovada pelo LQA, ou CPS não for aprovado pelo cliente, tenta-se uma renegociação. Caso não seja possível a renegociação, comunica-se o cliente.

5.3 DA

Verifica-se a LVTR e assinam-se os REs.

5.4 GQ

Verifica-se o LVRD.

\section{ANEXOS}

Anexo 1 - Análise Crítica de Pedidos, Propostas e Contratos (ACC).

Anexo 2 - Contrato de Prestação de Serviço (CPS).

Anexo 3 - Plano de Amostragem (PA).

Anexo 4 - Conservação de Amostras (CA).

Anexo 5 - Cadeia de Custódia (CC).

Anexo 6 - Inspeção de Amostras (IA).

Anexo 8 - Anotação de Satisfação do Cliente (ASC).

Anexo 9 - Relatório de Amostra, Identificação e Planejamento de Ensaios (RAIPE).

Anexo 10 - Relatório de Ensaio (RE).

Anexo 11 - Controle de Relatórios de Ensaio (CRE).

Anexo 12 - Lista de Verificação Técnica dos Resultados (LVTR).

Anexo 13 - Lista de Verificação de Recursos e Documentação utilizados durante os ensaios (LVRD).

\section{APROVAÇÕES}

\begin{tabular}{|l|l|l|}
\hline Autor & Aprovado / Assinatura & Data \\
\hline & & \\
\hline
\end{tabular}


Figura 28. Cópia ilustrativa de uma página da Análise Crítica de Pedidos, Propostas e Contratos (ANEXO 1) do POP 017 - Prestação de Serviço

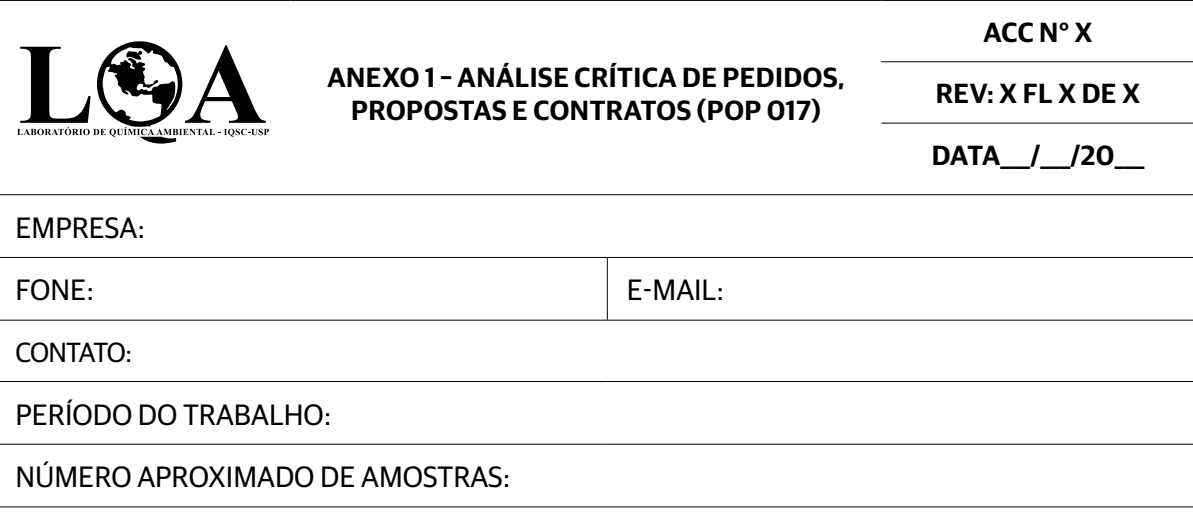

DESCRIÇÃO DO SERVIÇO:

\begin{tabular}{|l|l|l|}
\hline ANEXOS: & $\square$ SIM & $\square$ NÃO \\
\hline \hline TERCEIRIZAÇÃO DO SERVIÇO? & $\square$ SIM & $\square$ NÃO \\
\hline
\end{tabular}

LAB. TERCEIRIZADO:

\begin{tabular}{|c|c|c|}
\hline \multicolumn{3}{|c|}{ ANÁLISE CRÍTICA } \\
\hline \multicolumn{3}{|c|}{ VIABILIDADE TÉCNICA } \\
\hline EQUIPAMENTOS APROPRIADOS? & $\square$ SIM & $\square \mathrm{NÃO}$ \\
\hline METODOLOGIAS VALIDADAS? & $\square$ SIM & $\square$ NÃO \\
\hline IMPLEMENTAÇÃO DE MÉTODO (ME)? & $\square$ SIM. ME ${ }^{\circ}$ & $\square \mathrm{NÃO}$ \\
\hline \multicolumn{3}{|l|}{ Metodologias (especificar): } \\
\hline \multicolumn{3}{|c|}{ VIABILIDADE OPERACIONAL } \\
\hline TÉCNICO HABILITADO? & $\square \mathrm{SIM}$ & $\square$ NÃO \\
\hline MÃO DE OBRA DISPONÍVEL? & $\square \operatorname{SIM}$ & $\square$ NÃO \\
\hline PRAZO EXEQUÍVEL? & $\square \mathrm{SIM}$ & $\square$ NÃO \\
\hline \multicolumn{3}{|c|}{ VIABILIDADE FINANCEIRA } \\
\hline VALOR ADEQUADO? & $\square \mathrm{SIM}$ & $\square \mathrm{NÃO}$ \\
\hline PRAZO DE PAGAMENTO ADEQUADO? & $\square \operatorname{SIM}$ & $\square$ NÃO \\
\hline
\end{tabular}

\begin{tabular}{|l|l|l|l|}
\hline \multicolumn{4}{|c|}{ RESULTADOS DA ANÁLISE CRÍTICA PEDIDA } \\
\hline$\square$ APROVADO & $\square$ REPROVADO & VISTO GT: & DATA: \\
\hline
\end{tabular}


Figura 28. Continuação...

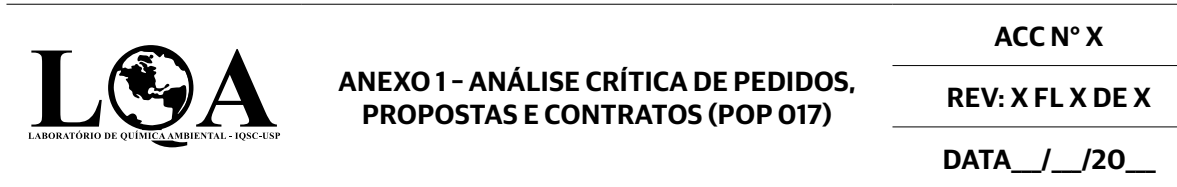

\begin{tabular}{|c|c|}
\hline OBSERVAÇÕES: & \\
\hline CPS $n^{\circ}:$ & \multirow[t]{7}{*}{ RELATÓRIOS DE ENSAIO: } \\
\hline PREÇO (R\$): & \\
\hline FORMA DE PAGAMENTO: & \\
\hline PRAZO DE ENSAIOS: & \\
\hline VALIDADE: & \\
\hline RESPONSÁVEL: & \\
\hline ACEITE DO CLIENTE - DATA & \\
\hline
\end{tabular}


Figura 29. Cópia ilustrativa do Contrato de Prestação de Serviço (ANEXO 2) do POP 017 - Prestação de Serviço

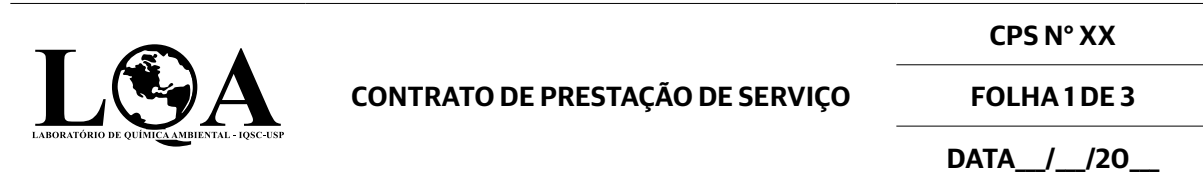

\section{DADOS DO CLIENTE}

Cliente: $x x x x$

Endereço: $x x x x$

Responsável: $x x x x$

Telefone: $x x x x$

E-mail: $x x x x$

\section{SERVIÇOS SOLICITADOS}

\begin{tabular}{|c|c|c|c|c|}
\hline Matriz & Parâmetros analíticos & Quant. de amostras & Valor unitário & Valor total \\
\hline- & - & - & - & - \\
\hline
\end{tabular}

\begin{tabular}{|c|}
\hline Metodologias adotadas \\
\hline- \\
\hline
\end{tabular}

\begin{tabular}{|l|c|}
\hline Preço total & - \\
\hline Prazo para entrega dos Relatórios de Ensaio & - \\
\hline
\end{tabular}

\section{CONDIÇÕES GERAIS}

Esta proposta é válida por 30 dias a partir da data de emissão.

Forma e condições de pagamento: via depósito bancário, xxx dias após a entrega dos resultados. Todos os pagamentos devem ser realizados via Fundação de Apoio à Física e à Química (FAFQ).

\section{OBSERVAÇÕES}

Para a realização do serviço, preencha a última folha deste documento: Autorização de Serviço, a qual deve ser encaminhada por e-mail ou com as amostras.

\section{OBSERVAÇÕES AO COLETOR}

Quando não contratada, a coleta é de inteira responsabilidade do CONTRATANTE e deve ser realizada por pessoal capacitado. A correta distribuição dos pontos de amostragem é de fundamental importância para a obtenção de uma amostragem de representação significativa da realidade.

- $\quad$ As amostras deverão vir acompanhadas da Cadeia de Custódia. Um modelo desse documento pode ser solicitado por e-mail. A Cadeia de Custódia deve ser preenchida pelo coletor e enviada com as amostras.

- $\quad$ Recipiente adequado para o envio da amostra: $x x x x x x x x x x x x x x x x x x x x x x x x x x x$ (material do frasco).

- $\quad$ Conservante adequado para a preservação da amostra: $x x x x x x x x x x x x x x x x x x x x x x x x x$.

- Volume ou massa necessários para as determinações: $\quad$ xxxxxxxxxxxxxxxxxxxxxxxxxxxx.

- $\quad$ Condições de transporte: $x x x x x x x x x x x x x x x x x x x x x x x x x$ (temperatura).

- $\quad$ Validade da amostra (após a coleta): $x x x x x x x x x x x x x x x x x x x x x x x x x x x$. 
Figura 29. Continuação...

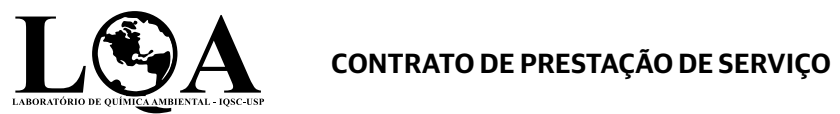

CPS $N^{\circ} X X$

FOLHA 2 DE 3

DATA $/ / 20$

\section{CONDIÇÕES GERAIS DE PRESTAÇÃO DE SERVIÇOS}

\section{Coleta das amostras}

Quando a coleta de amostras não for contratada, a coleta, a identificação, a preservação e o transporte das amostras serão de responsabilidade integral da contratante. Todas as informações referentes à coleta deverão ser transcritas na Cadeia de Custódia e encaminhada com as amostras. As amostras analisadas serão descartadas 30 dias após o envio dos resultados, salvo quando expressamente solicitada a estocagem ou devolução pela contratante.

\section{Condições de transporte e recebimento das amostras}

As amostras devem ser enviadas nas condições especificadas no item "OBSERVAÇÕES AO COLETOR".

Caso as amostras cheguem ao laboratório fora das condições ideais de preservação e identificação ou danificadas, a contratante será comunicada antes do início do serviço. Nesse caso, a responsabilidade pela realização do serviço e, consequentemente, por qualquer alteração dos resultados analíticos será exclusiva da contratante.

\section{Laboratórios Subcontratados}

A subcontratação de laboratórios pode ocorrer desde que o laboratório seja competente. A subcontratação atende aos requisitos da Norma NBR ISO/IEC 17025.

\section{Emissão dos Resultados}

Os resultados das análises serão emitidos no prazo indicado em cada item, contados em dias úteis a partir da entrada das amostras em nosso laboratório.

Para o início dos serviços, é indispensável a devolução da Autorização de Serviço devidamente preenchida. Os relatórios de ensaio e a nota fiscal serão enviados para o endereço presente na Autorização de Serviço.

\section{Preços}

O valor discriminado no orçamento inclui todos os impostos e demais encargos.

OLQA se reserva o direito de rever os preços estipulados no orçamento caso o número de amostras encaminhadas para análise, ou sua frequência, seja inferior ao inicialmente previsto, sendo cobrada a diferença eventualmente existente devido à economia de escala aplicada aos trabalhos.

\section{Pagamentos}

O prazo e a forma de pagamento estão estipulados na folha de rosto deste orçamento e em nenhuma hipótese serão alterados após o início dos trabalhos. Todos os pagamentos devem ser realizados via Fundação de Apoio à Física e à Química (FAFQ).

\section{Validade do orçamento}

As condições ora propostas serão válidas pelo período informado na folha de rosto deste orçamento.

\section{Termo de garantia}

Todas as informações referentes aos trabalhos, os resultados e os documentos afins serão mantidos arquivados e somente serão divulgados a terceiros mediante autorização prévia da contratante.

\section{Cancelamento}

O pedido de cancelamento, após o início do trabalho, não isenta o pagamento do valor desta proposta. 
Figura 29. Continuação..

\section{CONTRATO DE PRESTAÇÃO DE SERVIÇO}

CPS $N^{\circ} X X$

FOLHA 3 DE 3

DATA_I_/20_

\section{AUTORIZAÇÃO DE SERVIÇO}

Autorizo a realização: ( ) De todos os itens do orçamento

( ) Somente dos itens:

Autorizo o envio dos resultados por correio e para o e-mail

\section{A FATURA / COBRANÇA DEVE SER EMITIDA PARA:}

*Razão Social:

*Endereço:

*Cidade:

${ }^{*} \mathrm{CNPJ} / \mathrm{CPF}$ :

*Fone:

*Nome completo de quem deverá receber a cobrança/fatura:

*Estado:

${ }^{*} \mathrm{IE}$ :

E-mail:
*Bairro:

${ }^{*} \mathrm{CEP}$ :

\section{O RELATÓRIO DE ENSAIO DEVE SER EMITIDO PARA:}

Razão Social:

Endereço:

Cidade:

*CNPJ/CPF:

Fone:

Estado: Bairro:

Nome completo de quem deverá receber o relatório de ensaio:

Os campos marcados com $\left({ }^{*}\right)$ são de preenchimento obrigatório. As análises somente terão início mediante a devolução deste formulário devidamente preenchido.

Esta autorização deve ser encaminhada por e-mail ou com as amostras.

As amostras deverão vir acompanhadas da cadeia de custódia.

DATA

\section{CARIMBO, NOME E ASSINATURA DO RESPONSÁVEL}


Figura 30. Cópia ilustrativa do Plano de Amostragem (ANEXO 3) do POP 017 - Prestação de Serviço

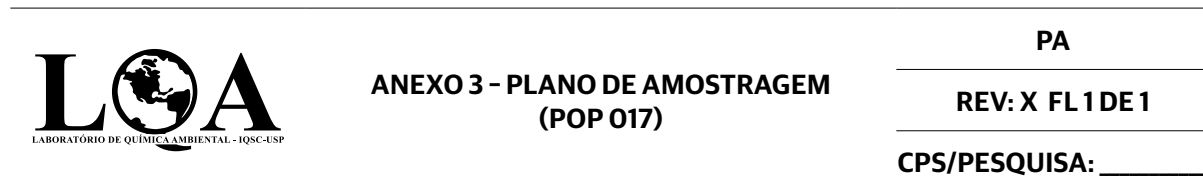

\begin{tabular}{|l|}
\hline \multicolumn{1}{|c|}{ AMOSTRAGEM } \\
\hline Finalidade do ensaio: \\
\hline Descrição do local: \\
\hline Histórico do local: \\
\hline Qual método reconhecido é utilizado para amostragem? \\
\hline $\begin{array}{l}\text { Anexos complementares (diagramas, métodos de amostragem, distribuição dos pontos de } \\
\text { amostragem e mapas): }\end{array}$ \\
\hline Quantidade de pontos a serem amostrados: \\
\hline Profundidade extração: \\
\hline Equipamentos requerem limpeza especial? \\
\hline Condições ambientais interferem na amostragem? \\
\hline
\end{tabular}

OBSERVAÇÕES

\section{RESPONSÁVEL}

Responsável pelo plano de amostragem: Data:

Responsável pela coleta: 
Figura 31. Cópia ilustrativa da Conservação de Amostras (ANEXO 4) do POP 017 - Prestação de Serviço

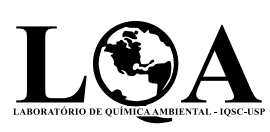

ANEXO 4 - CONSERVAÇÃO DE AMOSTRAS (POP 017)

CA

REV: X FL 1 DE 1

CPS/PESQUISA:

\section{CLIENTE:}

PROJETO:

\begin{tabular}{|c|c|c|c|c|c|c|c|}
\hline \multicolumn{8}{|c|}{ PLANEJAMENTO POR PARÂMETRO } \\
\hline \multirow[t]{2}{*}{ 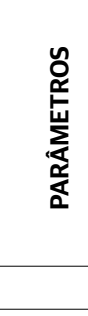 } & $\frac{\frac{N}{\alpha \tilde{E}}}{\frac{\Sigma}{\Sigma}}$ & 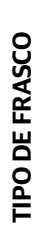 & 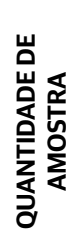 & 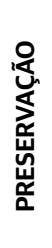 & 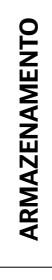 & 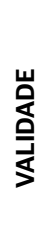 & 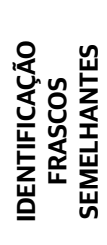 \\
\hline & & & & & & & \\
\hline & & & & & & & \\
\hline & & & & & & & \\
\hline & & & & & & & \\
\hline & & & & & & & \\
\hline & & & & & & & \\
\hline & & & & & & & \\
\hline & & & & & & & \\
\hline & & & & & & & \\
\hline & & & & & & & \\
\hline & & & & & & & \\
\hline & & & & & & & \\
\hline $\begin{array}{l}\text { Inform } \\
\square \text { Guia } \\
\square \text { Out }\end{array}$ & 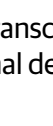 & & ão de & & & & \\
\hline
\end{tabular}

\begin{tabular}{|c|l|l|l|l|}
\hline \multicolumn{5}{|c|}{ PLANEJAMENTO POR FRASCOS SEMELHANTES } \\
\hline $\begin{array}{c}\text { IDENTIFICAÇÃO } \\
\text { FRASCOS } \\
\text { SEMELHANTES }\end{array}$ & $\begin{array}{c}\text { TIPO DE } \\
\text { FRASCO }\end{array}$ & $\begin{array}{c}\text { QUANTIDADE } \\
\text { DE AMOSTRA }\end{array}$ & PRESERVAÇÃO & ARMAZENAMENTO \\
\hline & & & & \\
\hline & & & & \\
\hline & & & & \\
\hline & & & & Data: \\
\hline \\
\hline
\end{tabular}


Figura 32. Cópia ilustrativa da Cadeia de Custódia (ANEXO 5) do POP 017 - Prestação de Serviço

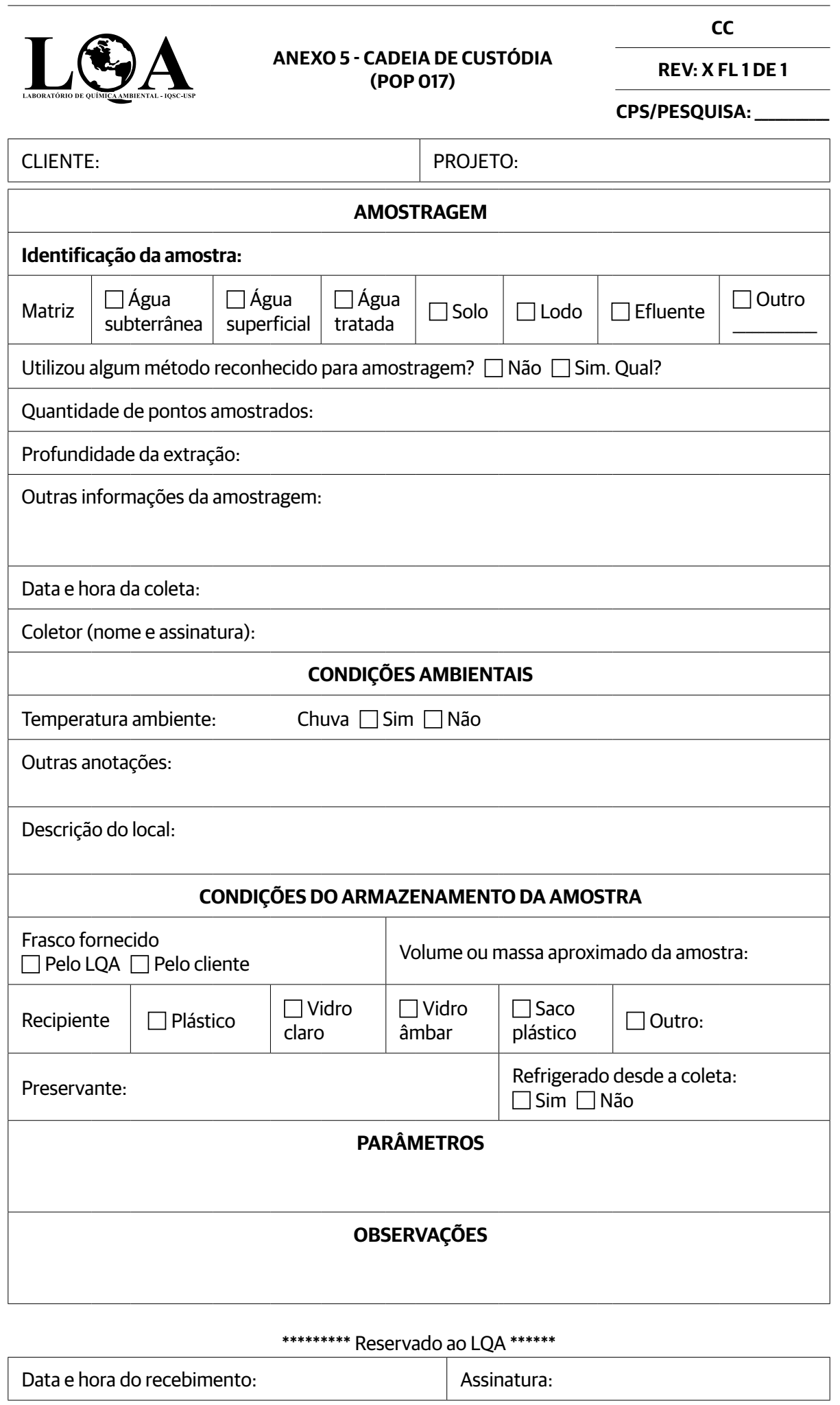


Figura 33. Cópia ilustrativa da Inspeção de Amostras (ANEXO 6) do POP 017 - Prestação de Serviço

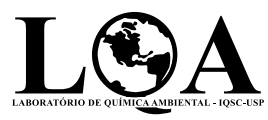
ANEXO 6 - INSPEÇÃO DE AMOSTRAS
(POP 017)

IA

REV: X FL 1 DE 1

DATA_I_/20

$\mathrm{N}^{\circ}$ contrato / Nome da pesquisa:

Responsável:

\begin{tabular}{|c|c|c|c|c|c|c|c|c|c|c|}
\hline \multicolumn{5}{|c|}{ Inspeção } & \multicolumn{5}{|c|}{$\begin{array}{c}\text { Avaliação* } \\
\text { C = Conforme } \\
\mathrm{NC}=\text { = Não conforme }\end{array}$} & \multirow{2}{*}{ 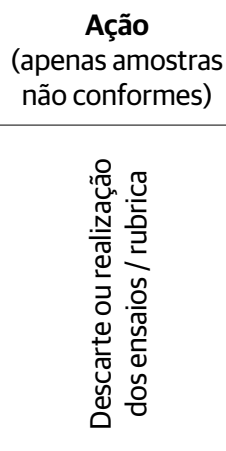 } \\
\hline 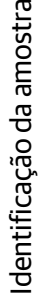 & 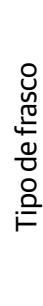 & 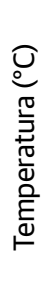 & 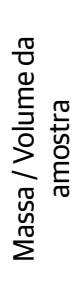 & 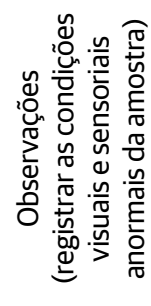 & 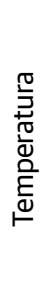 & 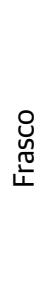 & 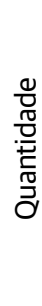 & 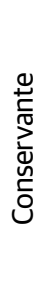 & $\begin{array}{l}\frac{0}{0} \\
\frac{\pi}{0} \\
\frac{D}{\pi}\end{array}$ & \\
\hline & & & & & & & & & & \\
\hline & & & & & & & & & & \\
\hline & & & & & & & & & & \\
\hline & & & & & & & & & & \\
\hline & & & & & & & & & & \\
\hline & & & & & & & & & & \\
\hline & & & & & & & & & & \\
\hline & & & & & & & & & & \\
\hline & & & & & & & & & & \\
\hline & & & & & & & & & & \\
\hline & & & & & & & & & & \\
\hline
\end{tabular}

*Avaliação:

Prestação de serviço: consulte a Cadeia de Custódia, o Contrato de Prestação de Serviço e, quando o LQA for responsável pela amostragem, o Plano de Amostragem.

Pesquisa: consulte a Cadeia de Custódia e o Plano de Amostragem.

\begin{tabular}{|l|l|l|}
\hline Inspeção das amostras & Data: & Assinatura: \\
\hline Avaliação das condições de recebimento & Data: & Assinatura: \\
\hline Ação (apenas amostras não conformes) & Data: & Assinatura \\
\hline
\end{tabular}


Figura 34. Cópia ilustrativa do Relatório de Reclamação de Cliente (ANEXO 7) do POP 017 - Prestação de Serviço

\begin{tabular}{|c|c|c|}
\hline \multirow{3}{*}{\multicolumn{2}{|c|}{$\begin{array}{l}\text { ANEXO 7 - RELATÓRIO DE RECLAMAÇÃO DE } \\
\text { CLIENTE (POP 017) }\end{array}$}} & $\operatorname{RRC~N}^{\circ} 1$ \\
\hline & & REV: X FL 1 DE 1 \\
\hline & & DATA_I_/20 \\
\hline \multicolumn{3}{|l|}{ EMPRESA: } \\
\hline \multicolumn{3}{|l|}{ CONTATO: } \\
\hline \multicolumn{3}{|l|}{ CPS n ${ }^{\circ}:$} \\
\hline \multicolumn{3}{|c|}{ DESCRIÇÃO DA RECLAMAÇÃO } \\
\hline \multicolumn{2}{|l|}{ VISTO GQ: } & DATA: \\
\hline \multicolumn{3}{|c|}{ ANÁLISE DA RECLAMAÇÃO } \\
\hline$\square$ PROCEDE & \multicolumn{2}{|l|}{$\square$ NÃO PROCEDE } \\
\hline \multicolumn{3}{|l|}{ JUSTIFICATIVA: } \\
\hline VISTO GQ: & \multicolumn{2}{|l|}{ DATA: } \\
\hline \multicolumn{3}{|c|}{ AÇÃO CORRETIVA? $\square$ NÃO $\square$ SIM. SAC n } \\
\hline \multicolumn{3}{|c|}{ COMUNICAÇÃO COM CLIENTE } \\
\hline VISTO DA: & & DATA: \\
\hline \multicolumn{3}{|c|}{ FECHAMENTO DO PROCESSO } \\
\hline $\begin{array}{l}\text { CLIENTE NOTIFICADO? } \\
\square \operatorname{Sim} \square \text { Não }\end{array}$ & $\begin{array}{l}\text { AÇÃO CORRETIVA? } \\
\square \operatorname{Sim} \square \text { Não se aplica }\end{array}$ & \\
\hline \multicolumn{2}{|l|}{ VISTO GQ: } & DATA: \\
\hline
\end{tabular}


Figura 35. Cópia ilustrativa de uma página da Anotação de Satisfação de Clientes (ANEXO 8) do POP 017 - Prestação de Serviço

\begin{tabular}{l} 
ANEXO 8-ANOTAÇÃO DE SATISFAÇÃO \\
$\begin{array}{ll}\text { DE CLIENTES (POP 017) } \\
\text { EMPRESA: }\end{array}$ \\
\hline CONTATO: \\
\hline CPS $\mathrm{n}^{\circ}:$
\end{tabular}

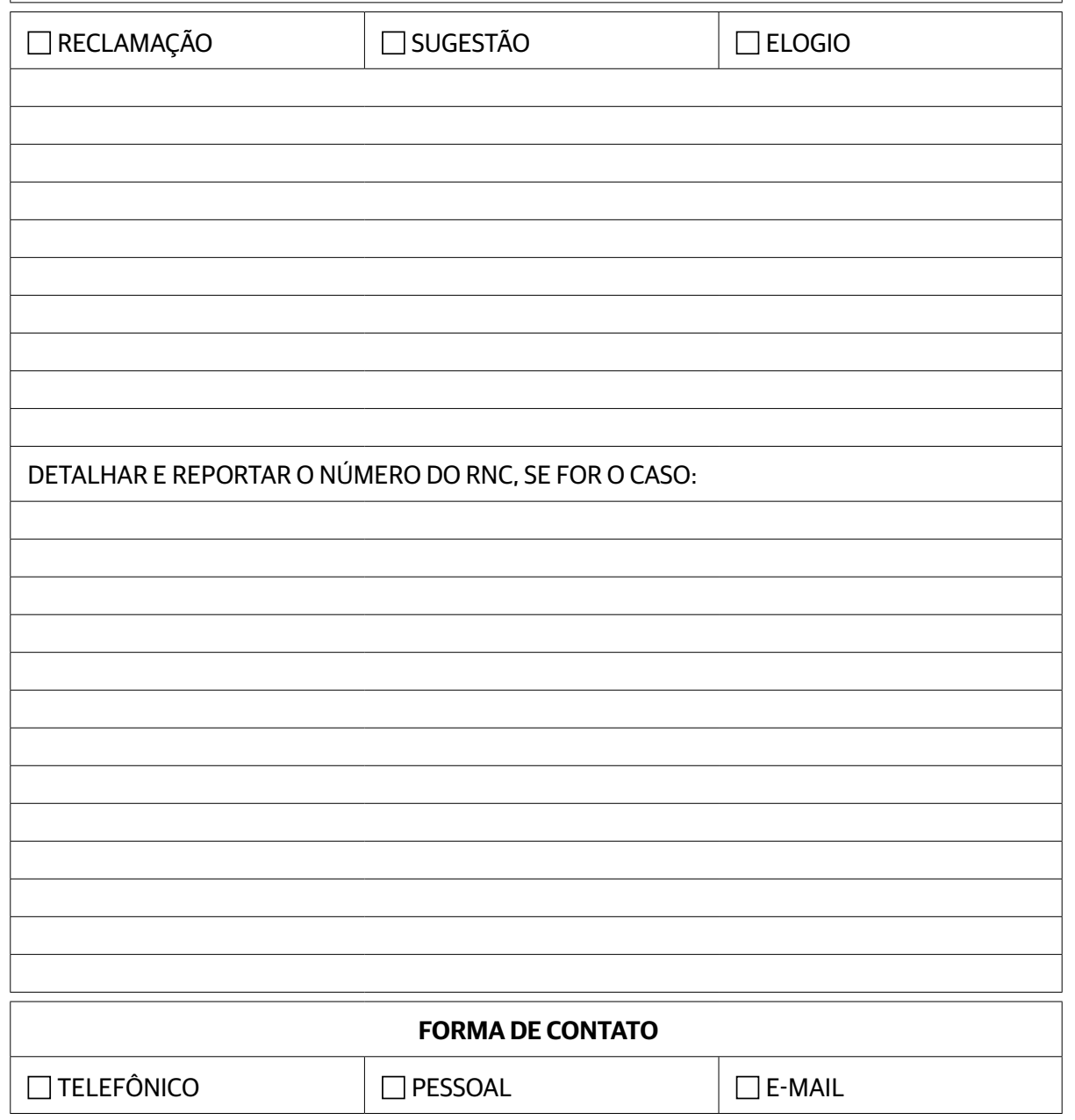

VISTO GT 
Figura 36. Cópia ilustrativa do Relatório de Amostras, Identificação e Planejamento de Ensaios (ANEXO 9) do POP 017 - Prestação de Serviço (A) aba Relatório; (B) Identificação; (C) Planejamento de Ensaio; (D) LQA; (E) Outro

(A)

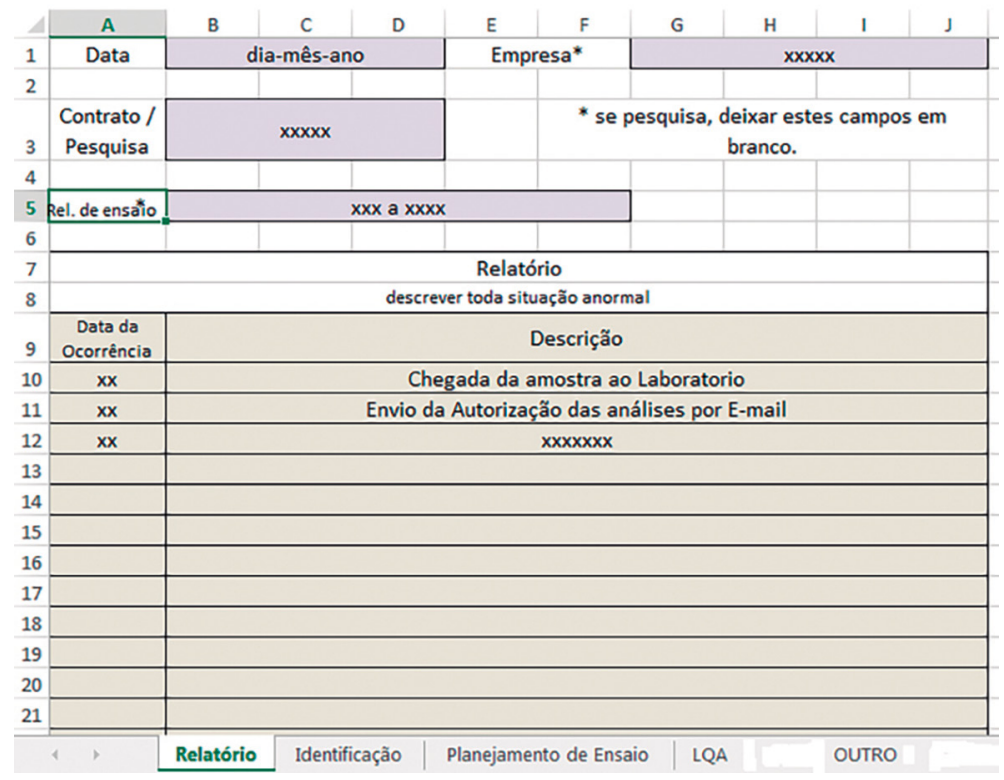

(B)

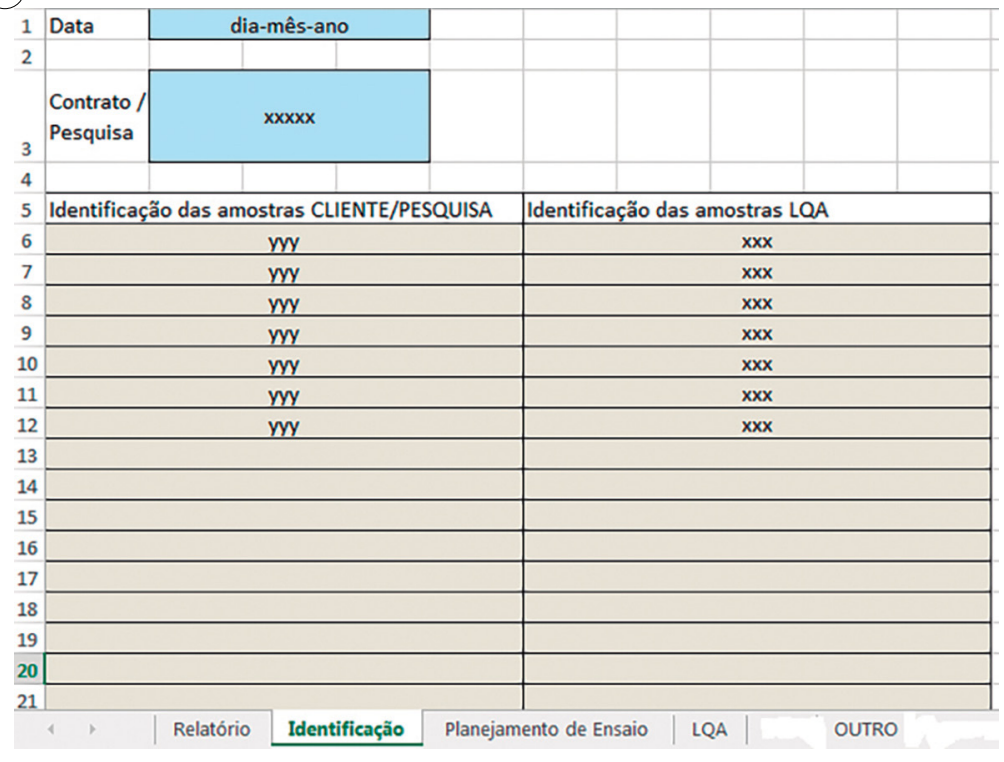


Figura 36. Continuação...

(C)

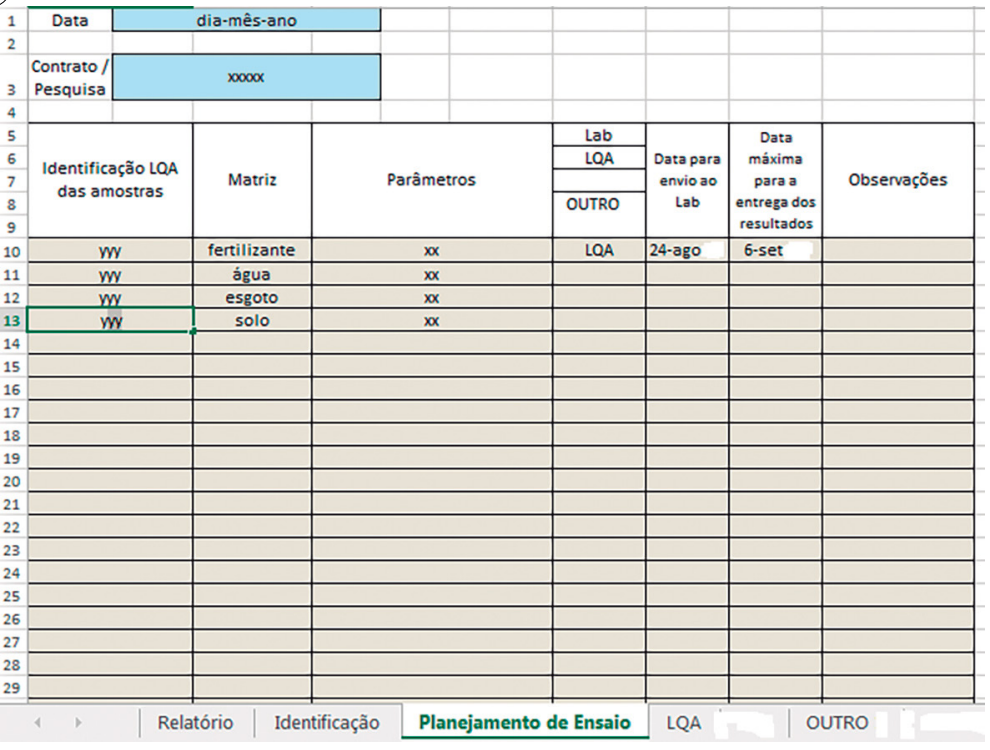

(D)

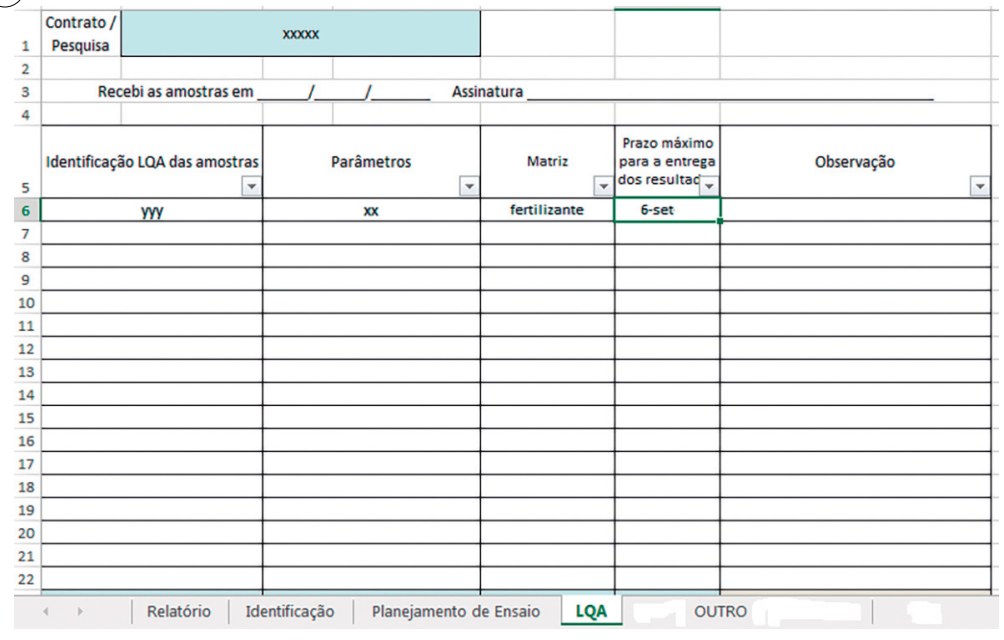


Figura 36. Continuação...

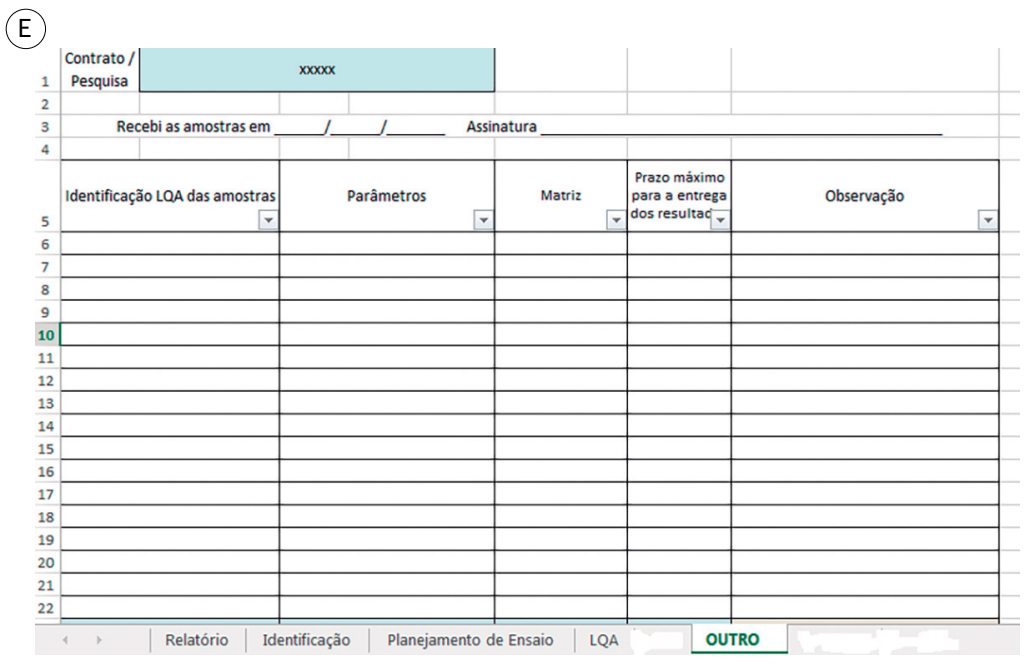

69

Capítulo 2 
Figura 37. Cópia ilustrativa do Relatório de Ensaio (ANEXO 10) do POP 017 - Prestação de Serviço

\begin{tabular}{|c|c|c|c|}
\hline & \multirow{3}{*}{\multicolumn{2}{|c|}{ RELATÓRIO DE ENSAIO }} & $R E-X X X-X X X X$ \\
\hline & & & PÁGINA 1 DE 2 \\
\hline & & & DATA_I_/20_ \\
\hline \multicolumn{4}{|c|}{ DADOS DO CLIENTE } \\
\hline \multicolumn{4}{|l|}{ Nome: } \\
\hline \multicolumn{3}{|l|}{ Endereço: } & \\
\hline Interessado: & Fone: & E-mail: & \\
\hline
\end{tabular}

\begin{tabular}{|c|c|}
\hline \multicolumn{2}{|c|}{ DADOS DA AMOSTRA E AMOSTRAGEM } \\
\hline \multicolumn{2}{|c|}{ Amostragem realizada $\square$ Pelo cliente $\square$ Pelo LQA } \\
\hline Identificação: & Matriz: \\
\hline \multicolumn{2}{|l|}{ Plano de amostragem: } \\
\hline Data e hora da coleta: & \\
\hline \multicolumn{2}{|l|}{ Condições ambientais: } \\
\hline
\end{tabular}

\section{DADOS DOS ENSAIOS}

\begin{tabular}{|c|c|c|c|c|c|}
\hline \multicolumn{2}{|l|}{ Chegada da amostra: } & \multicolumn{2}{l|}{ Temperatura no recebimento: } \\
\hline \multicolumn{2}{|l|}{ Início/término dos ensaios: } & \multicolumn{2}{l|}{ CPS n': } \\
\hline $\begin{array}{c}\text { PARÂMETRO } \\
\text { ANALÍTICO }\end{array}$ & $\begin{array}{c}\text { LIMITE DE } \\
\text { DETECÇÃO }\end{array}$ & BRANCO & VMP(1) & RESULTADO & UNIDADE \\
\hline & & & & & \\
\hline & & & & & \\
\hline
\end{tabular}

\section{INFORMAÇÕES ADICIONAIS}

(1) VMP - Valor Máximo Permitido segundo. $x x x x x x x x$

\section{METODOLOGIA(S) UTILIZADA(S)}

(descrição de todas as metodologias utilizadas)

\section{DESVIOS, ADIÇÕES OU EXCLUSÕES DO MÉTODO DE ENSAIO OU NA AMOSTRAGEM}

(se pertinente, descrever qualquer alteração nos métodos de ensaio, por exemplo, troca do ácido para digestão da amostra)

\section{OPINIÕES/INTERPRETAÇÕES}

(opiniões e interpretações do resultado) 
Figura 37. Continuação...

\begin{tabular}{|c|c|}
\hline \multirow{3}{*}{ RELATÓRIO DE ENSAIO } & RE - XXX-XXXX \\
\hline & PÁGINA 2 DE 2 \\
\hline & DATA_I_/20_ \\
\hline \multicolumn{2}{|c|}{$\begin{array}{l}\text { REFERÊNCIA(S) } \\
\text { (se pertinente, citar a legislação adotada como referência, por exemplo, Portaria do Ministério da } \\
\text { Saúde n⿳0 518) }\end{array}$} \\
\hline \multicolumn{2}{|c|}{$\begin{array}{l}\text { COMPARAÇÃO COM REQUISITOS E/OU ESPECIFICAÇÕES } \\
\text { (se pertinente, declarar conformidade ou não conformidade aos requisitos e/ou às } \\
\text { especificações, por exemplo, Portaria do Ministério da Saúde n⿳0 518) }\end{array}$} \\
\hline
\end{tabular}

Este relatório técnico exprime a opinião da autora e não a opinião da Universidade de São Paulo.

$\mathrm{O}(\mathrm{s})$ resultado(s) da(s) análise(s) refere(m)-se exclusivamente à(s) amostra(s) analisada(s). Este Relatório de Ensaio só pode ser reproduzido por inteiro e sem nenhuma alteração.

$$
\text { Responsável Técnico - CRQ }
$$

Rodapé: Preencher com o nome do laboratório, endereço e contatos 
Figura 38. Cópia ilustrativa de uma página do Controle de Relatórios de Ensaio (ANEXO 11) do POP 017 - Prestação de Serviço

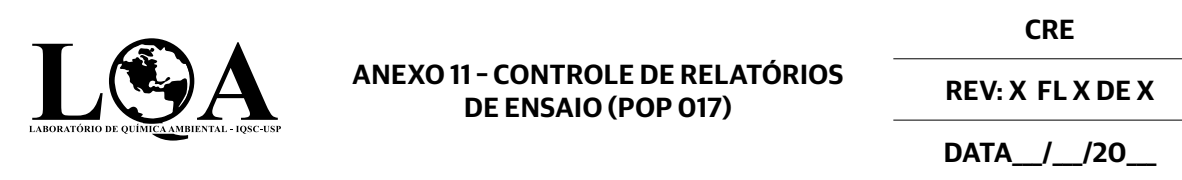

\begin{tabular}{|c|c|c|c|c|c|c|c|}
\hline \multicolumn{6}{|c|}{ EMISSÃO RE } & \multicolumn{2}{|c|}{ VERIFICAÇÃO RE } \\
\hline Data & CPS & Cliente & $\begin{array}{l}\text { Identificação da } \\
\text { Amostra (cliente) }\end{array}$ & $\begin{array}{c}\text { Relatório } \\
\text { Ensaio }\end{array}$ & Visto & $\begin{array}{c}\text { LVTR } \\
\text { (Visto DA) }\end{array}$ & $\begin{array}{c}\text { LVRD } \\
\text { (Visto GQ) }\end{array}$ \\
\hline & & & & & & & \\
\hline & & & & & & & \\
\hline & & & & & & & \\
\hline & & & & & & & \\
\hline & & & & & & & \\
\hline & & & & & & & \\
\hline & & & & & & & \\
\hline & & & & & & & \\
\hline & & & & & & & \\
\hline & & & & & & & \\
\hline & & & & & & & \\
\hline & & & & & & & \\
\hline & & & & & & & \\
\hline & & & & & & & \\
\hline & & & & & & & \\
\hline & & & & & & & \\
\hline & & & & & & & \\
\hline & & & & & & & \\
\hline & & & & & & & \\
\hline & & & & & & & \\
\hline & & & & & & & \\
\hline & & & & & & & \\
\hline & & & & & & & \\
\hline
\end{tabular}


Figura 39. Cópia ilustrativa de uma página da Lista de Verificação Técnica dos Resultados (ANEXO 12) do POP 017 - Prestação de Serviço

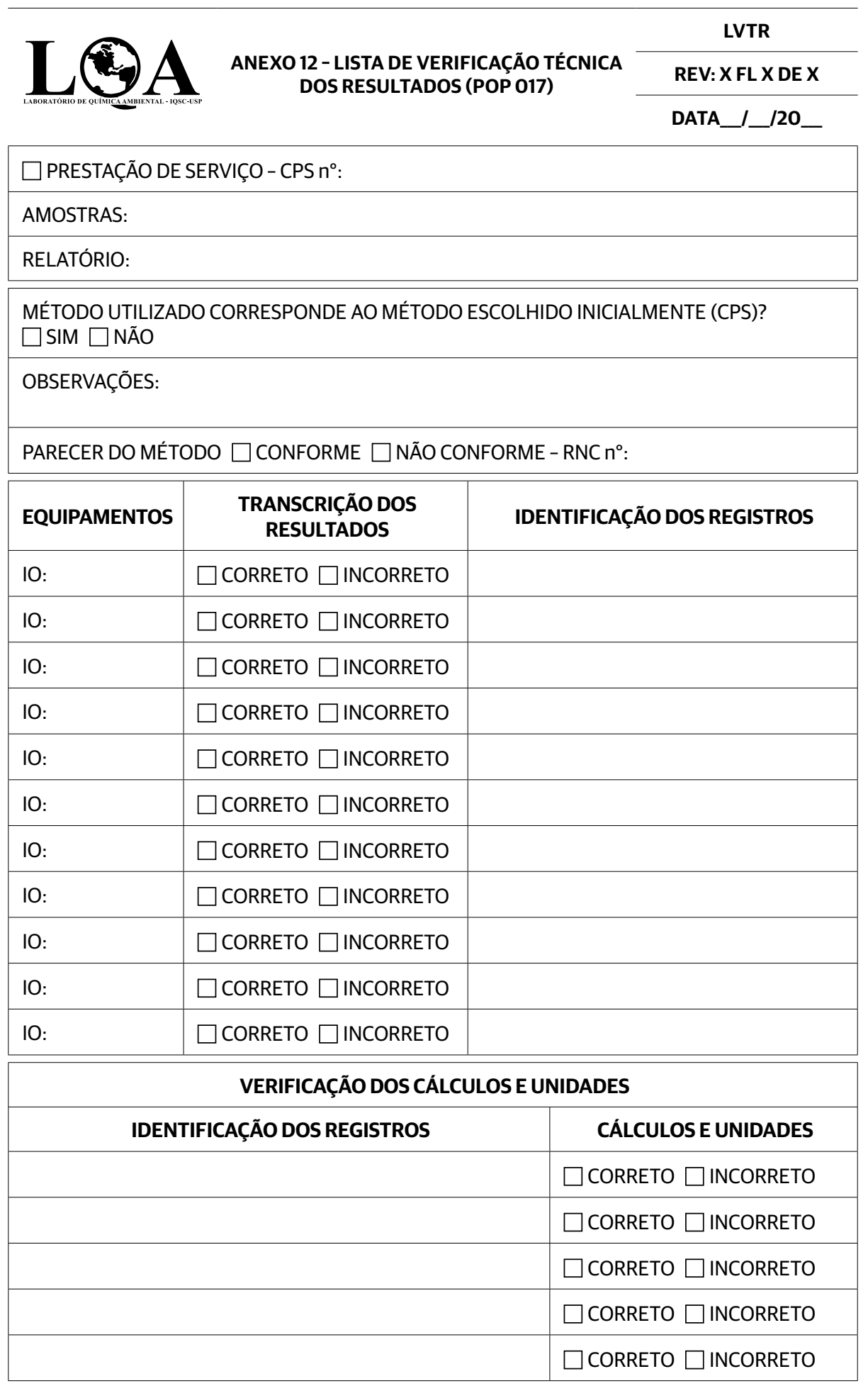


Figura 39. Continuação...

T2 ANEXO 12 - LISTA DE VERIFICAÇÃO TÉCNICA DOS RESULTADOS (POP 017)

LVTR

REV: XFL X DEX

DATA_I_/20

\begin{tabular}{|l|l|}
\hline \multicolumn{2}{|c|}{ VERIFICAÇÃO DOS CÁLCULOS E UNIDADES } \\
\hline IDENTIFICAÇÃO DOS REGISTROS & CÁLCULOS E UNIDADES \\
\hline & $\square$ CORRETO $\square$ INCORRETO \\
\hline & $\square$ CORRETO $\square$ INCORRETO \\
\hline & $\square$ CORRETO $\square$ INCORRETO \\
\hline & $\square$ CORRETO $\square$ INCORRETO \\
\hline
\end{tabular}

\section{VERIFICAÇÃO DO RELATÓRIO DE ENSAIO (RE)}

\begin{tabular}{l|l|}
\hline $\begin{array}{l}\text { "DADOS DO CLIENTE" CONFEREM COM } \\
\text { INFORMAÇÕES DO CPS (POP 017)? }\end{array}$ & $\square$ CORRETO $\square$ INCORRETO \\
\hline $\begin{array}{l}\text { "DADOS DA AMOSTRA E AMOSTRAGEM" CONFEREM } \\
\text { COM INFORMAÇÕES DA CC E PA (POP 017)? }\end{array}$ & $\square$ CORRETO $\square$ INCORRETO \\
\hline $\begin{array}{l}\text { "DADOS DO ENSAIO" CONFEREM COM IA (POP 017) } \\
\text { E RAIPE (POP 017)? }\end{array}$ & $\square$ CORRETO $\square$ INCORRETO \\
\hline INFORMAÇÕES COMPLEMENTARES ESTÃO CORRETAS? & $\square$ CORRETO $\square$ INCORRETO \\
\hline
\end{tabular}

OBSERVAÇÕES:

PARECER FINAL:

RESULTADO CONFORME NÃO CONFORME - RNC $n^{\circ}$ :

ASSINATURA DA: 
Figura 40. Cópia ilustrativa da Lista de Verificação de Recursos e Documentação (ANEXO 13) do POP 017 - Prestação de Serviço

\begin{tabular}{|c|c|c|c|c|c|c|c|}
\hline & & & & & & & LVRD No XX \\
\hline & & $\begin{array}{l}\text { ANEX } \\
\text { RECURS }\end{array}$ & $\begin{array}{l}13 \text { - LISTA DE V } \\
\text { SE DOCUMEN }\end{array}$ & $\begin{array}{l}\text { RIFICAÇ, } \\
\text { ACÃOC(P }\end{array}$ & $\begin{array}{l}\text { O DE } \\
\text { P 017) }\end{array}$ & & REV: $X$ \\
\hline & & & & & & & DATA_I_/20_ \\
\hline CONTRATC & & & & & E: & & \\
\hline PESQUISA: & & & & & & & \\
\hline AGENDA M & $A(A$ & & & & & & \\
\hline MÉ & & REGI & RO CARTA CO & ITROLE & & ESUL & $\begin{array}{l}\text { LTADO CARTA } \\
\text { ONTROLE }\end{array}$ \\
\hline ME: & & $\square \mathrm{C}[$ & & & $\square \mathrm{C}$ & NC & \\
\hline ME: & & $\square \mathrm{C}[$ & & & $\square \mathrm{C}$ & NC & \\
\hline ME: & & $\square \subset$ & & & $\square C$ & NC & \\
\hline 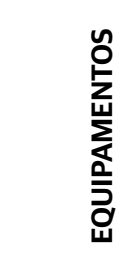 & & 足 & 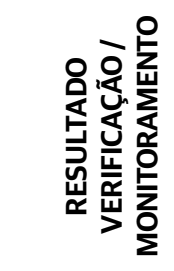 & & 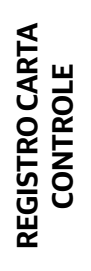 & & 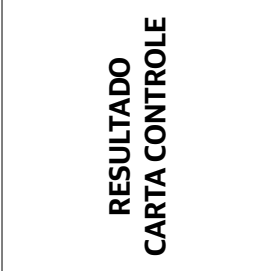 \\
\hline IO: & & $\square \mathrm{NC}$ & $\square \mathrm{C} \square \mathrm{NC}$ & $\square \mathrm{C}$ & $\square \mathrm{NC} \square$ & NA & $\square \mathrm{C} \square \mathrm{NC} \square \mathrm{NA}$ \\
\hline IO: & & $\square \mathrm{NC}$ & $\square \mathrm{C} \square \mathrm{NC}$ & $\square \mathrm{C}$ & $\square$ NC $\square$ & NA & $\square \mathrm{C} \square \mathrm{NC} \square \mathrm{NA}$ \\
\hline IO: & & $\square \mathrm{NC}$ & $\square \mathrm{C} \square \mathrm{NC}$ & $\square \mathrm{c}$ & $\square$ NC $\square$ & NA & $\square \mathrm{C} \square \mathrm{NC} \square \mathrm{NA}$ \\
\hline IO: & & $\square \mathrm{NC}$ & $\square \mathrm{C} \square \mathrm{NC}$ & $\square \mathrm{C}$ & $\square$ NC $\square$ & NA & $\square \mathrm{C} \square \mathrm{NC} \square \mathrm{NA}$ \\
\hline IO: & & $\square \mathrm{NC}$ & $\square \mathrm{C} \square \mathrm{NC}$ & $\square \mathrm{C}$ & $\square$ NC $\square$ & NA & $\square \mathrm{C} \square \mathrm{NC} \square \mathrm{NA}$ \\
\hline $\begin{array}{l}\text { MATE } \\
\text { REFEI }\end{array}$ & & REG & $\begin{array}{l}\text { TRO RCMR } \\
\text { OP 011) }\end{array}$ & REAG & NTES & & $\begin{array}{l}\text { REGISTRO RCR } \\
\text { (POP 011) }\end{array}$ \\
\hline MR: & & $\square c \square$ & & $\mathrm{R}:$ & & $\square \mathrm{C}$ & $\square \mathrm{NC}$ \\
\hline MR: & & $\square<\square$ & & $\mathrm{R}:$ & & $\square \mathrm{C}$ & $\square \mathrm{NC}$ \\
\hline MR: & & $\square c \square$ & & $\mathrm{R}:$ & & $\square \mathrm{C}$ & $\square \mathrm{NC}$ \\
\hline MR: & & $\square c \square$ & & $\mathrm{R}:$ & & $\square \mathrm{C}$ & $\square N C$ \\
\hline OBSERVAÇ & & & & & & & \\
\hline PARECER F & & & & & & & \\
\hline RESULTAD & S & VEL $\square \mathrm{N}$ & CONFIÁVEL & & & & \\
\hline ASSINATUP & & & & & & & \\
\hline
\end{tabular}




\subsection{Aquisição de Produtos e Serviços}

OLQA mantém uma política e procedimentos para a seleção, compra e avaliação dos serviços e suprimentos, definidos no POP 010 - Aquisição de serviços e de suprimentos (Figura 41).

Os documentos de aquisição dos itens contêm dados que descrevem os serviços e suprimentos solicitados. Esses documentos encontram-se: no POP 010 - Aquisição de serviços e de suprimentos, Anexo 1- Solicitação de Compra, Anexo 2 - Relatório de Inspeção de Serviços (RIS) e Anexo 3 - Relatório de Inspeção de Produtos (RIP); e no POP 011 - Insumos, Anexo 2 - Local de Armazenamento de Insumos (LAI), Anexo 3 - Registro de Controle de Materiais de Referência (RCMR), Anexo 4 - Registro de Controle de Reagentes (RCR), Anexo 5 - Registro de Controle de Gases (RCG), Anexo 6 - Modelo de Etiqueta de Identificação de Insumos (MEII), Anexo 7 - Modelo de Etiqueta de Identificação de Soluções (MEIS), Anexo 8 - Modelo de Etiqueta de Identificação de Insumos Vencidos (MEIIV), Anexo 9 - Lista de Materiais de Referência (LMR) e Anexo 10 - Lista de Reagentes (LR). Os anexos 8 e 9 não são apresentados por serem muito específicos de cada laboratório.

O LQA mantém procedimento para cadastro e avaliação de fornecedores, conforme POP 013 - Cadastro de fornecedores.

Nas Figuras 41 a 54, apresentam-se as cópias dos procedimentos citados e dos respectivos anexos.

O procedimento de aquisição de serviços e suprimentos deve ser realizado para itens que possam afetar a qualidade dos ensaios. O registro desses itens não é comum em laboratórios de pesquisa. No entanto, nosso entendimento é que esse procedimento é mandatório para a gestão da qualidade, pois melhora a organização do laboratório e é uma garantia para a qualidade dos resultados. Em outras palavras, é um procedimento necessário no processo de melhoria constante de um laboratório de pesquisa. 
Figura 41. Cópia ilustrativa do POP 010 - Aquisição de Serviços e de Suprimentos

AQUISIÇÃO DE SERVIÇOS
E DE SUPRIMENTOS $\frac{\text { POP } 010}{\text { DATA_I_/20__ }}$

\section{OBJETIVO}

Estabelecer a sistemática para aquisição de serviços e de suprimentos.

\section{APLICAÇÃO}

Este procedimento se aplica à aquisição de serviços, insumos, equipamentos, instrumentos e sistemas. Atende ao requisito 4.6 do Manual da Qualidade do Laboratório de Química Ambiental.

\section{CONDIÇÕES GERAIS}

O LQA tem várias fontes de verba para a aquisição de serviços e produtos. O responsável pela compra, tratado neste documento, é o mesmo pelo gerenciamento da verba utilizada no momento.

\section{CONDIÇÕES ESPECÍFICAS}

4.1 Requisição de serviços, insumos, equipamentos, instrumentos e sistemas

4.1.1 A requisição de serviços e produtos é realizada conforme a necessidade para garantir o abastecimento adequado e o bom andamento das atividades do LQA. O solicitante preenche os campos "Solicitação - Solicitante" da Solicitação de Compra - SC (Anexo 1).

4.2 Análise crítica de aquisição de serviços, insumos, equipamentos, instrumentos e sistemas 4.2.1 O conteúdo técnico das requisições de serviços e produtos é analisado criticamente, comparando as descrições dos materiais ou serviços e aplicações às exigências do LQA. O registro da análise crítica e aprovação ou não da requisição é feito na SC (Anexo 1).

4.3 Orçamentos

4.3.1 Sempre que viável, três orçamentos devem ser cotados e registrados na SC (Anexo 1).

4.4 Autorização de compra

4.4.1 Após a realização dos orçamentos, é escolhido o fornecedor que atenda às exigências do POP 013 - Cadastro de Fornecedores e do órgão responsável pelo pagamento e registrado na SC (Anexo 1).

4.5 Compra de serviços, insumos, equipamentos, instrumentos e sistemas

4.5.1 Após autorização, a compra é feita e registrada na SC (Anexo 1).

4.6 Recebimento

4.6.1 A data do recebimento é registrada na SC (Anexo 1).

4.7 Inspeção

4.7.1 Insumos e materiais de referência são analisados para garantir que suas características físico-químicas sejam atendidas. Padrões são verificados para garantir a situação da calibração. Equipamentos e instrumentos são testados para garantir que estejam em perfeito funcionamento. Sistemas são testados de acordo com sua natureza.

4.7.2 Inspeção no recebimento

a) Serviços: os registros de inspeção no recebimento de serviços são feitos no Relatório de Inspeção de Serviços - RIS (Anexo 2).

b) Produtos: os registros de inspeção no recebimento de produtos são feitos no Relatório de Inspeção de Produtos - RIP (Anexo 3).

c) Os registros de inspeção no recebimento de padrões, vidrarias e equipamentos comprados já calibrados são feitos no RIP e também no RIS.

4.8 Armazenamento de produtos e certificados

4.8.1 Os insumos e certificados são identificados e armazenados conforme POP 011 - Insumos.

4.8.2 Os equipamentos e padrões são gerenciados conforme POP 001 - Equipamentos.

4.9 Serviços e produtos que apresentaram não conformidades 
Figura 41. Continuação...

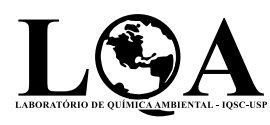

\section{AQUISIÇÃO DE SERVIÇOS E DE SUPRIMENTOS}

POP 010

REV: X FL 2 DE 2

DATA_I_/20

4.9.1 Um Relatório de Não Conformidade (RNC) é gerado conforme POP 014 - Controle de Não Conformidades.

4.9.2 A aprovação ou reprovação para o aceite de produtos e serviços é definida conforme o grau da não conformidade e o impacto no Sistema da Qualidade e depois é avaliada no RNC.

\section{RESPONSABILIDADES}

5.1 Solicitante

Preenche os campos correspondentes da SC. Todos podem solicitar um serviço ou produto, cabendo a responsabilidade maior pela solicitação ao maior usuário do serviço ou produto.

5.2 Gerente da qualidade

Confere a SC e, no recebimento, preenche o RIS e o RIP. Cuida da identificação e do armazenamento de insumos e equipamentos.

5.3 Diretor Acadêmico

Analisa criticamente o conteúdo técnico da SC e decide sobre a aprovação da solicitação. Registra na SC.

5.4 Responsável pela compra

Efetua os orçamentos e escolhe o fornecedor. Registra na SC.

5.5 Diretor acadêmico

Decide sobre a aprovação da solicitação e escolha do fornecedor. Verifica se o fornecedor está qualificado no Cadastro de fornecedores - CF (POP 013) e autorizado pelo órgão responsável pelo pagamento.

5.6 Responsável pela compra Confirma o pedido com o fornecedor.

5.7 Responsável pelo recebimento Registra a data do recebimento na SC.

\section{REGISTROS}

Solicitação de Compra (SC).

Relatório de Inspeção de Serviços (RIS).

Relatório de Inspeção de Produtos (RIP).

\section{ANEXOS}

Anexo 1 - Solicitação de Compra (SC).

Anexo 2 - Relatório de Inspeção de Serviços (RIS).

Anexo 3 - Relatório de Inspeção de Produtos (RIP).

\section{APROVAÇÕES}

\begin{tabular}{|l|l|l|}
\hline Autor & Aprovado / Assinatura & Data \\
\hline & & \\
\hline
\end{tabular}


Figura 42. Cópia ilustrativa de uma página da Solicitação de Compra (ANEXO 1) do POP 010 Aquisição de Serviços e de Suprimentos

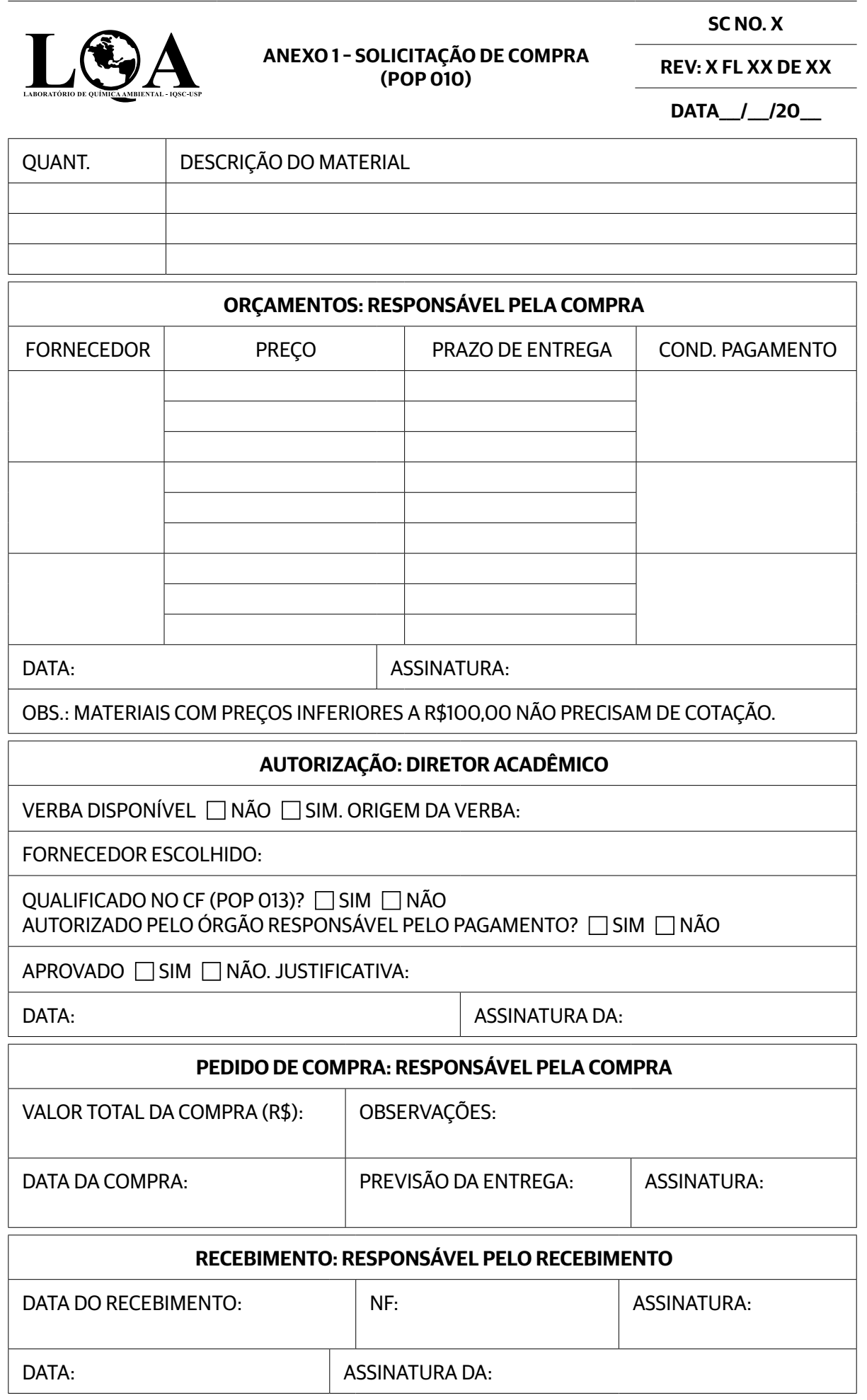


Figura 43. Cópia ilustrativa de uma página do Relatório de Inspeção de Serviços (ANEXO 2) do POP 010 - Aquisição de Serviços e de Suprimentos
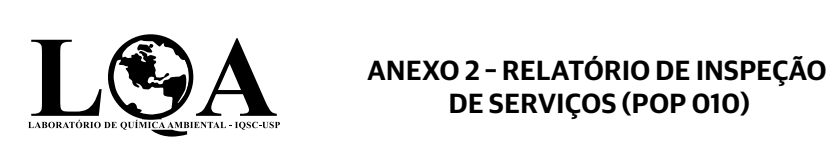

RIS DE SERVIÇOS (POP 010)

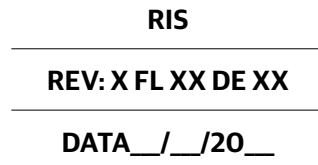

\begin{tabular}{|l|l|}
\hline FORNECEDOR: & $N^{\circ} \mathrm{NF}:$ \\
\hline SERVIÇO: & \\
\hline IDENTIFICAÇÃO PRODUTOS: & \\
\hline
\end{tabular}

\begin{tabular}{|c|c|c|c|c|c|c|c|c|c|}
\hline \multirow{7}{*}{ 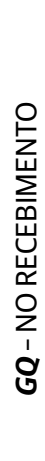 } & \multicolumn{3}{|c|}{$\begin{array}{c}\text { CONDIÇÕES DO SERVIÇO } \\
\text { CARACTERÍSTICAS AVALIADAS }\end{array}$} & \multicolumn{2}{|c|}{ CONFORME } & \multicolumn{2}{|c|}{$\begin{array}{c}\text { NÃO } \\
\text { CONFORME }\end{array}$} & \multicolumn{2}{|c|}{ OBSERVAÇÃO } \\
\hline & \multicolumn{3}{|c|}{ SOLICITAÇÃO DE COMPRA } & & & & & \multicolumn{2}{|l|}{ No } \\
\hline & \multicolumn{3}{|c|}{ CADASTRO DE FORNECEDOR } & & & & & \multicolumn{2}{|l|}{ No } \\
\hline & \multicolumn{3}{|c|}{ PRAZO DE ENTREGA } & & & & & & \\
\hline & \multicolumn{3}{|c|}{ DOCUMENTOS/CERTIFICADOS } & & & & & & \\
\hline & \multicolumn{3}{|c|}{ EMBALAGEM (QUANDO APLICÁVEL) } & & & & & & \\
\hline & \multicolumn{9}{|c|}{ OBSERVAÇÃO: } \\
\hline \multicolumn{2}{|c|}{ PARECER GQ } & $\mathrm{RNC} \mathrm{n}^{\mathrm{O}}$ & \multicolumn{2}{|c|}{$\square$ APROVADO } & \multicolumn{2}{|c|}{$\square$ REPROVADO } & \multicolumn{2}{|c|}{ ASSINATURA: } & DATA: \\
\hline
\end{tabular}

\begin{tabular}{|l|l|}
\hline FORNECEDOR: & $N^{\circ} \mathrm{NF}:$ \\
\hline SERVIÇO: & \\
\hline IDENTIFICAÇÃO PRODUTOS: & \\
\hline
\end{tabular}

\begin{tabular}{|c|c|c|c|c|c|c|c|c|c|}
\hline \multirow{7}{*}{ 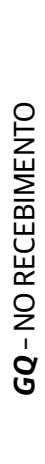 } & \multicolumn{3}{|c|}{$\begin{array}{l}\text { CONDIÇÕES DO SERVIÇO } \\
\text { CARACTERÍSTICAS AVALIADAS }\end{array}$} & \multicolumn{2}{|c|}{ CONFORME } & \multicolumn{2}{|c|}{$\begin{array}{c}\text { NÃO } \\
\text { CONFORME }\end{array}$} & \multicolumn{2}{|c|}{ OBSERVAÇÃO } \\
\hline & \multicolumn{3}{|c|}{ SOLICITAÇÃO DE COMPRA } & & & & & \multicolumn{2}{|l|}{ No } \\
\hline & \multicolumn{3}{|c|}{ CADASTRO DE FORNECEDOR } & & & & & \multicolumn{2}{|l|}{ No } \\
\hline & \multicolumn{3}{|c|}{ PRAZO DE ENTREGA } & & & & & & \\
\hline & \multicolumn{3}{|c|}{ DOCUMENTOS/CERTIFICADOS } & & & & & & \\
\hline & \multicolumn{3}{|c|}{ EMBALAGEM (QUANDO APLICÁVEL) } & & & & & & \\
\hline & \multicolumn{9}{|c|}{ OBSERVAÇÃO: } \\
\hline \multicolumn{2}{|c|}{ PARECER GQ } & $\mathrm{RNC} \mathrm{n}^{\mathrm{O}}$ & \multicolumn{2}{|c|}{$\square$ APROVADO } & \multicolumn{2}{|c|}{$\square$ REPROVADO } & \multicolumn{2}{|c|}{ ASSINATURA: } & DATA: \\
\hline
\end{tabular}


Figura 44. Cópia ilustrativa de uma página do Relatório de Inspeção de Produtos (ANEXO 3) do POP 010 - Aquisição de Serviços e de Suprimentos

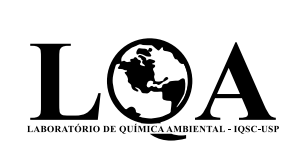

ANEXO 3 - RELATÓRIO DE INSPEÇÃO DE PRODUTOS (POP 010)

RIP No XX

\begin{tabular}{|c|c|c|c|c|}
\hline \multicolumn{2}{|c|}{ FORNECEDOR: } & & \multicolumn{2}{|c|}{$\mathrm{N}^{\circ} \mathrm{NF}$} \\
\hline \multicolumn{2}{|c|}{ ITEM (apenas UM item): } & & \multicolumn{2}{|c|}{ ID } \\
\hline \multirow{6}{*}{ 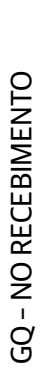 } & $\begin{array}{l}\text { CONDIÇÕES DO PRODUTO } \\
\text { CARACTERÍSTICAS AVALIADAS }\end{array}$ & CONFORME & $\begin{array}{c}\text { NÃO } \\
\text { CONFORME }\end{array}$ & OBSERVAÇÃO \\
\hline & SOLICITAÇÃO DE COMPRA (SC) & & & No \\
\hline & PRAZO & & & \\
\hline & QUANTIDADE, EMBALAGEM E RÓTULO & & & \\
\hline & DOCUMENTOS & & & \\
\hline & \multicolumn{4}{|l|}{ OBSERVAÇÃO: } \\
\hline
\end{tabular}

\begin{tabular}{|c|c|c|c|}
\hline \multicolumn{4}{|c|}{ PARA MATERIAL DE REFERÊNCIA } \\
\hline \multirow{4}{*}{ 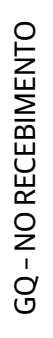 } & RCMR no: & \multicolumn{2}{|l|}{ N CERTIFICADO: } \\
\hline & \multicolumn{2}{|c|}{$\begin{array}{l}\text { Certificado apresenta logotipo do organismo } \\
\text { certificador da ISO Guia 34? }\end{array}$} & $\square$ CONFORME $\square$ NÃO CONFORME \\
\hline & \multicolumn{2}{|c|}{$\begin{array}{l}\text { Certificado apresenta logotipo do organismo } \\
\text { certificador da NBR ISO/IEC 17025? }\end{array}$} & $\square$ CONFORME $\square$ NÃO CONFORME \\
\hline & \multicolumn{2}{|c|}{$\begin{array}{l}\text { MR não certificado - rótulo e ficha de } \\
\text { informação atendem ao DOQ-CGCRE-003? }\end{array}$} & $\square$ CONFORME $\square$ NÃO CONFORME \\
\hline \multirow{7}{*}{ 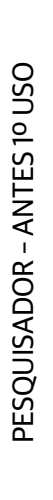 } & $\begin{array}{l}\text { CARACTERÍSTICAS } \\
\text { AVALIADAS }\end{array}$ & $\begin{array}{l}\text { TIPO AVALIAÇÃO } \\
\text { (visual, olfativo etc.) }\end{array}$ & RESULTADO \\
\hline & & & $\square$ CONFORME $\square$ NÃO CONFORME \\
\hline & & & $\square$ CONFORME $\square$ NÃO CONFORME \\
\hline & & & $\square$ CONFORME $\square$ NÃO CONFORME \\
\hline & DATA VERIFICAÇÃO: & \multicolumn{2}{|l|}{ RESPONSÁVEL: } \\
\hline & \multicolumn{3}{|c|}{ ESPECIFICAR ANEXOS GERADOS (CROMATOGRAMA, CURVA, ENTRE OUTROS): } \\
\hline & \multicolumn{2}{|c|}{$\square$ MATERIAL DE REFERÊNCIA CONFORME } & $\begin{array}{l}\square \text { MATERIAL DE REFERÊNCIA NÃO } \\
\text { CONFORME }\end{array}$ \\
\hline
\end{tabular}


Figura 44. Continuação...

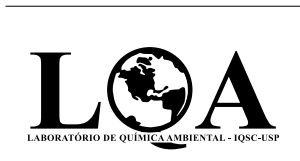

\section{ANEXO 3 - RELATÓRIO DE INSPEÇÃO DE PRODUTOS (POP 010)}

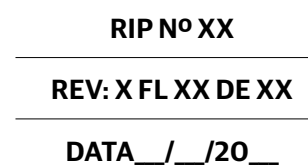

\begin{tabular}{|c|c|c|c|c|c|c|c|}
\hline \multicolumn{8}{|c|}{ PARA REAGENTE } \\
\hline GQ & \multicolumn{2}{|l|}{$\mathrm{RCR} \mathrm{n}^{\mathrm{O}}$ : } & \multicolumn{5}{|c|}{ N CERTIFICADO, SE HOUVER: } \\
\hline \multirow{4}{*}{ 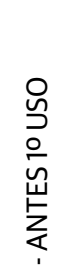 } & \multicolumn{2}{|c|}{$\begin{array}{l}\text { CARACTERÍSTICAS } \\
\text { AVALIADAS }\end{array}$} & \multicolumn{2}{|c|}{$\begin{array}{l}\text { TIPO AVALIAÇÃO } \\
\text { (visual, olfativo etc.) }\end{array}$} & \multicolumn{3}{|c|}{ RESULTADO } \\
\hline & & & & & \multicolumn{3}{|c|}{$\square$ CONFORME $\square$ NÃO CONFORME } \\
\hline & & & & & \multicolumn{3}{|c|}{$\square$ CONFORME $\square$ NÃO CONFORME } \\
\hline & & & & & \multicolumn{3}{|c|}{$\square$ CONFORME $\square$ NÃO CONFORME } \\
\hline \multirow{3}{*}{ 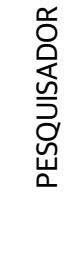 } & DATA VE & IFICAÇÃO: & \multicolumn{5}{|l|}{ RESPONSÁVEL: } \\
\hline & \multicolumn{4}{|c|}{ EQUIPAMENTO USADO NA VERIFICAÇÃO: } & \multicolumn{3}{|l|}{ IO no: } \\
\hline & \multicolumn{4}{|c|}{$\square$ REAGENTE CONFORME } & \multicolumn{3}{|c|}{$\square$ REAGENTE NÃO CONFORME } \\
\hline \multicolumn{2}{|c|}{ PARECER GQ } & $\mathrm{RNC} \mathrm{n}^{\circ}$ & $\square$ APROVADO & $\square \mathrm{R}$ & EPROVADO & ASSINATURA: & DATA: \\
\hline \multicolumn{2}{|c|}{$\begin{array}{l}\text { PARECER } \\
\text { PESQUISADOR }\end{array}$} & $\mathrm{RNC} \mathrm{n}^{\circ}$ & $\square$ APROVADO & \multicolumn{2}{|r|}{ OVADO } & ASSINATURA: & DATA: \\
\hline
\end{tabular}


Figura 45. Cópia ilustrativa do POP 011 - Insumos

INSUMOS $\frac{\text { POP } 011}{\text { REV:X FL 1DE } 3}$

\section{OBJETIVO}

Estabelecer a sistemática para identificação, registros de controle e armazenamento de materiais de referência, reagentes, gases e soluções.

\section{APLICAÇÃO}

Este procedimento se aplica ao armazenamento após inspeção e uso diário de reagentes, gases e soluções, além de atender ao requisito 4.6.1 do Manual da Qualidade do Laboratório de Química Ambiental.

\section{CONDIÇÕES GERAIS}

Após o recebimento, os insumos são inspecionados conforme POP 010. Concomitantemente à inspeção, adotam-se os procedimentos aqui descritos e os certificados são armazenados.

O armazenamento dos insumos é tratado neste documento.

\section{CONDIÇÕES ESPECÍFICAS}

\subsection{Identificação}

4.1.1 Insumos são identificados de acordo com seu tipo.

- $\quad$ Material de referência: letras "MR" seguidas de um número crescente a partir do 1.

- $\quad$ Reagente, indicador: letra "R" seguida de um número crescente a partir do 1.

- $\quad$ Gases: letra "G" seguida de um número crescente a partir do 1.

4.2 Registros de controle

4.2.1 Cada tipo de insumo tem o seu registro de controle, atualizado no recebimento ou preparo do insumo, utilização, disposição intermediária e descarte.

4.2.1. Adota-se o Registro de Controle de Materiais de Referência - RCMR (Anexo 3) para o gerenciamento de materiais de referência.

4.2.1.1. A Lista de Materiais de Referência - LMR (Anexo 9) apresenta a lista de todos os materiais de referência em ordem alfabética e auxilia na busca de produtos.

4.2.1.2 Adota-se o Registro de Controle de Reagentes - RCR (Anexo 4) para o gerenciamento de reagentes.

4.2.1.2.1 A Lista de Reagentes - LR (Anexo 10) apresenta todos os reagentes em ordem alfabética e auxilia na busca de produtos.

4.2.1.3 Adota-se o Registro de Controle de Gases - RCG (Anexo 5) para o gerenciamento de gases.

4.3 Rótulo de identificação

4.3.1 Adota-se o Modelo de Etiqueta de Identificação de Insumos - MEII (Anexo 6) para a identificação de insumos comprados prontos (materiais de referência, reagentes, indicadores e gases).

4.3.2 Adota-se o Modelo de Etiqueta de Identificação de Soluções - MEIS (Anexo 7) para a identificação de insumos preparados internamente (soluções estoque e soluções de trabalho).

4.3.3 Adota-se o Modelo de Etiqueta de Identificação de Insumos Vencidos - MEIIV (Anexo 8) para a identificação de insumos vencidos.

4.4 Solução estoque e solução de trabalho

4.4.1 Soluções estoque-mãe, soluções estoque e soluções de trabalho são de uso e responsabilidade restrita do pesquisador que as preparou. Soluções que serão guardadas não recebem uma identificação alfanumérica nem são incluídas nos registros de controle, mas são identificadas conforme o MEIS (Anexo 7). 
Figura 45. Continuação...

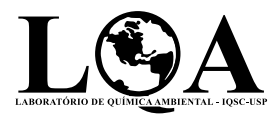

POP 011

INSUMOS

REV: X FL 2 DE 3

DATA_I_/20

4.5 Local de Armazenamento

4.5.1 As condições de armazenamento dos insumos são definidas pelo fabricante. Os locais de armazenamento são definidos no Local de Armazenamento de Insumos - LAI (Anexo 2).

NOTA: Insumos que necessitam de refrigeração são identificados com etiqueta esférica azul.

4.6 Disposição intermediária

4.6.1 Quando vencidos, são realocados e identificados. Este procedimento denomina-se disposição intermediária.

4.6.2 A LMR (Anexo 9) e a LR (Anexo 10) são atualizadas periodicamente. Durante a atualização, os insumos vencidos são destacados. O responsável deve então identificá-los como vencidos com o MEIIV (Anexo 8), atualizar o RCMR (Anexo 3) e o RCR (Anexo 4) e armazená-los em novo local.

4.6.3 É de responsabilidade do usuário do insumo vencido verificar que sua homogeneidade e estabilidade não foram alteradas.

4.7 Descarte final

4.7.1 Insumos impróprios para os ensaios e frascos vazios são descartados conforme POP 006 - Descarte de Resíduos Químicos.

4.8 Requisição de insumos

4.8.1 Quando o LQA mantiver o uso do insumo, recomenda-se que ele seja solicitado de acordo com o critério que ocorrer primeiro: estoque ou validade. A solicitação é de responsabilidade do usuário.

\begin{tabular}{|c|c|r|c|}
\hline \multicolumn{2}{|c|}{ INSUMO } & $\begin{array}{c}\text { ESTOQUE } \\
\text { (Consulta ao RCMR, RCR e RCG) }\end{array}$ & $\begin{array}{c}\text { VALIDADE } \\
\text { (Consulta ao RCMR e RCR) }\end{array}$ \\
\hline \multirow{2}{*}{$\begin{array}{c}\text { Material de } \\
\text { Referência }\end{array}$} & Em solução & Abertura da última ampola & \\
\cline { 2 - 3 } & $\begin{array}{c}\text { Solido } \\
\text { calibção de }\end{array}$ & $10 \%$ do frasco original & \multirow{2}{*}{3 meses da expiração } \\
\cline { 2 - 3 } & $15 \%$ do frasco original & \\
\hline Reagente & $15 \%$ do frasco original & \multirow{2}{*}{1 mês da expiração } \\
\hline \multicolumn{2}{|c|}{ Gases } & $2.000 \mathrm{kPa}$ & Não se aplica \\
\hline
\end{tabular}

4.8.2 Insumos são solicitados conforme POP 010 - Aquisição de Serviços e de Suprimentos.

\section{RESPONSABILIDADES}

5.1 Gerente da qualidade

Após o recebimento, atualiza o RCMR, a LMR, o RCR, a LR e o RCG.

Identifica o insumo conforme o MEII.

Atualiza a LMR e a LR periodicamente. Quando necessário, identifica o insumo vencido com o MEIIV, atualiza o RCMR e o RCR e, por fim, realoca o insumo (disposição intermediária).

\subsection{Gerente técnico}

Armazena e atualiza o RCG.

5.3 Gerente técnico e Laboratórios de Pesquisa 2, 3 e 4

Atualiza o RCMR e o RCR conforme utilização.

Armazena insumos utilizados que requerem refrigeração conforme o LAl. 
Figura 45. Continuação...

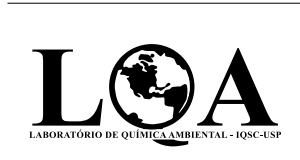

POP 011

INSUMOS

REV: X FL 3 DE 3

DATA_I_/20

Identifica soluções estoque e soluções após o preparo conforme o MEIS.

Solicita os insumos, quando necessário, conforme POP 010 - Aquisição de Serviços e Suprimentos. Descarta conforme POP 006 - Descarte de Resíduos. Atualiza o RCMR, a LMR, o RCR, a LR e o RCG.

\section{REGISTROS}

Registro de Controle de Materiais de Referência (RCMR).

Registro de Controle de Reagentes (RCR).

Registro de Controle de Gases (RCG).

\section{ANEXOS}

ANEXO 2 - Local de Armazenamento de Insumos (LAI).

ANEXO 3 - Registro de Controle de Materiais de Referência (RCMR).

ANEXO 4 - Registro de Controle de Reagentes (RCR).

ANEXO 5 - Registro de Controle de Gases (RCG).

ANEXO 6 - Modelo de Etiqueta de Identificação de Insumos (MEII).

ANEXO 7 - Modelo de Etiqueta de Identificação de Soluções (MEIS).

ANEXO 8 - Modelo de Etiqueta de Identificação de Insumos Vencidos (MEIIV).

ANEXO 9 - Lista de Materiais de Referência (LMR).

ANEXO 10 - Lista de Reagentes (LR).

\section{APROVAÇõES}

\begin{tabular}{|l|l|l|}
\hline Autor & Aprovado/ Assinatura & Data \\
\hline & & \\
\hline
\end{tabular}


Figura 46. Cópia ilustrativa do Local de Armazenamento de Insumos (ANEXO 2) do POP O11 - Insumos

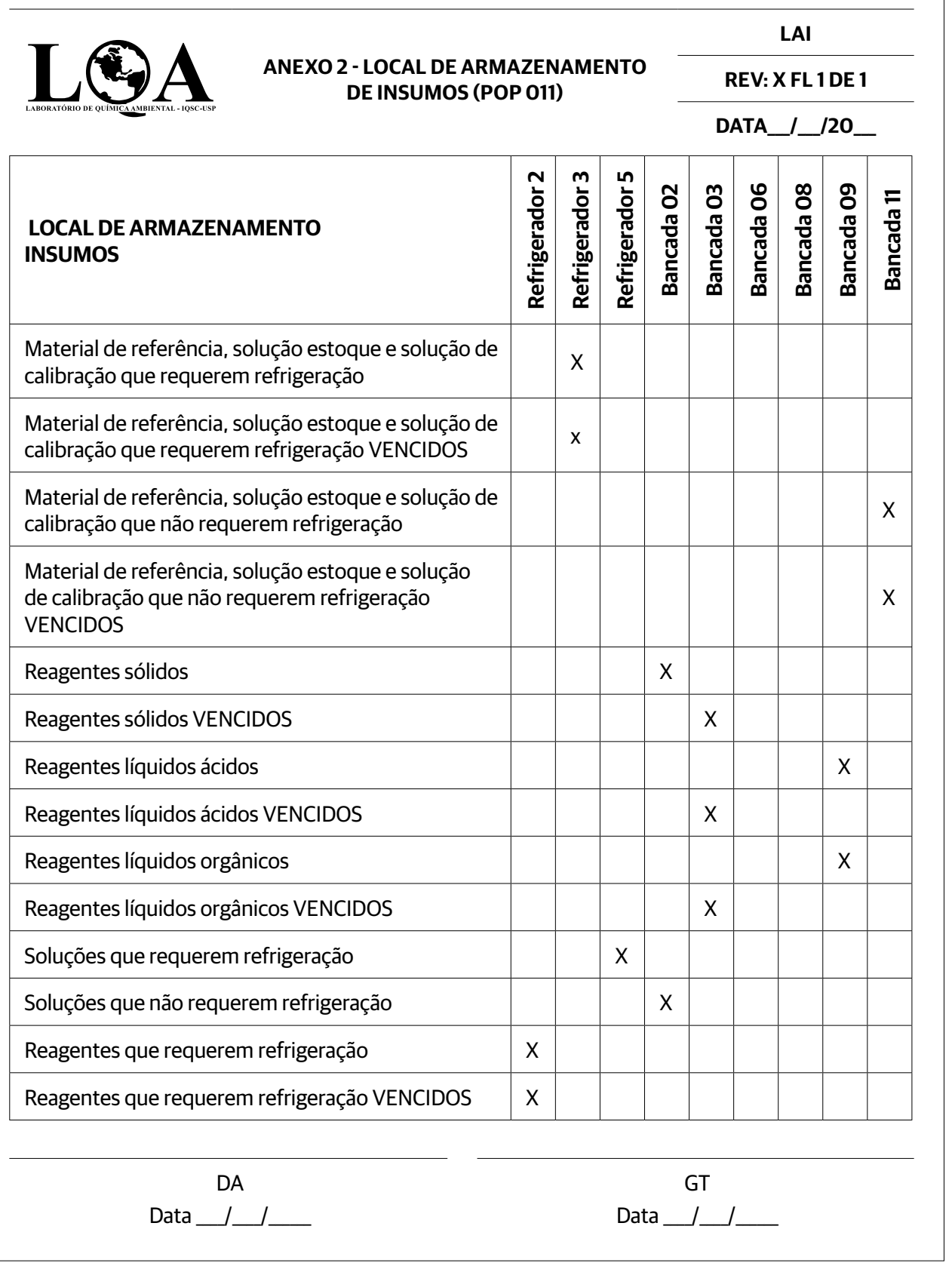


Figura 47. Cópia ilustrativa de uma página do Registro de Controle de Materiais de Referência (ANEXO 3) do POP 011 - Insumos

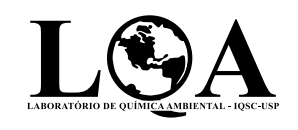

\section{ANEXO 3 - REGISTRO DE CONTROLE DE MATERIAIS DE REFERÊNCIA (POP 011)}

RCMR. ID MR

REV: X FL XX DE XX

DATA_I_/20

\begin{tabular}{|l|l|l|l|}
\hline$\square$ MATERIAIS DE REFERÊNCIA & $\square$ SOL. DE CALIBRAÇÃO & $\square$ SOL. ESTOQUE. ORIGEM*: \\
\hline $\begin{array}{l}\text { MASSA OU VOLUME } \\
\text { ORIGINAL }\end{array}$ & $\begin{array}{l}\text { MR / SOLUÇÃO DE CALIBRAÇÃO / } \\
\text { SOLUÇÃO ESTOQUE }\end{array}$ & $\begin{array}{l}\text { ESPECIFICAÇÕES } \\
\text { TÉCNICAS }\end{array}$ \\
\hline FINANCIAMENTO E NO PROJETO & FABRICANTE & LOTE \\
\hline NO RIP (POP 010) & DATA VALIDADE & RESPONSÁVEL \\
\hline
\end{tabular}

* ORIGEM: ID dos materiais de referência e reagentes utilizados no preparo da solução estoque.

\begin{tabular}{|l|l|l|l|}
\hline \multicolumn{5}{|c|}{ INDICAÇÕES DE ARMAZENAMENTO } \\
\hline$\square$ AO ABRIGO DA LUZ & $\square$ REFRIGERADOR & $\square$ FREEZER & $\square$ TEMPERATURA AMBIENTE \\
\hline \multicolumn{2}{|c|}{ DISPOSIÇÃO INTERMEDIÁRIA } & \multicolumn{2}{c|}{ DESCARTE FINAL } \\
\hline DATA & RESPONSÁVEL & DATA & RESPONSÁVEL \\
\hline
\end{tabular}

\begin{tabular}{|c|c|c|c|c|c|}
\hline \multicolumn{6}{|c|}{ HISTÓRICO DE USO } \\
\hline \multirow{2}{*}{ DATA } & \multicolumn{3}{|c|}{ USO** } & \multirow{2}{*}{ VOLUME OU MASSA USADO } & \multirow{2}{*}{ RESPONSÁVEL } \\
\hline & SE & $A C$ & $\mathrm{CC}$ & & \\
\hline & & & & & \\
\hline & & & & & \\
\hline & & & & & \\
\hline & & & & & \\
\hline & & & & & \\
\hline & & & & & \\
\hline & & & & & \\
\hline & & & & & \\
\hline & & & & & \\
\hline & & & & & \\
\hline & & & & & \\
\hline & & & & & \\
\hline & & & & & \\
\hline & & & & & \\
\hline & & & & & \\
\hline & & & & & \\
\hline & & & & & \\
\hline & & & & & \\
\hline
\end{tabular}

USO**: SE - solução estoque; AC - amostra controle; CC - curva de calibração. 
Figura 48. Cópia ilustrativa de uma página do Registro de Controle de Reagentes (ANEXO 4) do POP 011 - Insumos

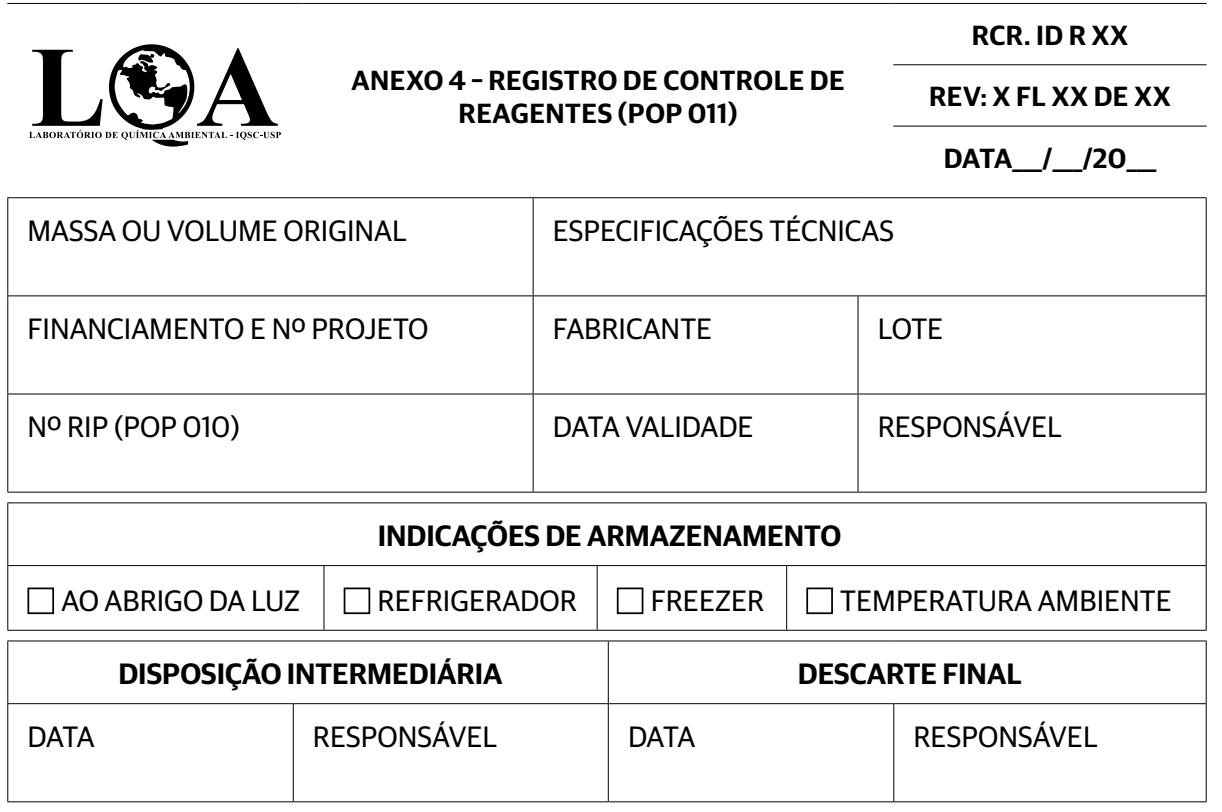

HISTÓRICO DE USO

\begin{tabular}{|l|l|l|}
\hline DATA & VOLUME OU MASSA USADO & RESPONSÁVEL \\
\hline & & \\
\hline & & \\
\hline & & \\
\hline & & \\
\hline & & \\
\hline & & \\
\hline & & \\
\hline & & \\
\hline & & \\
\hline & & \\
\hline & & \\
\hline & & \\
\hline & & \\
\hline & & \\
\hline & & \\
\hline & & \\
\hline
\end{tabular}


Figura 49. Cópia ilustrativa de uma página do Registro de Controle de Gases (ANEXO 5) do POP O11 - Insumos

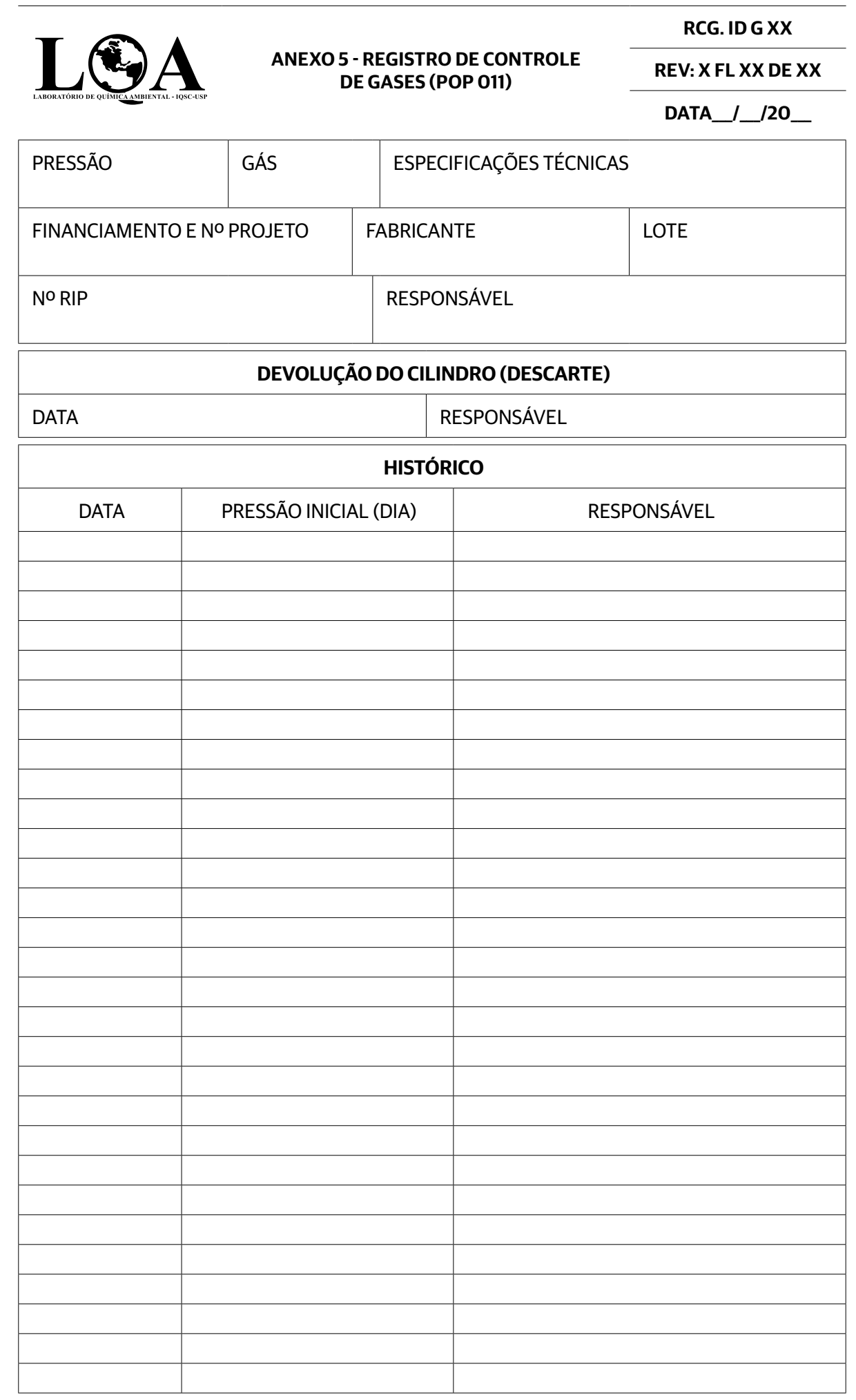


Figura 50. Cópia ilustrativa do Modelo de Etiqueta de Identificação de Insumos (ANEXO 6) do POP 011 - Insumos IDENTIFICAÇÃO DE INSUMOS (POP 011)

MEII

REV: X FL 1 DE 1

DATA_I_/20_

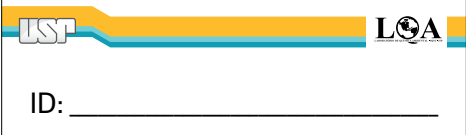


Figura 51. Cópia ilustrativa do Modelo de Etiqueta de Identificação de Soluções (ANEXO 7) do POP 011 - Insumos

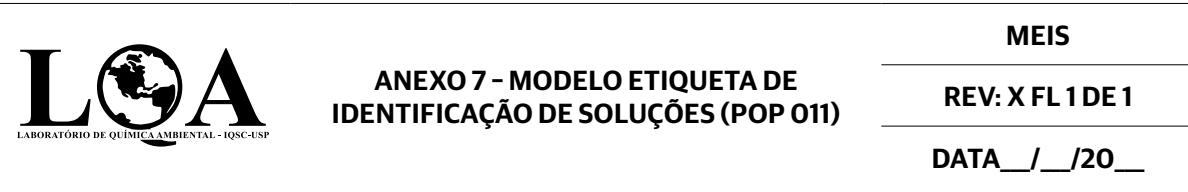


Figura 52. Cópia ilustrativa do Modelo de Etiqueta de Identificação de Insumos Vencidos (ANEXO 8) do POP 011 - Insumos

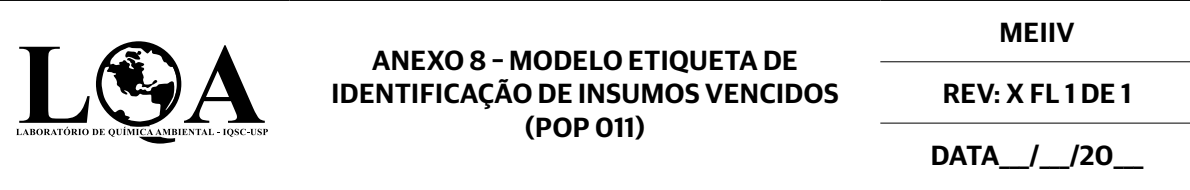


Figura 53. Cópia ilustrativa do POP 013 - Cadastro de Fornecedores

CADASTRO DE FORNECEDORES $\frac{\text { POP } 013}{\text { REV:X FL } 1 \text { DE } 1}$

\section{OBJETIVO}

Estabelecer a sistemática de cadastro de fornecedores.

\section{APLICAÇÃO}

Este procedimento atende ao requisito 4.6 do Manual da Qualidade do Laboratório de Química Ambiental. Aplica-se aos fornecedores dos produtos e serviços que impactam na confiabilidade dos serviços do LQA.

\section{CONDIÇÕES}

3.1 Avaliação do fornecedor (pré-compra)

3.1.1 A avaliação é feita pelo fornecedor com o preenchimento do Cadastro de Fornecedores - CF (Anexo 2).

3.2 Avaliação de fornecedor no recebimento (pós-compra)

3.2.1 A inspeção de serviços e produtos recebidos pelo LQA é realizada conforme POP 010 Aquisição de Serviços e de Suprimentos.

3.2.2 Inspeções relevantes são registradas no CF (Anexo 1).

3.2.3 Avaliações não conformes podem desqualificar o fornecedor.

\section{RESPONSABILIDADES}

4.1 DA

Verifica se o fornecedor é qualificado.

4.2 Gerente da qualidade Registra o fornecedor no CF.

No recebimento, registra no CF uma ocorrência negativa significativa, se for o caso.

\section{REGISTROS}

Cadastro de Fornecedores (CF).

\section{ANEXOS}

Anexo 1 - Cadastro de Fornecedores (CF).

\section{APROVAÇÕES}

\begin{tabular}{|l|l|l|}
\hline Autor & Aprovado / Assinatura & Data \\
\hline & & \\
\hline
\end{tabular}


Figura 54. Cópia ilustrativa do Cadastro de Fornecedores (ANEXO 1) do POP 013 - Cadastro de Fornecedores

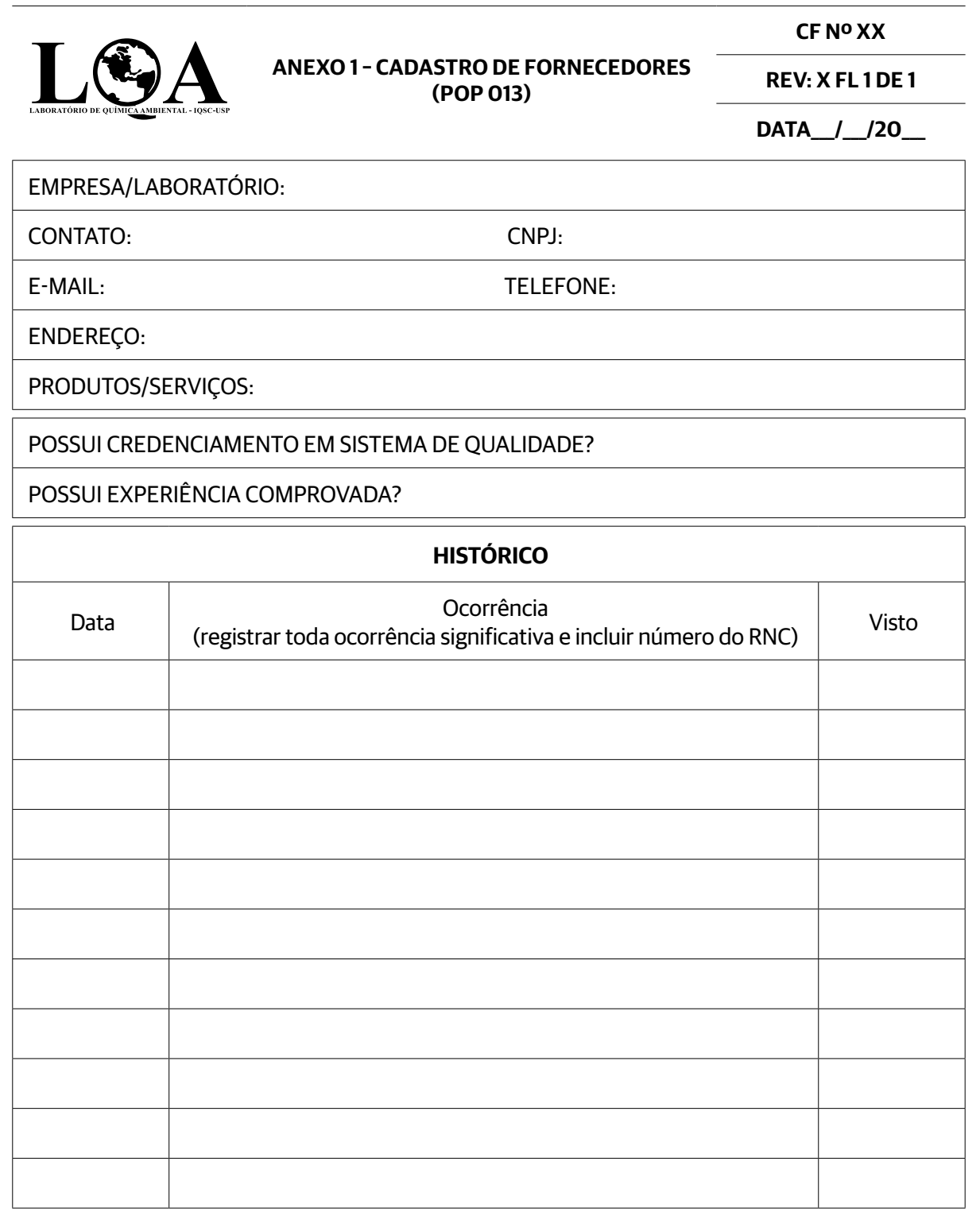




\subsection{Não Conformidades, Ações Corretivas e Preventivas}

Na rotina do LQA, não conformidades devem ser registradas no Relatório de Não Conformidades, analisadas pela alta direção e tomadas medidas relevantes; ademais, deve ser feito o monitoramento das ações corretivas tomadas, conforme descrito no POP 014 - Controle das não conformidades.

As não conformidades podem ser identificadas por meio de várias atividades, tais como: auditorias internas e externas, reclamações de clientes, observação do pessoal do laboratório, resultados de ensaios de proficiência etc.

Possíveis reclamações são tratadas de acordo com o estabelecido no POP 017 - Prestação de serviço (Figura 27), e as não conformidades, especificamente no POP 014 - Controle das não conformidades (Figuras 55 e 56).

Ações preventivas referem-se a tomadas de ações corretivas antes que não conformidades ocorram. Elas podem ser detectadas por meio de cartas controle, resultados de ensaios de proficiência e na rotina do laboratório.

No POP 014, são analisadas as causas, a seleção e implementação das ações corretivas e preventivas, assim como o monitoramento dessas ações e as possíveis auditorias necessárias às melhorias contínuas do LQA. 
Figura 55. Cópia ilustrativa do POP 014 - Controle das Não Conformidades

CONTROLE DAS NÃO CONFORMIDADES $\frac{\text { POP } 014}{\frac{\text { REV:X FL } 1 \text { DE } 1}{\text { DATA_I_/20__ }}}$

\section{OBJETIVO}

1.1 Estabelecer a sistemática de controle das não conformidades oriundas do sistema de qualidade.

\section{APLICAÇÃO}

2.1 Este procedimento se aplica às não conformidades e atende aos requisitos 4.9 do Manual da Qualidade do Laboratório de Química Ambiental.

\section{CONDIÇÕES}

3.1 Identificação da Não Conformidade

3.1.1 Todos do LQA podem gerar um Relatório de Não Conformidade - RNC (Anexo 1) caso detectem alguma rotina operacional ou técnica não conforme.

3.2 Ações imediatas/corretivas

3.2.1 Uma ação imediata é definida a fim de interromper a não conformidade.

3.2.2 Uma ação corretiva é definida a fim de detalhar a correção da não conformidade.

3.3 Descrição das ações imediatas

3.3.1 Citar registros atualizados, com identificação das páginas. Nunca registrar com data retroativa. Fazer menção à data original da informação e à identificação do RNC, mas com a data real do registro.

\section{AÇÕES}

4.1 Ação imediata

4.1.1 Uma ação imediata é definida a fim de interromper a não conformidade.

4.2 Ações corretivas/preventivas

4.2.1 Ações corretivas ou preventivas são definidas a fim de detalhar a correção da não conformidade.

As ações para interromper e corrigir a não conformidade são detalhadas no Relatório de Não Conformidade - RNC (Anexo 1).

4.3 Caso a ação corretiva/preventiva apresente dúvidas, inicia-se um processo de auditoria interna, conforme POP 012 - Auditoria.

\section{RESPONSABILIDADES}

\subsection{Todos}

Identificam a não conformidade com o sistema da qualidade e comunicam ao GQ, DA ou GT. Emitem RNC.

\section{$5.2 \mathrm{GQ}, \mathrm{GT}$ e DA}

Atualizam o RNC e realizam as ações imediatas/corretivas.

\section{ANEXOS}

Anexo 1 - Relatório de Não Conformidades (RNC).

\section{APROVAÇÕES}

\begin{tabular}{|l|l|l|}
\hline Autor & Aprovado / Assinatura & Data \\
\hline & & \\
\hline
\end{tabular}


Figura 56. Cópia ilustrativa de uma página do Relatório de Não Conformidade (ANEXO 1) do POP 014

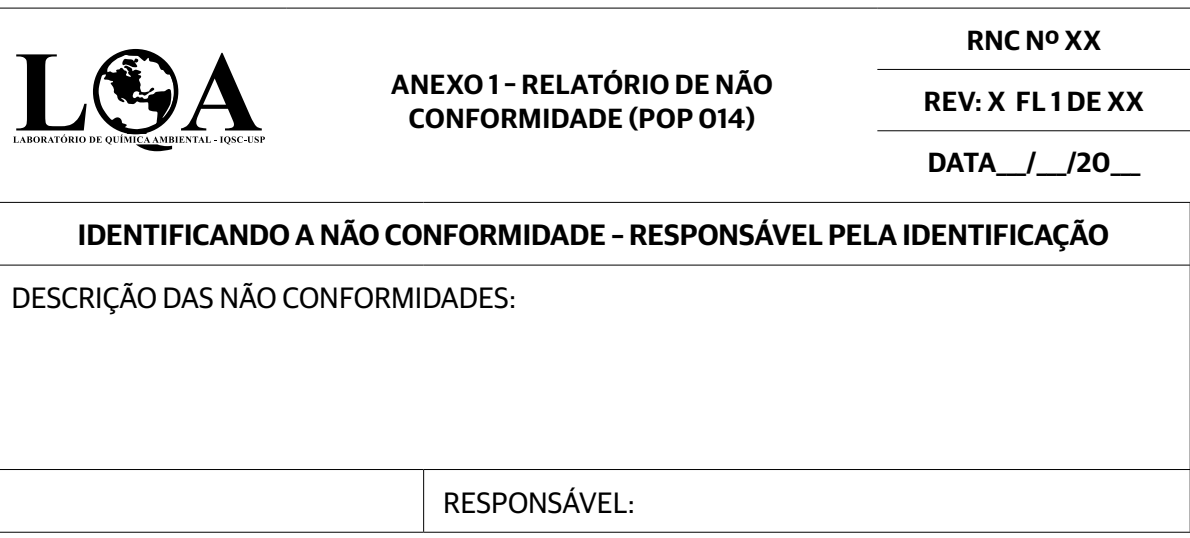

AÇAO IMEDIATA:

AÇÃO PREVENTIVA / PRAZO:

AÇÃO CORRETIVA / PRAZO:

FECHAMENTO DO PROCESSO - DA E GQ

AÇÕES SATISFATÓRIAS?

$\square$ SIM $\square$ NÃO. Reiniciar o processo.

\begin{tabular}{|l|l|}
\hline VISTO GQ: & DATA: \\
\hline VISTO DA: & DATA: \\
\hline
\end{tabular}




\subsection{Análise Crítica pela Direção}

O LQA estabeleceu um procedimento periódico, com cronograma preestabelecido, para uma análise crítica do Sistema de Gestão da Qualidade e das atividades de ensaio, o que permite assegurar sua contínua adequação para introduzir mudanças ou melhorias necessárias. NoLQA, a análise crítica pela direção é realizada a cada 12 meses, normalmente entre janeiro e fevereiro.

A análise crítica considera: ( $i$ ) adequação das políticas e procedimentos; (ii) resultados de auditorias internas recentes; (iii) ações corretivas; (iv) resultados das comparações interlaboratoriais de proficiência, se for o caso; $(v)$ recomendações para melhoria; ( $v i)$ outros fatores relevantes, tais como atividades de controle da qualidade e treinamento de pessoal.

A avaliação dos resultados obtidos permite que se definam metas, objetivos e planos de ação para o ano.

A avaliação e ações decorrentes da análise crítica pela direção são registradas e monitoradas.

\subsection{Auditoria}

\subsubsection{Auditoria Interna}

OLQA realiza auditorias internas para assegurar que suas atividades continuem a atender aos requisitos do sistema de gestão. O procedimento encontra-se detalhado no POP 012-Auditoria (Figura 57). O registro das auditorias internas é descrito no Relatório de Auditoria (Figura 58) e o monitoramento registrado no Monitoramento de Auditoria (Figura 59). 
Figura 57. Cópia ilustrativa do POP 012 - Auditoria

AUDITORIA $\frac{\text { POP } 012}{\text { REV: FL 1DE } 2}$

\section{OBJETIVO}

Estabelecer a sistemática para realização das auditorias e seu monitoramento.

\section{APLICAÇÃO}

Este procedimento se aplica às atividades de auditoria de todas as áreas do laboratório, visando à manutenção da eficiência, à melhoria contínua e ao monitoramento do Sistema de Gestão da Qualidade, e atende aos requisitos 4.10 e 4.11 do Manual da Qualidade do Laboratório de Química Ambiental.

\section{CONDIÇÕES GERAIS}

As auditorias são realizadas pela alta gerência do LQA. Os auditores irão adotar todos os registros abordados neste documento. Após a auditoria e definição de metas para o próximo período, podem ser planejadas ações de monitoramento de melhoria do Sistema da Qualidade.

\section{CONDIÇÕES ESPECÍFICAS}

\subsection{Escopo}

Todas as áreas de atividades e responsabilidades do LQA abrangidas pelo seu Manual da Qualidade são auditadas periodicamente.

4.2 Formas e cronograma de auditoria

- A auditoria consiste em verificar se o Sistema de Gestão do LQA atende a todos os requisitos do Manual da Qualidade do Laboratório de Química Ambiental.

- É realizada anualmente no mês de janeiro, de preferência.

\subsection{Responsabilidade}

4.3.1 É de responsabilidade do Gerente da Qualidade planejar, organizar e registrar as auditorias internas e garantir que as deficiências sejam corrigidas rápida e efetivamente.

\subsection{Registros da auditoria}

4.4.1 As auditorias são registradas no Relatório de Auditoria - RA (Anexo 2). No RA, são registradas as constatações, evidências, situações e possíveis registros gerados durante a auditoria.

NOTA: O RA (Anexo 2), os anexos gerados e o MA (Anexo 3) são impressos e encadernados em um mesmo volume ou mantidos em computador.

4.5 Não conformidades encontradas na auditoria

4.5.1 Toda não conformidade constatada dá origem a um Relatório de Não Conformidade (POP 014).

4.5.2 O detalhamento da ação corretiva, os prazos, os responsáveis, o planejamento das ações, a interrupção do trabalho e a investigação de trabalhos anteriores são registrados no RA (Anexo 2), e a ação corretiva, monitorada no MA (Anexo 3).

4.6 Monitoramento da qualidade

4.6.1 A melhoria constante da qualidade baseia-se nos resultados da auditoria e nas ações de melhoria. As anotações do monitoramento da qualidade estão no Anexo 3 Monitoramento da Qualidade (MA).

\section{RESPONSABILIDADES}

5.1 GQ, GT e DA

Gerenciam o cronograma e coordenam a realização de auditorias. São responsáveis pela implementação da ação corretiva. 
Figura 57. Continuação...

AUDITORIA

\section{REGISTROS}

Relatório de Auditoria (RA).

Monitoramento de Auditoria (MA).

\section{ANEXOS}

Anexo 2 - Relatório de Auditoria (RA).

Anexo 3 - Monitoramento de Auditoria (RA).

\section{APROVAÇÕES}

\begin{tabular}{|l|l|l|}
\hline Autor & Aprovado/ Assinatura & Data \\
\hline & & \\
\hline
\end{tabular}


Figura 58. Cópia ilustrativa de uma página do Relatório de Auditoria (ANEXO 1) do POP 012 - Auditoria

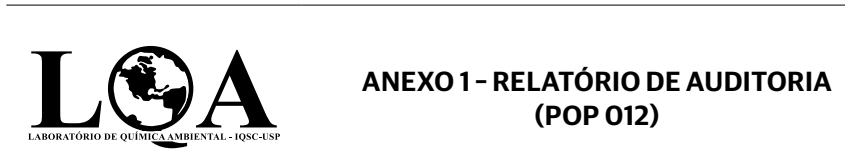

RA NOXX

REV: X FL 1 DE 1

DATA_I_/20

Auditor(es):

Requisito da Norma do Manual da Qualidade:

Descrição do Requisito:

Não conformidades:

MA no: 
Figura 59. Cópia ilustrativa de uma página do Monitoramento de Auditoria (ANEXO 2) do POP 012 Auditoria

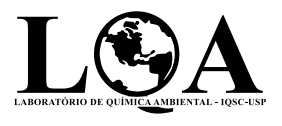

ANEXO 2 - MONITORAMENTO DE AUDITORIA (POP 012)

MA No XX

REV: X FL 1 DE 1

DATA_I_/20_

RA no:

Ação Corretiva:

Monitoramento e planejamento: 


\subsubsection{Auditoria Externa}

O LQA realiza auditorias externas para assegurar que esteja cumprindo com os requisitos da norma ABNT NBR ISO/IEC 17025:2005. A auditoria é registrada por um relatório entregue pelo auditor externo. Auditor externo é um profissional especializado na norma ABNT NBR ISO/ IEC 17025:2005, que não pertença ao quadro do LQA. 


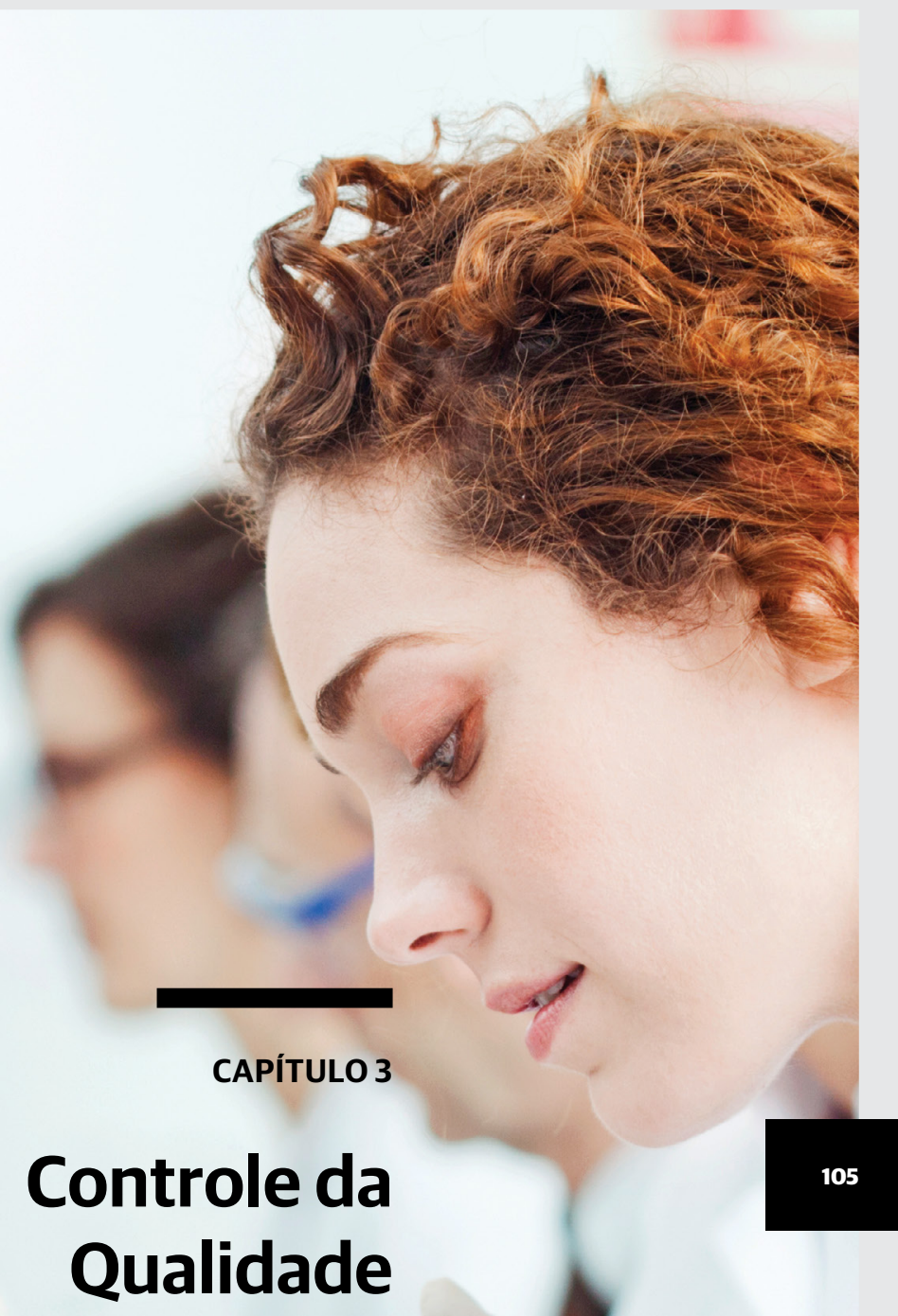




\section{RESUMO}

Neste capítulo, apresentamos os documentos para o registro da validação de metodologia analítica e para monitoramento dos resultados. Para ter confiabilidade nos resultados analíticos, deve-se trabalhar em condições ambientais adequadas, utilizar reagentes de pureza conhecida, materiais de referência certificados e equipamentos calibrados e/ou verificados. Todos

esses quesitos foram apresentados no Capítulo 2. Em adição, o método analítico deve ser validado, e os resultados avaliados criticamente, de acordo com normas técnicas vigentes. Quando o método não for normalizado por algum órgão regulador (EPA, MAPA, CONAMA, INMETRO etc.), a validação é necessária. Neste capítulo, apresentamos os procedimentos de validação e de controle estatístico requerido pela norma ABNT NBR ISO/IEC 17025:2005.

\subsection{Validação}

O método apropriado ao ensaio deve atender às necessidades do pesquisador/cliente.

O LQA utiliza métodos oficialmente normatizados e, quando necessário, realiza a normatização via validação e controle estatístico dos procedimentos.

OLQA valida os métodos não normatizados deacordo com oPOP008-Validação(Figura60), mantém o controle estatístico de acordo com o POP 018 - Cartas Controle, e, quando requerido pela pesquisa, o cálculo da incerteza é aplicado de acordo com o Guia EURACHEM/ CITAC: Determinando a Incerteza nas Medições Analíticas.

O cálculo da incerteza é uma das várias ferramentas de avaliação dos resultados, porém, para a rotina de alguns laboratórios de pesquisa, o cálculo da incerteza torna-se inviável. Para garantir a qualidade dos resultados de forma simplificada, são suficientes a validação do método, o controle estatístico do processo utilizando cartas controle e a participação do laboratório em ensaios de proficiência. Sugere-se que, se houver necessidade da expressão do cálculo da incerteza, o Guia EURACHEM/ CITAC: Determinando a Incerteza nas Medições Analíticas como referência deve ser consultado.

O método normatizado pelo LQA é registrado de acordo com o POP 016 - Método de Ensaios (Figura 11).

Há um procedimento explicativo de verificação da balança, conforme POP 007 - Verificação de Balanças (Figura 61). O uso das balanças é registrado no registro de gerenciamento da balança da respectiva Instrução Operacional (Figura 62).

\subsection{Garantia dos resultados}

Os dados são registrados nos respectivos formulários de cada equipamento e descritos na Agenda Mestra (POP 003), a metodologia é validada (POP 008), e as balanças verificadas (POP 007). 
Figura 60. Cópia ilustrativa do POP 008 - Validação

VALIDAÇÃO $\frac{\text { POP } 008}{\text { REV:X FL 1DE 5 }}$

\section{OBJETIVO}

Estabelecer a sistemática para construção de curvas de calibração.

\section{DOCUMENTOS COMPLEMENTARES}

DOQ-CGCRE-008 - Orientação Sobre a Validação de Métodos Analíticos, Revisão 4, julho de 2011.

\section{PROCEDIMENTO}

3.1 Manuseio de materiais de referência

3.1.1 Os materiais de referência são manuseados conforme POP 002 - Manuseio de Materiais de Referência e Preparo de Soluções Estoque.

3.2 Pontos da curva de calibração

3.2.1 A construção da curva de calibração é feita conforme o ME com, pelo menos, cinco pontos (DOQ-CGCRE-008, item 8.2.2) definidos:

a) O ponto inferior, quando aplicável, não deve ser maior que a metade do Valor Máximo Permitido (VMP) da legislação que se pretende seguir.

b) O ponto superior é, quando aplicável, maior que o VMP.

c) Os pontos centrais são distribuídos uniformemente pela curva.

3.2.2 As curvas são construídas com a adição de padrão e ausência de interferentes.

3.3 Análise crítica de uma curva de calibração

3.3.1 A qualidade da curva de calibração e de sua linearidade pode ser avaliada visualmente. Os pontos experimentais deverão estar próximos e aleatoriamente distribuídos ao redor da reta ajustada.

3.3.2 A curva de calibração deve apresentar um $\mathrm{R}^{2}$ (coeficiente de correlação) mínimo de 0,90 .

3.4 Validação

3.4.1 Seletividade

A seletividade deverá ser determinada a fim de isolar o sinal analítico referente ao analito dos demais, ou seja, aqueles pertencentes à matriz analítica.

Para a avaliação da seletividade, consulte o DOQ-CGCRE-008, item 8.2.1.

3.4.2 Linearidade

Para determinação da linearidade, deverão ser construídas curvas analíticas com, no mínimo, cinco pontos (DOQ-CGCRE-008, item 8.2.2), ou seja, cinco concentrações diferentes: baixas, médias e altas (escolhidas em função da resposta dada pelo equipamento ou instrumento e legislação à qual se pretende atender). As curvas analíticas são construídas com a adição de padrão e ausência de interferentes.

A curva analítica deverá ser representada por uma equação da reta, determinada via método dos mínimos quadrados, assim descrita:

$y \pm S_{y}=\left(a \pm S_{a}\right) \cdot x+\left(b \pm S_{b}\right)$

Em que: $y$ é o sinal analítico; $x$ é a concentração analisada; a é a inclinação da curva analítica; b é o intercepto no eixo y; $S_{y^{\prime}} S_{a}$ e $S_{b}$ são os desvios-padrão relacionados a cada parâmetro.

Entende-se que uma boa linearidade é aquela que apresenta um coeficiente de correlação $\left(R^{2}\right)$ acima de 0,9.

Para maiores informações, consulte o DOQ-CGCRE-008, item 8.2.2.

3.4.3 Limite de Detecção (LD)

"O limite de detecção é a menor quantidade do analito presente em uma amostra que pode ser detectado, porém não necessariamente quantificado, sob as condições experimentais estabelecidas." RE 899, p. 5.

O limite de detecção será determinado via linearidade da curva analítica. Para isso, a equação a seguir deverá ser aplicada: 
Figura 60. Continuação...

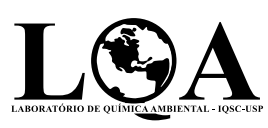

POP 008

$\mathrm{LD}=\frac{\mathrm{DP}_{\mathrm{a}} \times 3}{\mathrm{IC}}$

Em que: $\mathrm{DP}_{\mathrm{a}}$ é o desvio-padrão do intercepto com o eixo y de, no mínimo, três curvas de calibração construídas contendo concentrações próximas ao suposto limite de quantificação. Esse desvio-padrão pode ainda ser obtido a partir da curva de calibração proveniente da análise de um número apropriado de amostras do branco; IC é a inclinação da curva de calibração. Esse parâmetro será determinado (calculado) de acordo com a recomendação da RE 899, item 2.5.

A parte estatística é somente uma orientação, e o LD deve ser obtido experimentalmente. Consulte o DOQ-CGCRE-008, item 8.2.4, para os procedimentos experimentais.

Consulte o NIT-DICLA-057, item 6.3, para as definições de limite de detecção do instrumento, inferior e do método.

3.4.4 Limite de Quantificação (LQ)

"O limite de quantificação é a menor quantidade do analito em uma amostra que pode ser determinada com precisão e exatidão aceitáveis sob as condições experimentais estabelecidas." RE 899, item 2.6.

O limite de quantificação será determinado via linearidade da curva analítica. Para isso, a equação a seguir deverá ser aplicada:

$\mathrm{LQ}=\frac{\mathrm{DP} \times 10}{\mathrm{IC}}$

Em que: $\mathrm{DP}_{\mathrm{a}}$ é o desvio-padrão do intercepto com o eixo y de, no mínimo, três curvas de calibração construídas contendo concentrações próximas ao suposto limite de quantificação. Esse desvio-padrão pode ainda ser obtido a partir da curva de calibração proveniente da análise de um número apropriado de amostras do branco; IC é a inclinação da curva de calibração. Esse parâmetro será determinado (calculado) de acordo com a recomendação do RE 899, item 2.6.

Consulte o DOQ-CGCRE-008, item 8.2.5, para os procedimentos experimentais. Consulte o NIT-DICLA-057, item 6.3, para as definições de limite de quantificação e limite prático de quantificação.

3.4.5 Faixa de Trabalho e Faixa Linear

A faixa de trabalho compreenderá o intervalo entre o LQ e a maior concentração determinada pelo método. Deverão ser utilizadas as mesmas concentrações empregadas na construção da curva analítica.

A faixa linear será o intervalo dentro da faixa de trabalho em que poderá existir uma faixa de resposta linear, e, dentro desta, a resposta do sinal terá uma relação linear com o analito. A extensão dessa faixa pode ser estabelecida durante a avaliação da faixa de trabalho.

Consulte o DOQ-CGCRE-008, item 8.2.3, para os procedimentos experimentais.

3.4.6 Recuperação / Tendência

\subsubsection{Ensaios de recuperação}

A recuperação do analito é estimada fortificando uma amostra real com o analito em estudo (adição de padrão). Comparam-se os resultados obtidos com a amostra fortificada, com a amostra não fortificada e com a concentração conhecida adicionada à amostra fortificada. A recuperação pode ser expressa como:

$R(\%)=\left(\frac{C_{1}-C_{2}}{C_{3}}\right) \times 100$ 
Figura 60. Continuação...

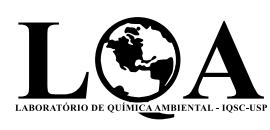

POP 008

VALIDAÇÃo

REV: X FL 3 DE 5

DATA_I_/20

Em que: $C_{1}$ é a concentração do analito na amostra fortificada; $C_{2}$ é a concentração do analito na amostra não fortificada; $C_{3}$ é a concentração do analito adicionada à amostra fortificada.

Deverão ser analisadas, pelo menos, três concentrações diferentes, uma alta, uma média e outra baixa (escolhidas de acordo com a faixa de trabalho), no mínimo em triplicata.

O critério de aceitação é $70 \% \leq R \leq 120 \%$ no limite inferior de quantificação, porém, dependendo da complexidade analítica e da amostra, esse valor pode ser de 50 a 120\% (RIBANI, M.; et. al, p. 777, 2004).

NOTA: a exatidão é avaliada numericamente por meio da tendência.

Consulte o DOQ-CGCRE-008, item 8.2.6.2, para as limitações desse método.

\subsubsection{Precisão}

Conforme DOQ-CGCRE-008, item 8.2.6.3, a precisão pode ser analisada por meio da repetitividade, reprodutibilidade e precisão intermediária. Usualmente, a precisão será calculada pelo coeficiente de variação (CV) - também conhecido como desvio-padrão relativo - e pelo desvio-padrão:

$\mathrm{CV}=\mathrm{DVP}=\frac{\mathrm{S}_{\mathrm{i}}}{\mathrm{X}_{\mathrm{i}}} \times 100 \%$

Em que: $S_{i}$ é o desvio-padrão da determinação; $X_{i}$ é a média aritmética dos resultados. A repetitividade e a precisão intermediária serão realizadas em matrizes isentas dos analitos em estudo. Quando não existir uma matriz disponível, deve ser utilizado um material o mais próximo possível da matriz real. Para métodos de matrizes aquosas, utiliza-se água destilada; para métodos de matrizes sólidas (solo, lodo ou vermicomposto), pode-se utilizar $\mathrm{Na}_{2} \mathrm{SO}_{4}$.

Essas amostras serão submetidas ao mesmo processo de preparação e determinação das amostras reais.

Para matrizes menos complexas, nas quais se espera uma recuperação de 70 a $120 \%$, a precisão deve ser de até $\pm 20 \%$; para matrizes e analitos mais complexos, nos quais se espera uma recuperação de 50 a 120\%, a precisão deve ser de $\pm 15 \%$ (RIBANI, M.; et. al, p. 777, 2004).

Repetitividade (intracorrida)

As condições de repetitividade serão caracterizadas quando utilizadas as mesmas condições (método, analista, equipamento e laboratório) e repetidas no menor tempo possivel.

Deverão ser analisadas duas concentrações diferentes: uma alta e uma baixa (escolhidas de acordo com a faixa de trabalho), realizadas em decuplicação. Essas duas concentrações serão utilizadas posteriormente para as planilhas de cartas controle (POP 018 - Cartas Controle), os desvios-padrão obtidos serão utilizados como referência para a avaliação das cartas controle.

São admitidos coeficientes de variação inferiores a 15\%, exceto para o limite inferior de quantificação e matrizes muito complexas, para o qual se admitem valores menores ou iguais a $20 \%$. (RE 899, item 3.3).

NOTA: a repetitividade é realizada durante a validação.

Precisão intermediária

As condições de precisão intermediária serão caracterizadas quando se utilizam o mesmo método e o mesmo laboratório, mas com variação de analistas e/ou equipamentos e/ou tempos (tempos diferentes devem ter, no mínimo, intervalo de dois dias, conforme RE 899, item 2.4.2). 
Figura 60. Continuação...

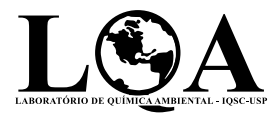

POP 008

VALIDAÇÃO

REV: X FL 4 DE 5

DATA $/ Z / 20$

A precisão intermediária é calculada após a emissão do ME e, ao menos, 15 resultados de amostras controle. Será calculada por meio da expressão:

${ }^{\text {Spi }}(j, k)=\sqrt{\frac{1}{t(n-1)} \sum_{j=1}^{t} \sum_{k=1}^{n}\left(y_{j k}-\bar{y}_{i}^{2}\right)}$

Em que: Spi ${ }_{(\mathrm{j}, \mathrm{k})}$ é o desvio-padrão de precisão intermediária; t é o total de amostras ensaiadas (não confundir com t de Student); n é o total de ensaios efetuados por amostras; j é o número da amostra, j=1,t; k é o número do ensaio da amostra, j, k=1, n; $\mathrm{y}_{\mathrm{j}, \mathrm{k}}$ é o valor do resultado $\mathrm{k}$ para a amostra $\mathrm{j}_{;} \mathrm{y}_{\mathrm{j}}$ é o representa a média aritmética dos resultados da amostra j.

O desvio-padrão da precisão intermediária é utilizado para o cálculo do coeficiente de variação.

Consulte o DOQ-CGCRE-008, item 8.2.6.3.2, para os procedimentos experimentais e controle da precisão intermediária. A precisão intermediária representa a variabilidade dos resultados em um laboratório.

Reprodutibilidade

A garantia da qualidade dos resultados é utilizada para a avaliação da reprodutibilidade do método, conforme POP 008 - Validação e POP 018 - Cartas Controle. Consulte o DOQ-CGCRE-008, item 8.2.6.3.3, para a definição do termo.

3.4.8 Robustez

Conforme DOQ-CGCRE-008, item 8.2.6.4, a robustez do método pode ser determinada via teste estatístico de Youden. Usa-se uma concentração intermediária (adição de padrão e ausência de interferentes), variando-se os parâmetros recomendados para cada técnica ou instrumento da Tabela 4 do RE 899, item 2.8 .

Tabela 1. Fatores que devem ser considerados na determinação da robustez do método analítico (Tabela 4, RE 899, item 2.8.)

\begin{tabular}{ll}
\hline \multirow{2}{*}{ Preparo de amostras } & Estabilidade das soluções analíticas \\
\cline { 2 - 2 } & Tempo de extração \\
\hline \multirow{3}{*}{ Cromatografia líquida } & Temperatura do $\mathrm{pH}$ da solução \\
\hline & Diferentes fabricantes de solventes \\
\hline & Variação do pH da fase móvel \\
\hline & Diferentes lotes ou fabricantes de colunas \\
\hline & Temperatura \\
\hline \multirow{3}{*}{ Cromatografia } & Fluxo da fase móvel \\
\hline & Diferentes lotes ou fabricantes de colunas \\
\hline & Temperatura \\
\hline & Velocidade do gás de arraste \\
\hline
\end{tabular}

Deverão ser analisados, no mínimo, três parâmetros instrumentais ou analíticos, que formarão uma combinação ensaiada (numerada de 1 a 8), conforme Tabela 2. Essa combinação deverá ser composta pelos parâmetros em validação (identificados por letras maiúsculas: $A, B$ e C) e pelas pequenas variações aplicadas a esses parâmetros (identificadas por letras minúsculas: $a, b$ e c). Cada combinação receberá uma letra para identificação dos resultados (de s até z). 
Figura 60. Continuação...

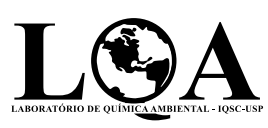

POP 008

VALIDAÇÃO

REV: X FL 5 DE 5

DATA $/ L / 20$

Tabela 2. Combinações ensaiadas para teste estatístico de Youden

\begin{tabular}{lcccccccc} 
& \multicolumn{7}{c}{ Combinação ensaiada } \\
\cline { 2 - 10 } & 1 & 2 & 3 & 4 & 5 & 6 & 7 & 8 \\
\hline Parâmetro A & (A) & (a) & (A) & (a) & (A) & (a) & (A) & (a) \\
\hline Parâmetro B & (B) & (B) & (B) & (B) & (b) & (b) & (b) & (b) \\
\hline Parâmetro C & (C) & (C) & (c) & (c) & (C) & (C) & (c) & (c) \\
\hline $\begin{array}{l}\text { Letras para identificação } \\
\text { dos resultados }\end{array}$ & s & t & u & v & w & X & y & z \\
\hline
\end{tabular}

O teste de Youden permite analisar o efeito de cada parâmetro, isoladamente, na robustez do método. Esse cálculo é realizado subtraindo os resultados obtidos com letras minúsculas por aqueles simbolizados por letras maiúsculas para cada uma das situações. Nas equações a seguir são apresentados os cálculos pertinentes. Os cálculos para o Parâmetro $A(A / a)$, para o Parâmetro B $(B / b)$ e para o Parâmetro $C(C / C)$ na robustez do método foram realizados de acordo com as equações, respectivamente.

$A / a=\frac{s+u+w+y}{4}-\frac{t+v+x+z}{4}$
$B / b=\frac{s+t+u+v}{4}-\frac{w+x+y+z}{4}$
$C / C=\frac{s+t+w+x}{4}-\frac{u+v+y+z}{4}$

O critério de aceitação é $\pm 10 \%$.

3.5 Não conformidades no monitoramento do método

3.5.1 Quando o erro em amostras controle for superior a 10\% da concentração e/ou do tempo de retenção, em relação à curva de calibração, os componentes do método ou equipamentos, incluindo a situação da calibração, que podem ter contribuído com o erro observado, são investigados.

3.5.2 Quando necessário, a curva de calibração é refeita.

\section{RESPONSABILIDADES}

4.1 Todos os pesquisadores.

\section{APROVAÇÕES}

\begin{tabular}{|l|l|l|}
\hline Autor & Aprovado / Assinatura & Data \\
\hline & & \\
\hline
\end{tabular}

O POP 008 - Validação foi baseado em várias legislações, entre elas a norma RE 899. Quando da finalização deste texto, foi revogada a norma RE 899 e atualizada. No portal da ANVISA, pode-se ler: "Já está disponível no portal da ANVISA, "o Guia $n^{\circ} 10$, versão 1 para Tratamento Estatístico da Validação Analítica. O documento expressa o entendimento da Anvisa em relação à Resolução da Diretoria Colegiada - RDC n 166/2017, que trata da validação de métodos analíticos. A norma revoga a $R E n^{\circ} 899 / 2003$, além do inciso XXXI do artigo 10, do parágrafo único do artigo 11 e o anexo I da RDC 31/2010". "Com a publicação, o Guia n 10 , versão 1 já está valendo. Porém, nos próximos 180 dias, será possível oferecer sugestões e críticas ao texto. As contribuições serão recebidas até o dia 12 de março de 2018 por meio de formulário FormSUS". O Sistema de Gestão da Qualidade é dinâmico e preza pelo compromisso com a melhoria contínua. O POP 008, portanto, será revisado, após avaliação da nova norma. 
Figura 61. Cópia ilustrativa do POP 007 - Verificação de Balanças

VERIFICAÇÃO DE BALANÇAS $\frac{\text { POP } 007}{\text { REV:X FL } 1 \text { DE } 3}$

\section{OBJETIVO}

Estabelecer a sistemática para a análise crítica da verificação de balanças.

\section{DOCUMENTOS COMPLEMENTARES}

DOG-CGCRE-036 - Orientações sobre Verificação Intermediária das Balanças - Rev. 00, dezembro de 2012.

Manual para elaboração de cartas controle para monitoramento de processos de medição quantitativos em laboratórios de ensaio. Governo do estado de São Paulo - Secretaria de Estado da Saúde - Coordenadoria de Controle de Doenças - Instituto Adolfo Lutz, 2013.

\section{PROCEDIMENTO}

3.1 Verificação

3.1.1 A verificação das balanças é necessária para a manutenção da confiança na situação da calibração e é realizada conforme procedimentos descritos nos IOs.

3.2 Análise crítica da verificação de balanças

A VERIFICAÇÃO SIMPLES

3.2.1 A verificação simples da balança é realizada diariamente ou a cada uso.

3.2.2 Conforme DOQ-CGCRE-036, item 11.1, para cada ponto selecionado, o usuário deve:

a) Tarar a balança e registrar a leitura no ponto zero $\left(z_{1}\right)$.

b) Posicionar o peso (M) na balança e registrar a leitura da indicação da balança $\left(m_{1}\right)$.

c) Retirar o peso da balança e não tarar a balança.

d) Posicionar o peso (M) na balança e registrar a leitura da indicação da balança $\left(m_{2}\right)$.

e) Retirar o peso da balança e registrar e leitura no ponto zero $\left(z_{2}\right)$.

3.2.3 O erro de uma balança é definido como:

\begin{tabular}{|c|c|c|c|}
\hline $\begin{array}{c}\text { Valor verdadeiro } \\
\text { condicional (Padrão)* }\end{array}$ & $\begin{array}{l}\text { [Leitura (da balança) - Leitura } \\
\text { do zero (sem tarar a balança)] }\end{array}$ & $=$ & Erro \\
\hline M & $r_{i}=m_{i}-z_{i}$ & $=$ & Erro \\
\hline
\end{tabular}

3.2.4 A medição é feita em duplicidade e é calculada a média dos erros.

$$
\frac{\text { Erro 1+Erro 2 }}{2}
$$

3.2.5 A análise crítica da verificação é feita conforme DOG-CGCRE-036, item 11.1, em que:

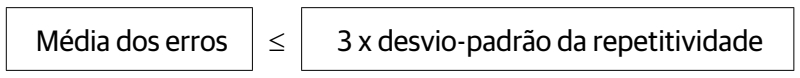

a) O erro adotado para cada análise crítica é o erro obtido das médias das medições em avaliação.

b) O desvio-padrão da repetitividade é obtido com a calibração da balança.

c) Para cada análise crítica, utilizam-se então a média dos erros da medição atual e o desvio-padrão da repetitividade dado no certificado de calibração.

* "O valor de massa utilizado como referência (...) deve ser o valor declarado no certificado de calibração (valor convencional, por exemplo, 100,005 g) e não o valor nominal do peso padrão (100 g neste mesmo exemplo)." (DOQCGCRE-036, item 11) 
Figura 61. Continuação...

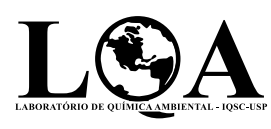

POP 007

VERIFICAÇÃO DE BALANÇAS

REV: X FL 2 DE 3

DATA $/ Z / 20$

3.2.6 O critério de aceitação adotado pelo LQA corresponde a três vezes o desvio-padrão da repetitividade.

CRITÉRIO DE ACEITAÇÃO = 3 x desvio padrão da repetitividade

NOTA: O critério de aceitação varia com cada calibração.

B VERIFICAÇÃO DA REPETITIVIDADE

3.2.7 A verificação da repetitividade da balança é realizada semestralmente.

3.2.8 Conforme DOQ-CGCRE-036, item 11.1, para cada ponto selecionado, o usuário deve:

a) Tarar a balança e registrar a leitura no ponto zero $\left(z_{1}\right)$.

b) Posicionar o peso $(M)$ na balança e registrar a leitura da indicação da balança $\left(m_{1}\right)$.

c) Retirar o peso da balança e registrar e leitura no ponto zero $\left(\mathrm{z}_{2}\right)$.

d) Sem tarar a balança, posicionar o mesmo peso $(M)$ na balança e registrar a leitura da indicação da balança $\left(\mathrm{m}_{2}\right)$.

e) Retirar o peso da balança e registrar e leitura no ponto zero $\left(z_{3}\right)$.

f) Repetir os passos d e e até que sejam obtidas as 10 leituras.

3.2.9 Calcular a diferença $\left(r_{\text {; }}\right)$ entre cada leitura de pesagem e a leitura do zero correspondente.

$$
r_{i}=m_{i}-z_{i}
$$

3.2.10 Calcular o desvio-padrão das diferenças $r_{1}, r_{2}, \ldots r_{10}$, utilizando a fórmula:

${ }^{s}$ usuário $=\sqrt{\frac{\sum\left(r_{i}-R\right)^{2}}{(n-1)}}$

Em que:

$\mathrm{i}=1$ até 10 ;

$\mathrm{R}=$ média dos valores de $\mathrm{r}_{\mathrm{i}}$;

$\mathrm{n}=$ número de repetições.

3.2.11 A análise crítica da verificação é feita conforme DOG-CGCRE-036, item 11.2, em que:

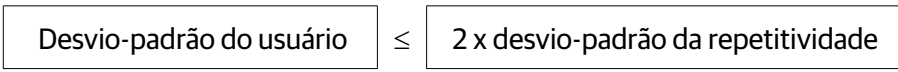

NOTA: O desvio-padrão da repetitividade é obtido com a calibração da balança.

3.3 Não conformidades nas verificações

3.3.1 Quando o erro for superior ao critério de aceitação, um Relatório de Não Conformidade - RNC (PG 014) é emitido.

3.3.2 Quando aplicável, adotam-se os procedimentos do POP 001 - Equipamentos.

3.4 Registro da verificação

3.4.1 O resultado e a análise crítica da verificação são registrados no Registro de Gerenciamento dos Equipamentos - POP 001.

\section{RESPONSABILIDADES}

4.1 Pesquisadores usuários dos equipamentos

* "O valor de massa utilizado como referência (...) deve ser o valor declarado no certificado de calibração (valor convencional, por exemplo, 100,005 g) e não o valor nominal do peso padrão (100 g neste mesmo exemplo)." (DOQCGCRE-036, item 11) 
Figura 61. Continuação...

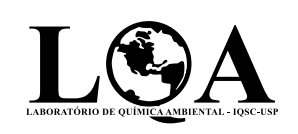

POP 007

REV: X FL 3 DE 3

DATA_I_/20_

Verificam as balanças, conforme IO, antes do uso. Registram a verificação nos Registros de Gerenciamento das Balanças.

Quando detectada uma não conformidade, emitem um RNC (POP 014) para investigar a causa do erro.

\section{REGISTROS}

Registro de gerenciamentos das balanças.

\section{APROVAÇÕES}

\begin{tabular}{|l|l|l|}
\hline Autor & Aprovado / Assinatura & Data \\
\hline & & \\
\hline
\end{tabular}

* "O valor de massa utilizado como referência (...) deve ser o valor declarado no certificado de calibração (valor convencional, por exemplo, 100,005 g) e não o valor nominal do peso padrão (100 g neste mesmo exemplo)." (DOQCGCRE-036, item 11) 
Figura 62. Cópia ilustrativa de uma página do Registro de Gerenciamento da Balança x*

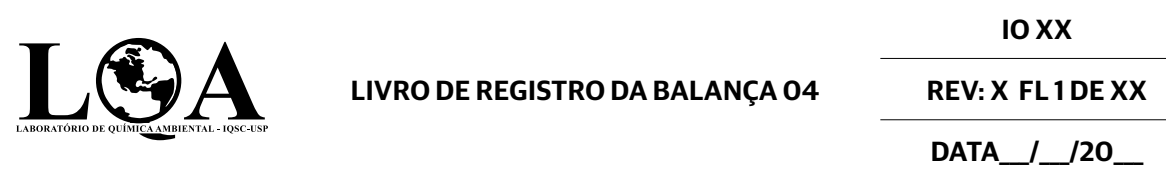

\begin{tabular}{|c|c|c|c|}
\hline Amostra & Massa Aferida & Data & Responsável \\
\hline & & & \\
\hline & & & \\
\hline & & & \\
\hline & & & \\
\hline & & & \\
\hline & & & \\
\hline & & & \\
\hline & & & \\
\hline & & & \\
\hline & & & \\
\hline & & & \\
\hline & & & \\
\hline & & & \\
\hline & & & \\
\hline & & & \\
\hline & & & \\
\hline & & & \\
\hline & & & \\
\hline & & & \\
\hline & & & \\
\hline & & & \\
\hline & & & \\
\hline & & & \\
\hline & & & \\
\hline & & & \\
\hline & & & \\
\hline & & & \\
\hline & & & \\
\hline & & & \\
\hline & & & \\
\hline & & & \\
\hline
\end{tabular}


O controle estatístico é atestado pela avaliação de cartas controle e/ou de comparações interlaboratoriais.

\subsubsection{Cartas controle}

A utilização de cartas controle para monitoramento do método é uma importante ferramenta da qualidade que auxilia na prevenção de não conformidades.

O LQA tem um procedimento específico para monitoramento dos resultados reportado no POP 018 - Cartas controle.

Nas Figuras 63 a 65, ilustram-se o POP 018 e os respectivos anexos.

\subsubsection{Ensaios de Proficiência}

A participação dos laboratórios em atividades de ensaio de proficiência é um dos mecanismos de controle da qualidade dos resultados previstos na norma NBR ISO/IEC17025. Os benefícios da participação em ensaios de proficiência incluem:

a. Avaliação externa e independente da qualidade dos resultados.

b. Comparação dos resultados com outros laboratórios que participam do programa de proficiência.

c. Avaliação obtida pode servir para implementação de ações preventivas e corretivas.

d. Disponibilização de relatórios, por alguns fornecedores de ensaio de proficiência, contendo avaliações estatísticas dos resultados, o que permite ao laboratório traçar as características de desempenho do método analítico. ${ }^{1}$

Por esses motivos, recomenda-se fortemente que o laboratório de pesquisa participe dos ensaios de proficiência.

1 http://inmetro.gov.br/credenciamento/ensaioProf.asp Acessado em 02/10/2017. 
Figura 63. Cópia ilustrativa do POP 018 - Cartas Controle

CARTAS CONTROLE $\frac{\text { POP } 018}{\text { REV: X FL 1DE } 4}$

\section{OBJETIVO}

Estabelecer a sistemática para elaboração e análise crítica de cartas controle.

\section{DOCUMENTOS COMPLEMENTARES}

Westgard, J.O., Barry, P. L., Hunt, M.R..(1981). A Multi-Rule Shewhart Chart for Quality Control in Clinical Chemistry. Clinical Chemistry, v 27 (3), p. 493-501, 1981. Tradução de ControlLab 2003. Gráfico Shewhart de Regras Múltiplas para Controle de Qualidade em Bioquímica. OGCOO2 - Guia para Acreditação de Laboratórios Químicos, 18 de maio de 2011.

Manual para elaboração de cartas controle para monitoramento de processos de medição quantitativos em laboratórios de ensaio. Governo do estado de São Paulo - Secretaria de Estado da Saúde - Coordenadoria de Controle de Doenças - Instituto Adolfo Lutz, 2013.

\section{CONDIÇÕES}

O monitoramento da qualidade é feito: internamente, com a construção de curvas de calibração, verificação dos equipamentos, instrumentos de medição e padrões, monitoramento dos métodos e elaboração e avaliação de cartas controle; e externamente, caso se deseje, com a participação em ensaios de proficiência.

\section{PROCEDIMENTO}

\subsection{Monitoramento de métodos}

4.1.1 O monitoramento dos métodos é realizado em equipamentos que dependem de um método para o monitoramento ou verificação. "Nestes casos, a rastreabilidade da calibração da totalidade do método pode ser obtida usando-se materiais de referência certificados." (DOQ-CGCRE-035, p. 8). Consiste em monitorar os resultados do branco e das amostras controle (materiais de referência certificados) em relação às curvas de calibração.

4.1.2 Entende-se como branco do método ou branco reagente "água reagente e todos os reagentes que normalmente estão em contato com a amostra durante todas as etapas do procedimento analítico. (...)" É uma porção de água reagente processada exatamente como a amostra, incluindo exposição a todo equipamento, vidraria, procedimentos e reagentes. (NIT-DICLA-057, item 6.2.2.)

\section{AMOSTRAS CONTROLE}

5.1 A construção das cartas controle é feita a partir dos resultados das amostras controle. As amostras controle podem ser soluções estoque originadas a partir de um material de referência. Os resultados são registrados no Registro de Controle Estatístico - RCE (Anexo 2).

\section{AMOSTRAS FORTIFICADAS}

6.1 Entende-se como amostra fortificada "uma porção adicional de uma amostra na qual, antes do seu processamento, são adicionadas quantidades conhecidas dos analitos de interesse." (NIT-DICLA-057, item 6.2.6.)

6.2 As amostras fortificadas são usadas quando há suspeita de interferência da matriz no resultado analítico ou para quantificar parâmetros atendidos pelos MEs e não contemplados pela curva de calibração.

NOTA 1: Especial atenção para a interferência da matriz nos métodos espectrofotométricos pela sensibilidade do equipamento à coloração das amostras.

NOTA 2: A capacidade de operar adequadamente um método validado é estendida aos parâmetros contemplados pelos mesmos métodos de extração e determinação, inclusive quando não incluídos nas curvas de calibração do ME. Após a varredura da amostra (ensaio), os picos identificados são quantificados com o auxílio da curva de calibração ou com a 
Figura 63. Continuação...

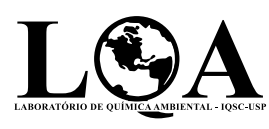

POP 018

CARTAS CONTROLE

REV: X FL 2 DE 4

DATA $/ Z / 20$

fortificação da amostra com o parâmetro identificado. Aplica-se uma regra de três simples quando a quantificação for feita com a fortificação da amostra.

\section{Uso de materiais de referência}

6.3 As verificações dos monitoramentos dos métodos são realizadas conforme os MEs.

6.4 Para o preparo das soluções estoque:

I) Preparam-se duas soluções estoque-mãe (soluções A e B, com concentrações diferentes) preferencialmente a partir de diferentes fontes de materiais de referência (por exemplo: fornecedores e lotes diferentes).

II) Quando isso não for possível, preparam-se as soluções estoque-mãe A e B a partir do mesmo material de referência.

NOTA: as soluções $A$ e $B$ podem ser preparadas a partir do material de referência ou de uma solução-mãe comum.

III) Cada solução estoque será utilizada sempre para o preparo de uma amostra controle com a mesma concentração previamente definida (solução A sempre usada para o preparo da amostra controle de concentração "x" e solução B para amostra controle de concentração "y"). Com isso, mesmo que o material de referência seja o mesmo, garante-se a independência no preparo (OGCO02, p. 7).

6.5 As duas amostras controle (de concentração " $x$ " e " $y$ ") são analisadas quando o método documentado é passível de monitoramento for adotado.

6.6 São adotadas sempre as mesmas concentrações (" $x$ " e "y") para as amostras controle de um mesmo método.

6.7 As concentrações " $x$ " e " $y$ " são escolhidas com base nos resultados mais prováveis de amostras reais.

\section{CARTAS CONTROLE}

As verificações, registradas no Registro de Controle Estatístico (Anexo 2), e os monitoramentos dos métodos são utilizados para a elaboração das cartas-controle.

7.1 Elaboração

7.1.1 Para escolha do tipo de carta controle, construção e definição de limites de interpretação dos resultados, manual de utilização do software Action e exemplos, consultar o Manual para Elaboração de Cartas Controle para Monitoramento de Processos de Medições Quantitativas em Laboratórios de Ensaio.

7.1.2 As cartas controle são atualizadas sempre que o equipamento for utilizado. O registro é feito no Registro de Controle Estatístico (Anexo 2) correspondente. A carta controle é apresentada na Planilha de Carta Controle (Anexo 3).

Nota: Poderão ser utilizados dados históricos a fim de se obterem os limites de controle preliminares. Entretanto, estes só indicarão que o processo estava ou não sob controle; para continuar o monitoramento, os limites devem ser frequentemente recalculados.

7.2 Regras de avaliação das cartas controle

7.2.1 Os critérios de decisão das cartas controle definidos por Westgard et al. (1981, p. 3) são:

"Por conveniência, são utilizados símbolos para representar as diferentes regras de controle. $O$ símbolo $A L$, onde $A$ é uma abreviação para uma estatística ou o número de observações de controle por corrida, e $L$ é o limite de controle.

$(\ldots)^{1}$

$1_{35}$ simboliza a regra de controle na qual uma corrida é rejeitada, quando uma observação de controle excede o limite $\bar{X} \pm 3 D P$. Estes são os limites de rejeição usuais em um gráfico de controle Shewhart. 
Figura 63. Continuação...

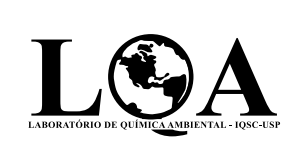

POP 018

CARTAS CONTROLE

REV: X FL 3 DE 4

DATA $\_/ 20$

$2_{25}$ é a regra de controle na qual a corrida é rejeitada quando duas observações de controle consecutivas excedem o mesmo limite, sendo $\bar{x}+2 \mathrm{DP}$ ou $\bar{x}-2 \mathrm{DP}$. A regra é inicialmente aplicada a duas observações dentro de uma corrida, uma em cada dois materiais de controle diferentes. A corrida é rejeitada quando as observações de controle em ambos materiais excedem seus respectivos limites de controle (+2DP ou -2DP). A regra também pode ser aplicada a duas observações consecutivas no mesmo material de controle, uma em cada duas corridas consecutivas. Quando aplicada em observações consecutivas em diferentes materiais, serão indicadas como "inter-materiais", para diferenciar de observações consecutivas no mesmo material, denominada "intra-materiais".

$R_{45}$ é a regra de controle utilizada em situações na qual a corrida é rejeitada quando a faixa ou a diferença entre duas observações de controle em uma corrida excedem 4DP. A regra é utilizada quando a observação para um material de controle excede um limite +2DP e a observação para outro excede um limite -2DP. Cada observação está fora por 2DP, mas em direções opostas, resultando em uma diferença total de 4DP entre elas. $41 s$ é a regra de controle na qual a corrida é rejeitada quando quatro observações de controle consecutivas excedem o mesmo limite, $\bar{x}+1 \mathrm{DP}$ ou $\bar{X}-1 \mathrm{DP}$. Essas observações consecutivas podem ocorrer em um material de controle, o que implica na necessidade de inspecionar as observações para as quatro corridas consecutivas, ou entre materiais de controle, o que implica em inspecionar apenas a corrida atual e a anterior a esta.

$10_{x}$ é a regra de controle que indica a rejeição da corrida quando 10 observações de controle consecutivas estão do mesmo lado da média $(\bar{X})$. Estas observações consecutivas podem ocorrer em um material de controle ou entre materiais de controle. Isto pode requerer a inspeção de dez ou cinco corridas consecutivas, respectivamente."

'Optamos por eliminar a regra de alerta $12 \mathrm{~s}$ (avaliar somente as corridas com resultados acima dos limites controle de $\bar{X} \pm 2 \mathrm{DP}$ ) por considerarmos relevante analisar todas as corridas.

Nota LQA: a expressão "material de controle" empregado no texto equivale à nossa definição de material de referência. Entende-se a expressão "observação de controle" como os resultados das amostras controle.

7.3 Avaliando as cartas controle

7.3.1 A regra $1_{35}$ não requer comparação entre amostras controle ou em corridas. A avaliação consiste em identificar um único ponto acima dos limites $\bar{X} \pm 3 \mathrm{DP}$.

7.3.2 A regra $2_{25}$ se aplica aos resultados entre amostras controle (concentrações diferentes) na mesma corrida e em amostras controle de mesma concentração em corridas consecutivas. Neste último caso, requer a avaliação da corrida atual e da anterior.

7.3.3 A regra $\mathrm{R}_{4} \mathrm{~s}$ se aplica somente aos resultados entre amostras controle (concentrações diferentes) na mesma corrida. Requer a avaliação apenas da corrida atual.

7.3.4 A regra 4 s se aplica aos resultados entre amostras controle (concentrações diferentes) na mesma corrida, quando requer a avaliação da corrida atual e da anterior, e em amostras controle de mesma concentração (em corridas consecutivas), quando requer a avaliação de quatro corridas consecutivas.

7.3.5 A regra 10 se aplica aos resultados entre amostras controle (concentrações diferentes) na mesma corrida, quando requer a avaliação de cinco corridas, e em amostras controle de mesma concentração (em corridas consecutivas), quando requer a avaliação de dez corridas consecutivas.

7.3.6 Rejeite a corrida atual quando qualquer uma das regras for infringida. 
Figura 63. Continuação...

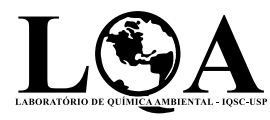

7.4 Erros em cartas controle

7.4.1 Após a rejeição de uma corrida, preenche-se um Relatório de Não Conformidade - RNC (POP 014). Determina-se o tipo de erro que está ocorrendo (aleatório, sistemático ou ambos) com base nas regras de controle que foram violadas.

a) Regras $1_{3 s}$ ou $R_{4 s}$ estão mais relacionadas a erros aleatórios que sistemáticos.

b) Erros sistemáticos são mais facilmente detectados pelas regras $2_{2 s^{\prime}} 4_{1 s}$ ou $10_{x}$. Revisar os resultados em amostras controle de concentrações diferentes ajuda a identificar erros que ocorrem por toda a faixa de concentração. Revisar os resultados em amostras controle de mesma concentração ajuda a identificar erros em faixas de concentrações específicas.

7.4.2 Quando o erro em amostras controle levar à rejeição da corrida, investigam-se os componentes do método ou equipamentos, incluindo a situação da calibração, que podem ter contribuído com o erro observado.

7.4.3 Quando possível, o problema é sanado, e a verificação, repetida no menor tempo possível.

7.4.4 No controle da nova corrida, não se incluem os resultados da corrida rejeitada anteriormente.

7.5 Utilização de resultados de amostras em corridas rejeitadas

7.5.1 Mesmo após a rejeição de uma corrida, o responsável pode decidir por utilizar os resultados quando (WESTGARD et. al., 1981, p. 5 e 6):

a) "O problema do controle pode estar relacionado aos próprios materiais de controle.

b) O problema do controle pode ser resultado de um acontecimento isolado, que não afeta o resto da corrida (troca de amostras ou erro de transcrição).

c) O problema do controle ocorre em uma faixa de concentração que é diferente das concentrações nas amostras (...). O método está sob controle na faixa das amostras (...).

d) O tamanho do erro analítico é pequeno em relação às necessidades (...) de exatidão."

\section{RESPONSABILIDADES}

8.1 GT, Laboratórios de pesquisa 2, 3 e 4.

Preparo das amostras controle. Realização dos ensaios com as amostras controle (a partir de MR).

8.2 Gerente da qualidade Atualiza as cartas controle.

Quando uma corrida for rejeitada, emissão do RNC (POP 014) para investigar a causa do erro.

\section{REGISTROS}

Anexo 2 - Registro de Controle Estatístico (RCE).

Anexo 3 - Planilhas de Cartas Controle (PCC).

\section{APROVAÇõES}

\begin{tabular}{|l|l|l|}
\hline Autor & Aprovado / Assinatura & Data \\
\hline & & \\
\hline
\end{tabular}


Figura 64. Cópia ilustrativa do Registro de Controle Estatístico (ANEXO 2) do POP 018 - Cartas Controle
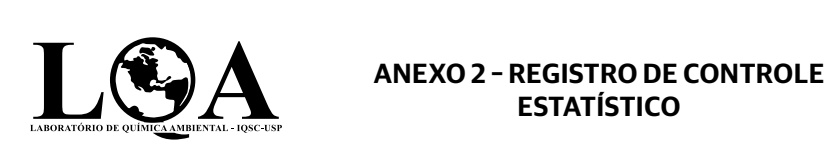

RCE

\begin{tabular}{|c|c|}
\hline Responsável: & Data: \\
\hline \multicolumn{2}{|l|}{ ID das Amostras: } \\
\hline \multicolumn{2}{|l|}{ Parâmetro: } \\
\hline Concentração-Alvo: & Concentração Obtida: \\
\hline \multicolumn{2}{|l|}{ Parâmetro: } \\
\hline Concentração-Alvo: & Concentração Obtida: \\
\hline \multicolumn{2}{|l|}{ Parâmetro: } \\
\hline Concentração-Alvo: & Concentração Obtida: \\
\hline \multicolumn{2}{|l|}{ Parâmetro: } \\
\hline Concentração-Alvo: & Concentração Obtida: \\
\hline \multicolumn{2}{|l|}{ Parâmetro: } \\
\hline Concentração-Alvo: & Concentração Obtida \\
\hline \multicolumn{2}{|l|}{ Limite Superior*: } \\
\hline \multicolumn{2}{|l|}{ Limite Inferior**: } \\
\hline \multicolumn{2}{|l|}{ Avaliação (C/ NC): } \\
\hline \multicolumn{2}{|l|}{ RNC no: } \\
\hline \multicolumn{2}{|l|}{ Responsável: } \\
\hline \multicolumn{2}{|l|}{ ID das Amostras: } \\
\hline \multicolumn{2}{|l|}{ Parâmetro: } \\
\hline Concentração-Alvo: & Concentração Obtida \\
\hline \multicolumn{2}{|l|}{ Parâmetro: } \\
\hline Concentração-Alvo: & Concentração Obtida \\
\hline \multicolumn{2}{|l|}{ Parâmetro: } \\
\hline Concentração-Alvo: & Concentração Obtida \\
\hline \multicolumn{2}{|l|}{ Parâmetro: } \\
\hline Concentração-Alvo: & Concentração Obtida \\
\hline \multicolumn{2}{|l|}{ Parâmetro: } \\
\hline Concentração-Alvo: & Concentração Obtida \\
\hline \multicolumn{2}{|l|}{ Limite Superior*: } \\
\hline \multicolumn{2}{|l|}{ Limite Inferior**: } \\
\hline \multicolumn{2}{|l|}{ Avaliação (C/ NC): } \\
\hline RNC no: & \\
\hline
\end{tabular}

* Limite Superior de acordo com Anexo 3 - Planilha de Carta Controle.

**Limite Inferior de acordo com Anexo 3 - Planilha de Carta Controle. 
Figura 65. Cópia ilustrativa de uma página da Planilha de Carta Controle (ANEXO 3) do POP O18 Cartas Controle
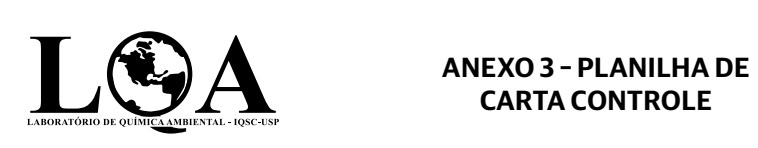

PCC

REV: X FL 1 DE 10

DATA_I_/20_

\section{PARÂMETROS}

1.1 Benzeno $-15 \mathrm{ppb}$

\begin{tabular}{|l|l|}
\hline \multicolumn{2}{|c|}{ ANÁLISE DE VARIÁVEIS DO CEP } \\
\hline \multicolumn{1}{|c|}{ DADOS DO PROCESSO } \\
\hline \multicolumn{1}{|c|}{ Limites } \\
\hline Limite Superior: 21,97408074 & 21,97408074 \\
\hline Linha de Centro: 16,0727 & 16,0727 \\
\hline Limite Inferior: 10,17131926 & 10,17131926 \\
\hline
\end{tabular}

\section{Gráfico de Valores Individuais}

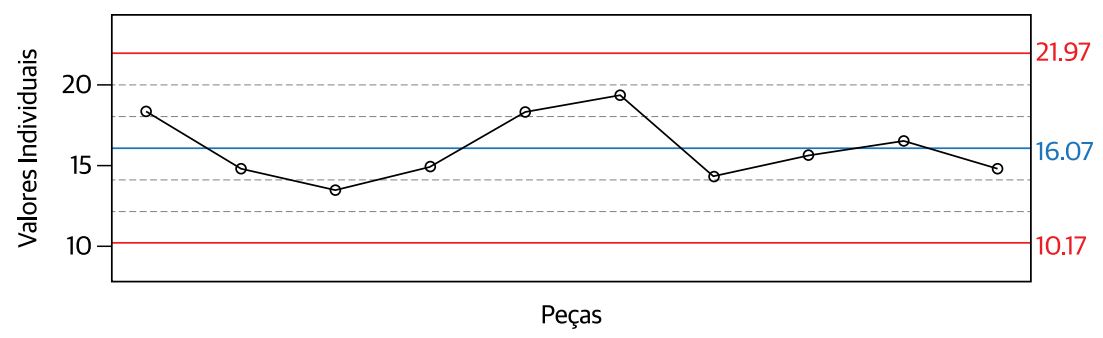

Gráfico de Amplitude Móvel

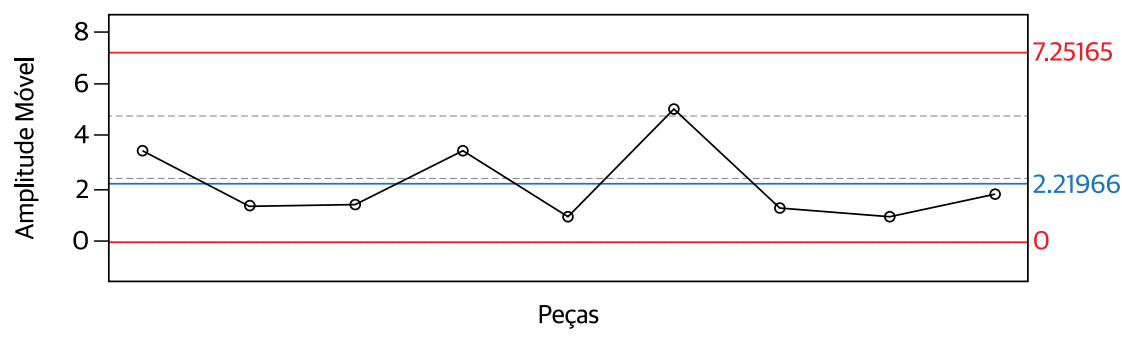


Figura 65. Continuação...

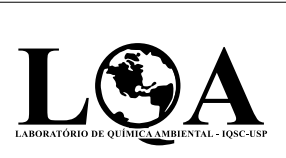

PCC
REV: X FL 2 DE 10
DATA $/ \angle / 20 \_$

ANEXO 3 - PLANILHA DE

CARTA CONTROLE

1.2 Benzeno - 40 ppb

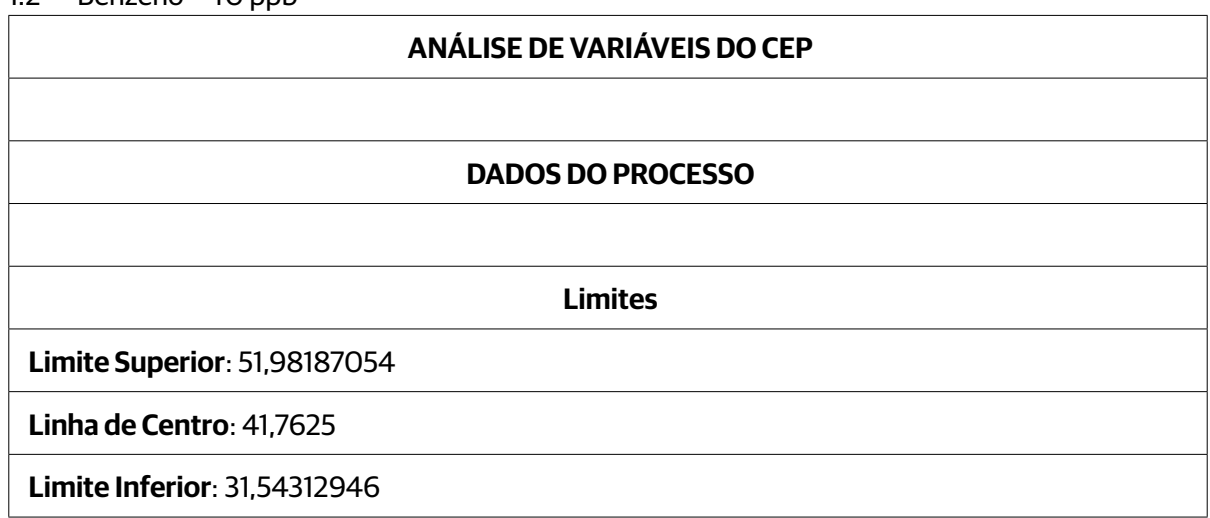

Gráfico de Valores Individuais

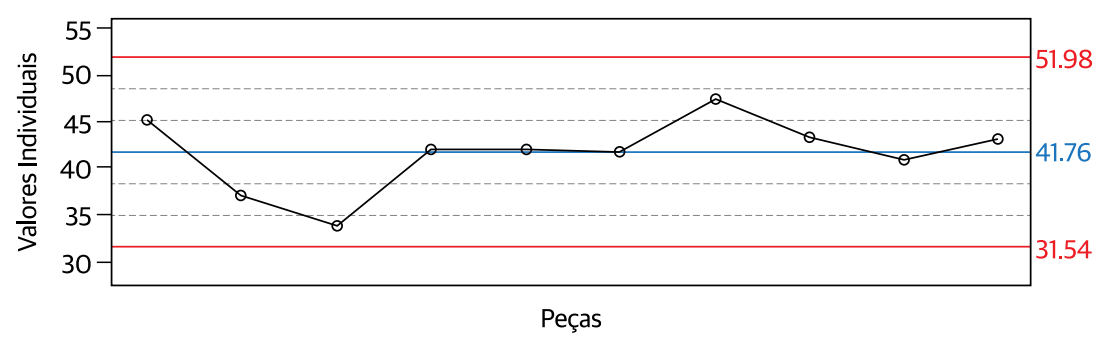

Gráfico de Amplitude Móvel

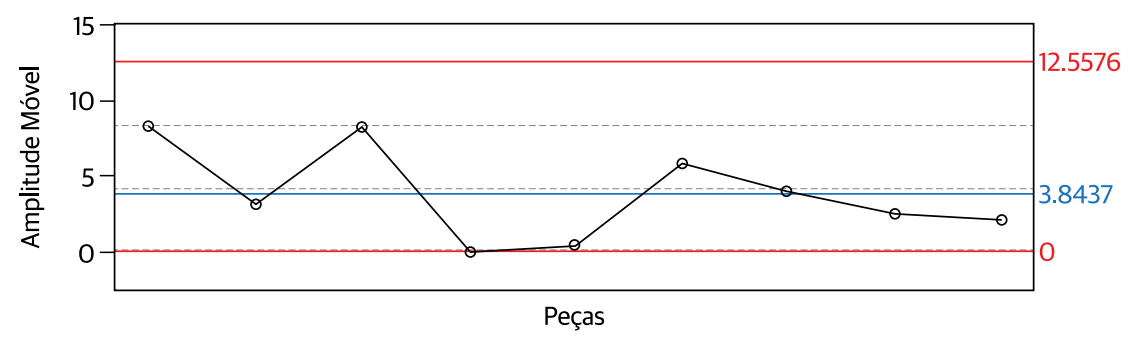


Figura 65. Continuação...

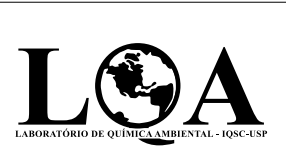

PCC

REV: X FL 3 DE 10

DATA_I_/20_

1.3 Tolueno $-15 \mathrm{ppb}$

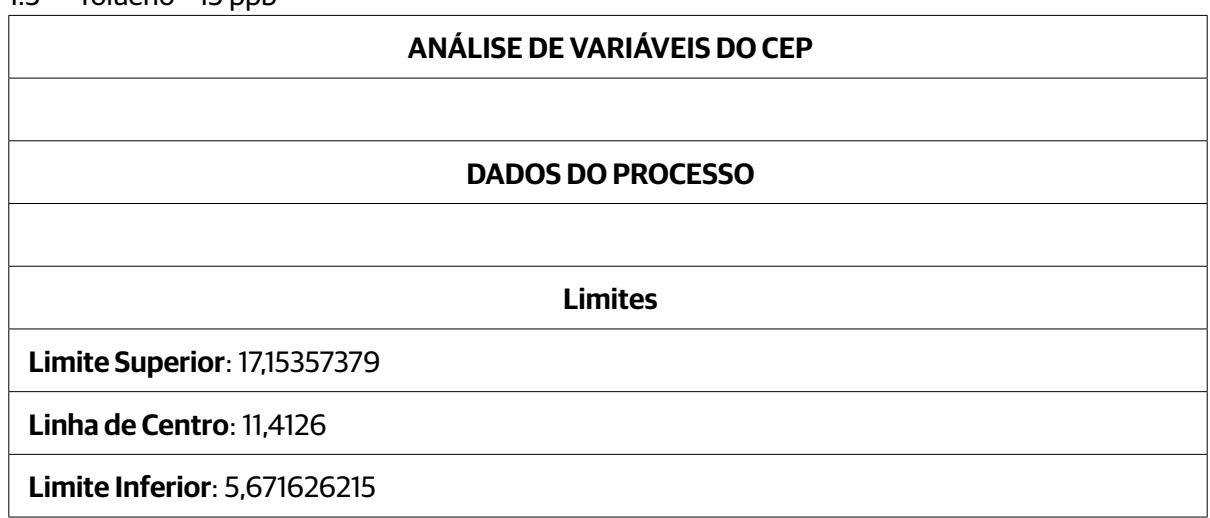

Gráfico de Valores Individuais

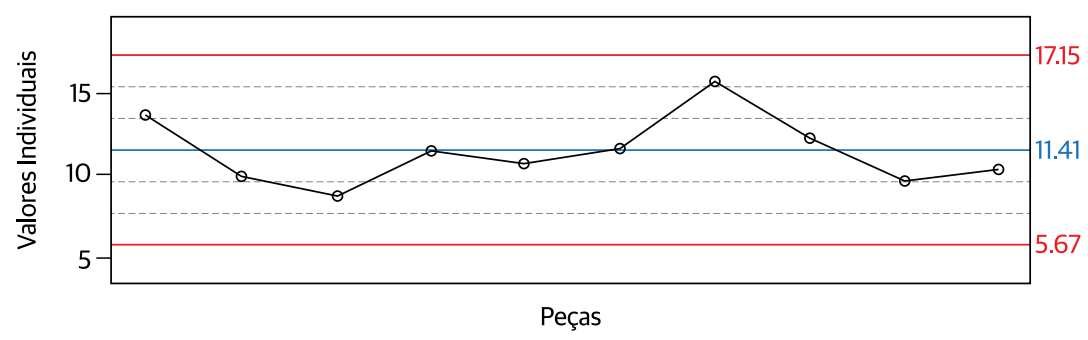

Gráfico de Amplitude Móvel

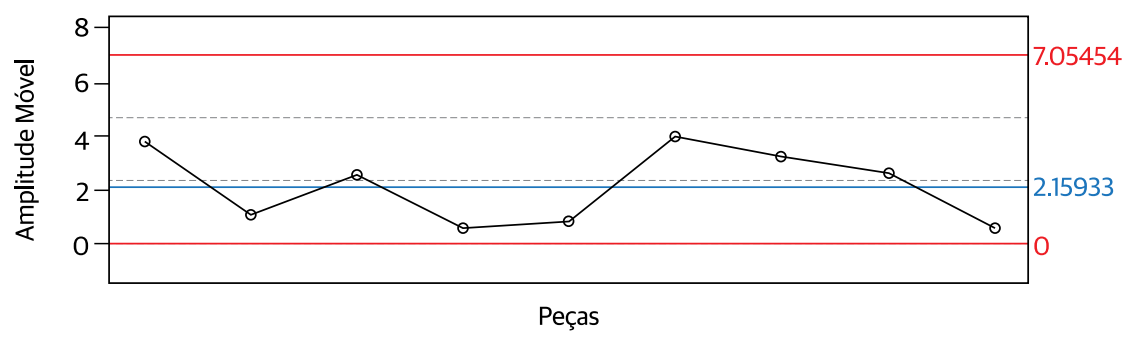


Figura 65. Continuação...

ANEXO 3-PLANILHA DE
CARTA CONTROLE $\frac{\text { PCC }}{\text { REV: X FL 4 DE } 10}$

1.4 Tolueno - 40 ppb

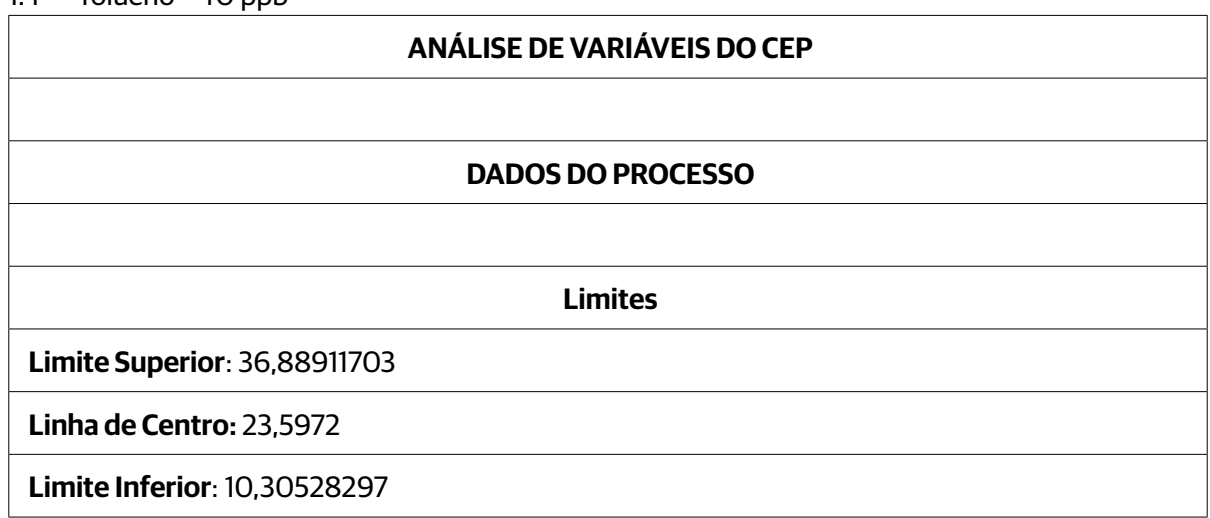

Gráfico de Valores Individuais
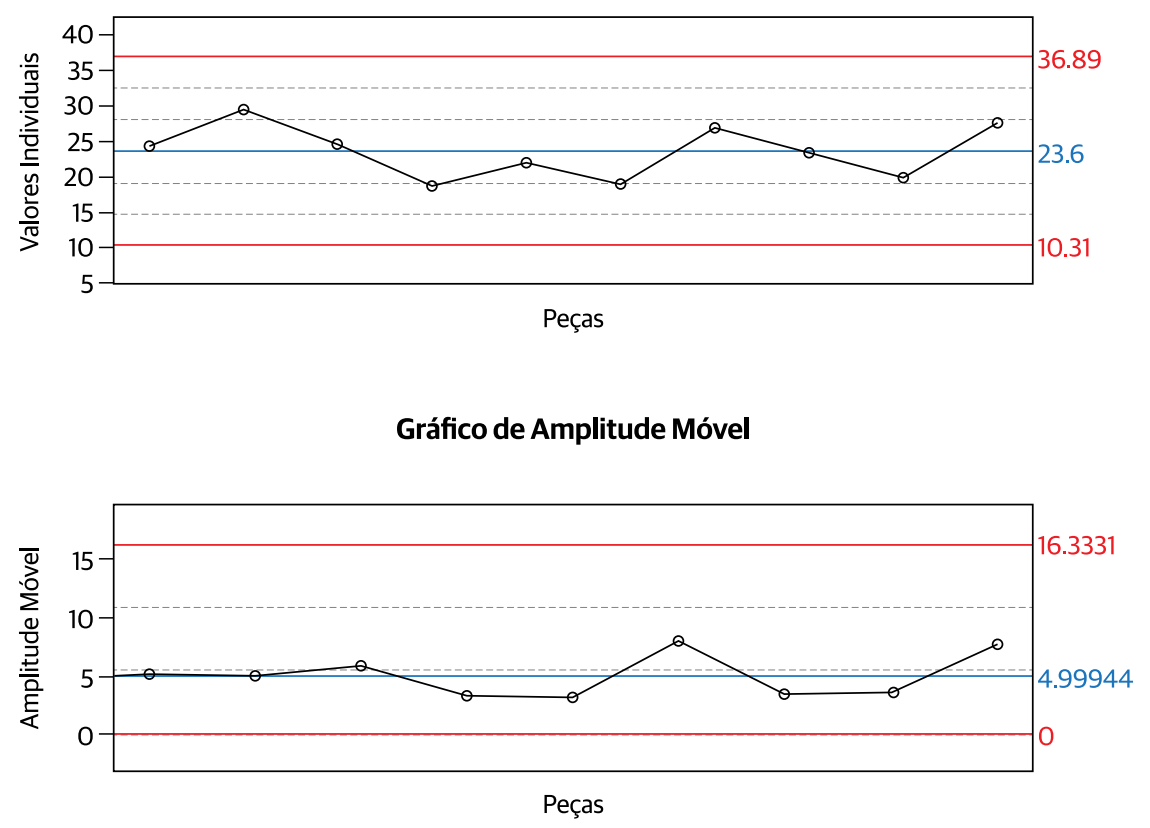
Figura 65. Continuação...

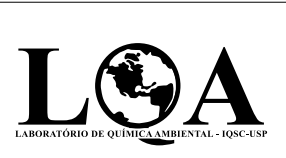

$\frac{\text { PCC }}{\text { REV: X FL 5 DE } 10}$

1.5 Etilbenzeno $-15 \mathrm{ppb}$

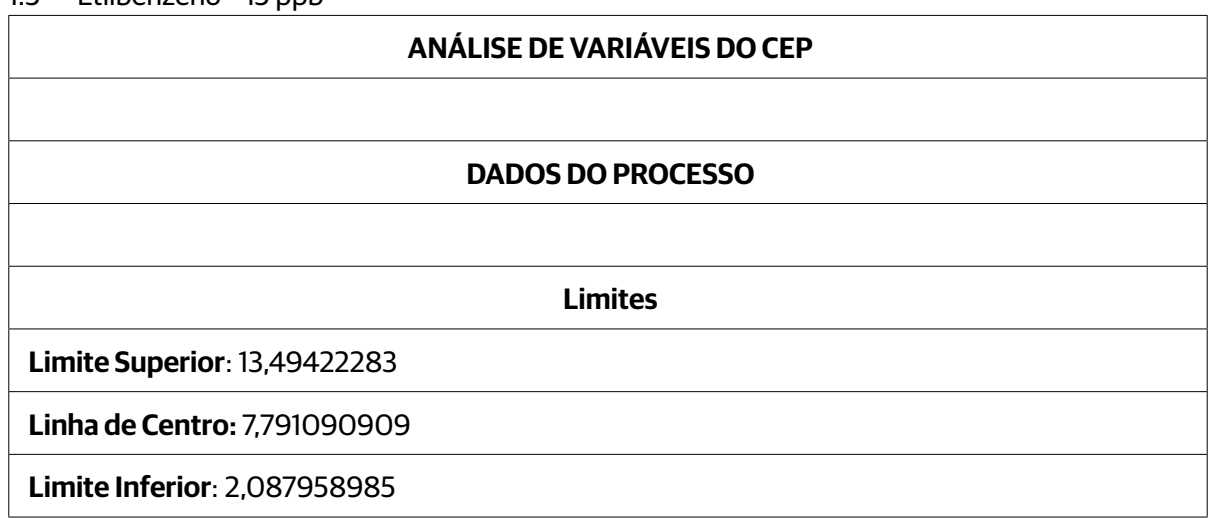

Gráfico de Valores Individuais

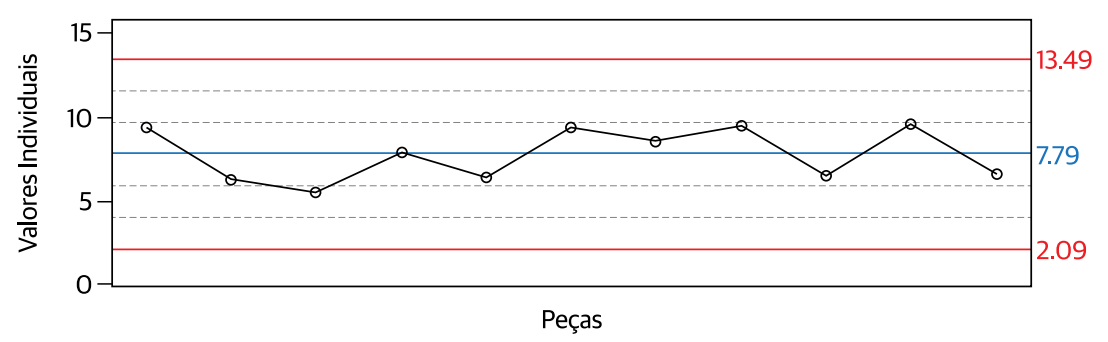

Gráfico de Amplitude Móvel

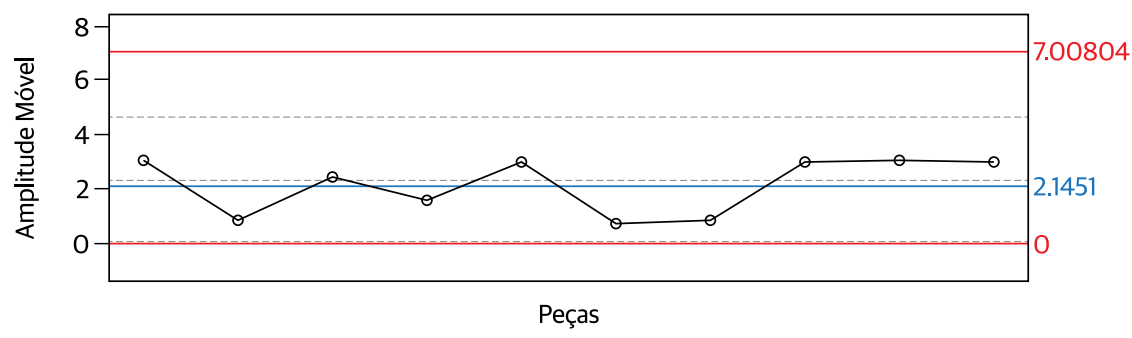


Figura 65. Continuação...

ANEXO 3-PLANILHA DE
CARTA CONTROLE

1.6 Etilbenzeno - $40 \mathrm{ppb}$

\begin{tabular}{|l|}
\hline \multicolumn{1}{|c|}{ ANÁLISE DE VARIÁVEIS DO CEP } \\
\hline \\
\hline \\
\hline \\
\hline DADOS DO PROCESSO \\
\hline Limite Superior: 31,46274555 \\
\hline Linha de Centro: 16,82990909 \\
\hline Limite Inferior: 2,197072635 \\
\hline
\end{tabular}

\section{Gráfico de Valores Individuais}

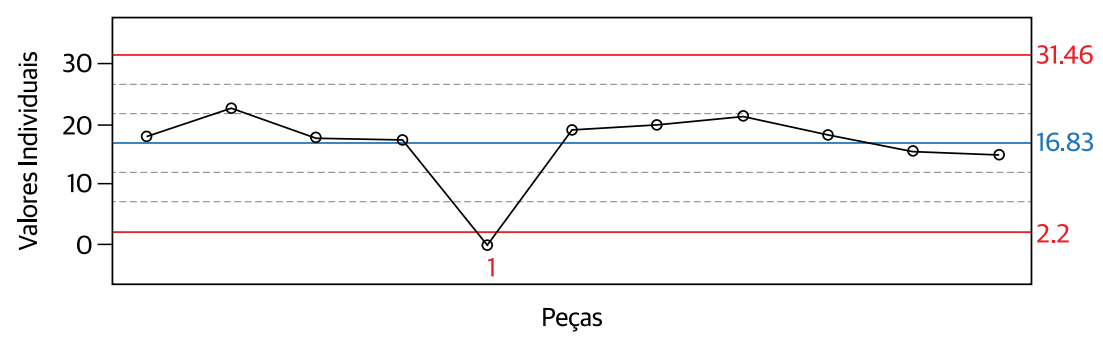

Gráfico de Amplitude Móvel

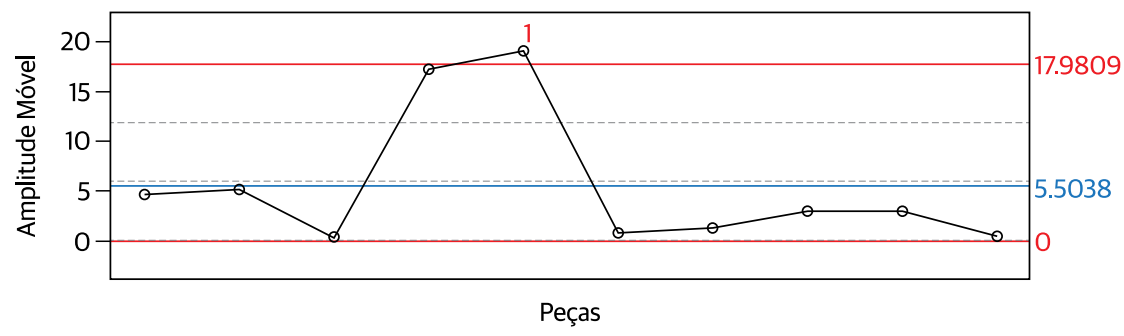

OBS.: um ponto fora do limite inferior. Como o erro é aleatório, não encontramos evidência para retirá-lo. O ponto permanecerá até que novos resultados confirmem o controle estatístico do processo. 
Figura 65. Continuação...

ANEXO 3-PLANILHA DE
CARTA CONTROLE $\frac{\text { PCC }}{\text { DATA_I_/20_ }}$

1.7 (m,p - Xileno $)-15 \mathrm{ppb}$

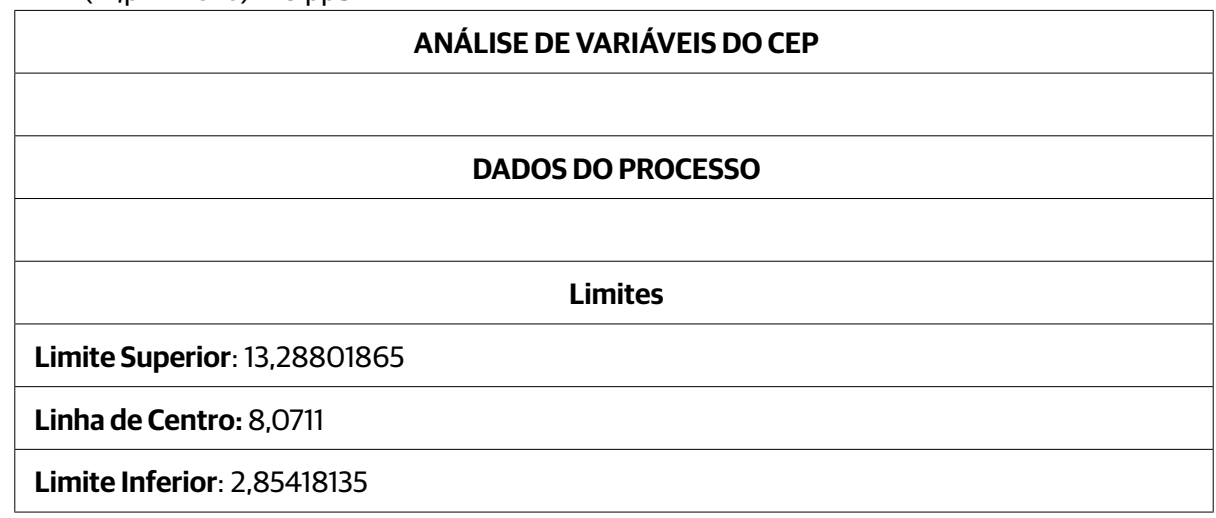

Gráfico de Valores Individuais
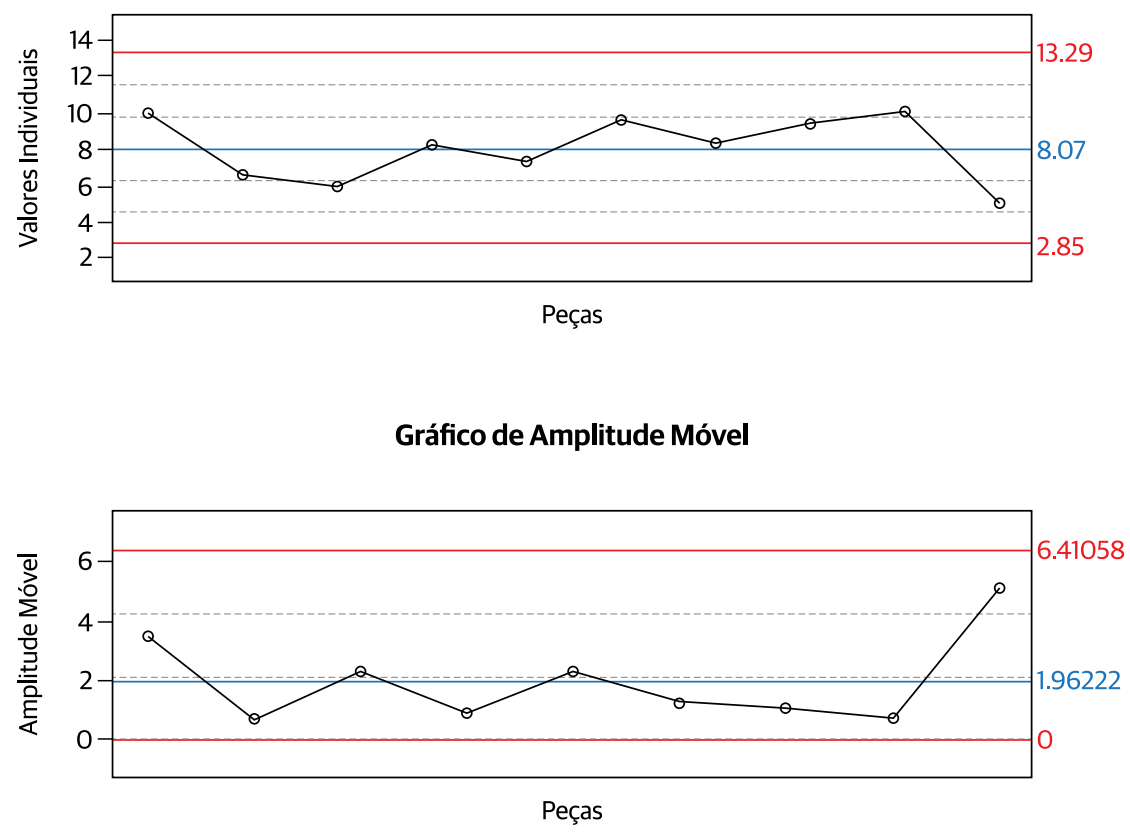
Figura 65. Continuação...

ANEXO 3-PLANILHA DE
CARTA CONTROLE $\frac{\text { PCC }}{\text { REV: X FL } 8 \text { DE } 10}$

1.8 (m,p - Xileno $)-40 \mathrm{ppb}$

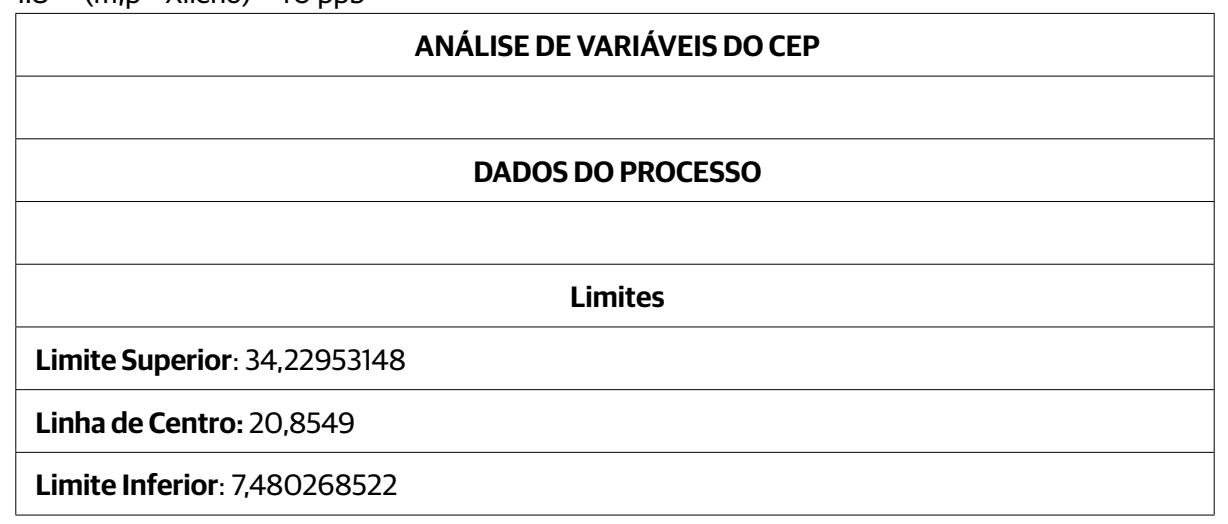

Gráfico de Valores Individuais

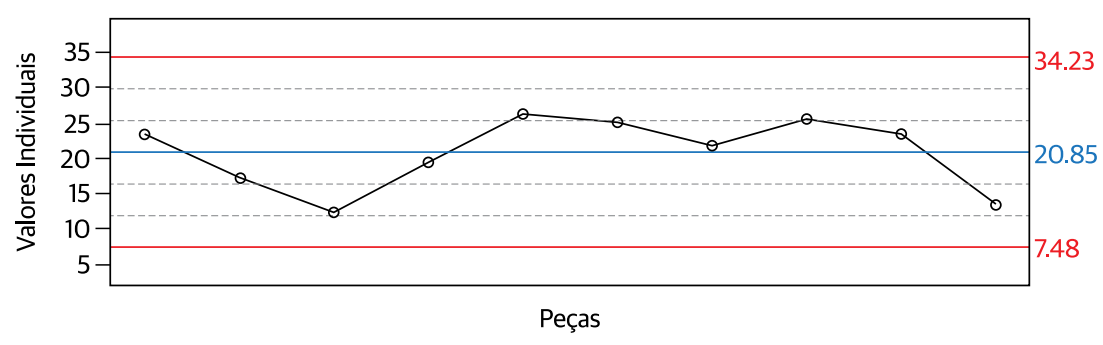

Gráfico de Amplitude Móvel

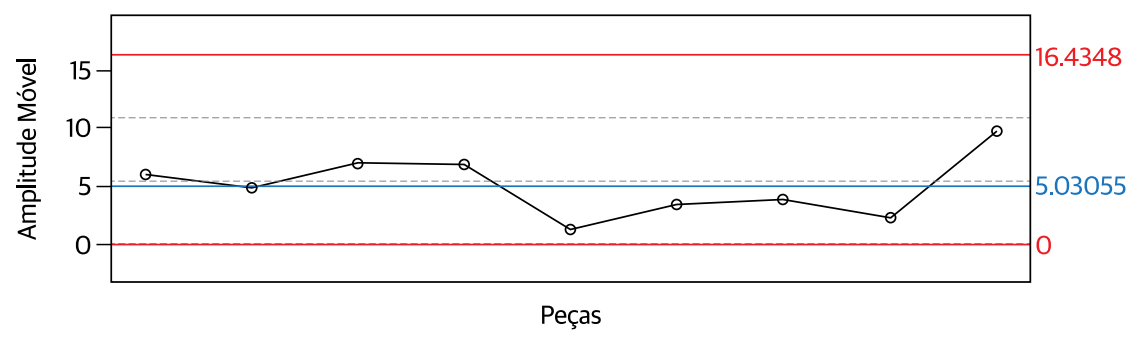


Figura 65. Continuação...

ANEXO 3-PLANILHA DE
CARTA CONTROLE

1.9 (o- Xileno) - $15 \mathrm{ppb}$

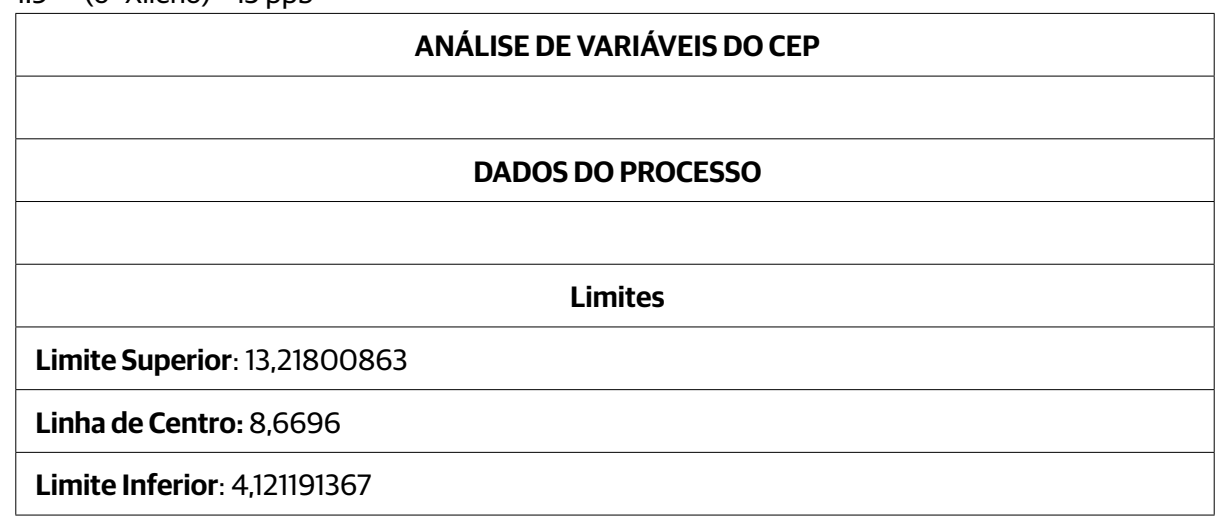

Gráfico de Valores Individuais

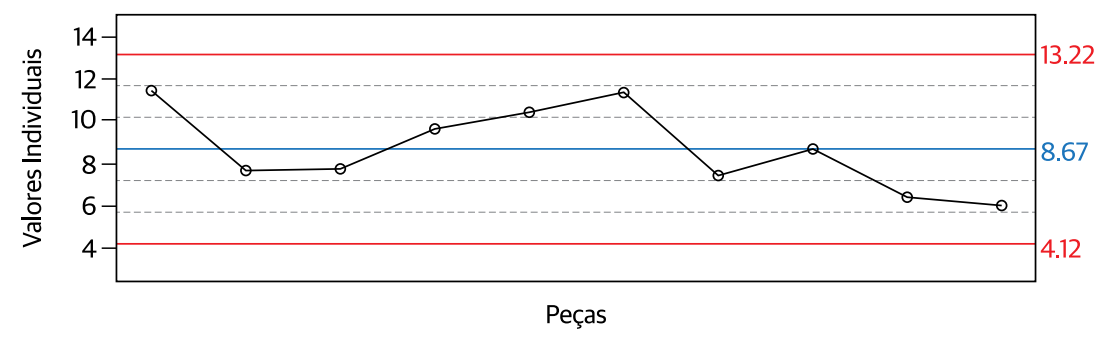

Gráfico de Amplitude Móvel

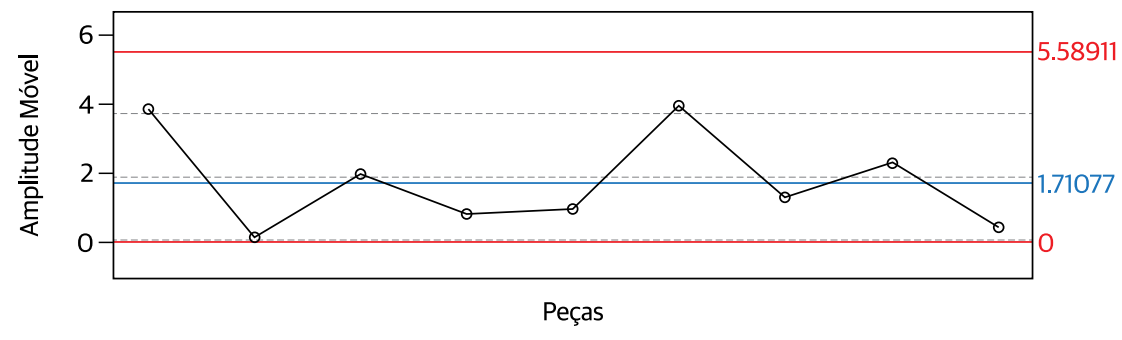


Figura 65. Continuação...

ANEXO 3-PLANILHA DE
CARTA CONTROLE

1.10 (o - Xileno) - 40 ppb

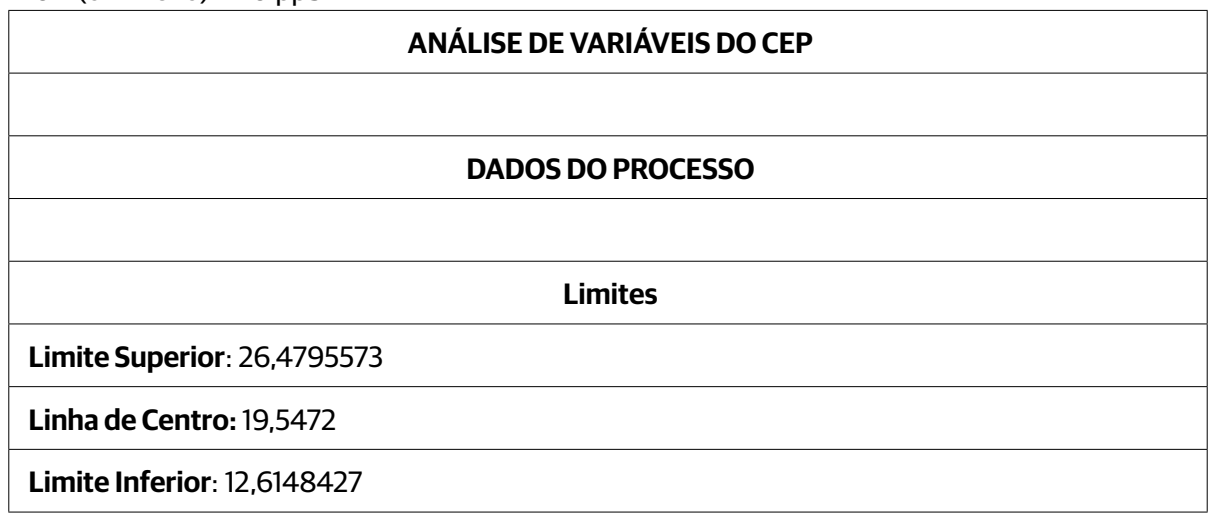
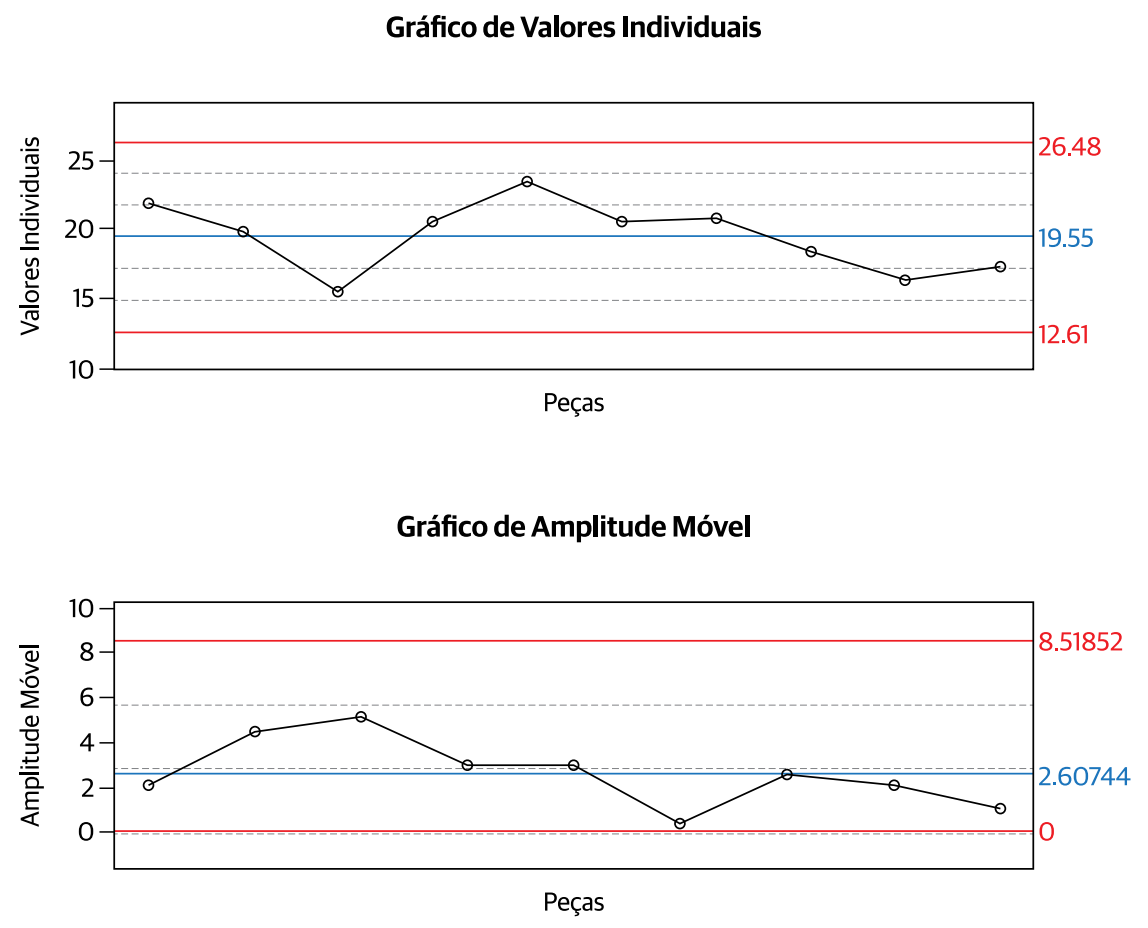
CAPÍTULO 4

\section{Limpeza de Vidraria e Descarte de Resíduos Químicos}


O Sistema de Gestão da Qualidade implementado e seguido no LQA-IQSC-USP tem por base a norma ABNT NBR ISO/IEC 17025:2005 e os princípios das Boas Práticas de Laboratório adaptados à nossa rotina diária, que é a de um laboratório de pesquisa cujo objetivo maior é a formação de pesquisadores.

Nessas normatizações não se destacam o modo de descarte de resíduos químicos nem a limpeza de vidraria. Embora haja citações acerca da necessidade de descartar adequadamente os resíduos químicos e de limpeza de vidraria, nós sentimos falta de documentos imperativos sobre o descarte de resíduos químicos e sobre a limpeza de vidraria.

A limpeza de vidraria é crucial em um laboratório que se propõe à determinação de espécies em nível traço, enquanto que o descarte ambientalmente adequadoé mandatório em qualquer atividade de pesquisa - em nosso caso particular, é vital, pois se trata de um laboratório de química ambiental.

Assim, criamos o POP 006 - Descarte de Resíduos Químicos e o POP 009 - Limpeza de Vidraria. As Figuras 66 a 68 apresentam esses procedimentos.

A lista de incompatibilidade de produtos químicos (Anexo 2 do POP 006 - Descarte de Resíduos Químicos) não está apresentada, pois pode ser acessada, por exemplo, no site do Laboratório de Resíduos Químicos do campus de São Carlos

Podemos afirmar que o desenvolvimento da indústria química está diretamente relacionado ao progresso do país. Os avanços na química refletem-se na agricultura, na medicina, no vestuário, na alimentação etc., ou seja, na qualidade de vida da população. Graças à química, nosso dia a dia pode ser mais saudável e confortável. No entanto, os resíduos gerados devem ser tratados para não agredir o meio ambiente e, consequentemente, a saúde pública. Nossa responsabilidade se dá na formação de mão de obra especializada, ou seja, além de formar químicos, devemos contribuir para a formação de cidadãos compromissados com a nação.

No campus de São Carlos, os resíduos químicos gerados em todas as atividades (laboratórios que utilizam produtos químicos, gráficas, oficinas mecânicas etc.) são encaminhados a um laboratório central - Laboratório de Resíduos Químicos (LRQ) -, para tratamento, reutilização, recuperação ou descarte adequados ${ }^{2,3}$. No entanto, a total responsabilidade pelo resíduo químico é de quem o gerou. O LRQ só recebe resíduos rotulados e encaminhados de acordo com as regras estabelecidas, por isso a necessidade de seguir um POP, tanto do ponto de vista técnico quanto educacional.

No procedimento específico para limpeza de vidrarias, procuramos abordar a necessidade da correta limpeza e secagem de vidrarias utilizadas no preparo de soluções estoque e de coleta de amostras.

Assim, consideramos queo POP 006-Descarte de Resíduos Químicos e oPOP009-Limpeza de Vidraria completam os procedimentos necessários à gestão da qualidade.

1 http://www.ccsc.usp.br/residuos/

2 ALBERGUINI, L.B.A.; SILVA, L.C.; REZENDE, M.O.O. Laboratório de Resíduos Químicos do câmpus USP-São Carlos - Resultados da experiência pioneira em gestão e gerenciamento de resíduos químicos em um câmpus universitário. Quim. Nova, Vol. 26, No. 2, 291-295, 2003.

3 TRATAMENTO DE RESÍDUOS QUÍMICOS: GUIA PRÁTICO PARA A SOLUÇÃO DOS RESÍDUOS QUÍMICOS EM INSTITUIÇÕES DE ENSINO SUPERIOR. Leny Borghesan Albertini Alberguini, Luís Carlos da Silva e Maria Olímpia de Oliveira Rezende. 1a ed. São Carlos: Rima Editora, 2005.100 p. 
Figura 66. Cópia ilustrativa do POP 006 - Descarte de Resíduos Químicos

DESCARTE DE RESÍDUOS QUÍMICOS $\frac{\text { POP } 006}{\text { REV:X FL } 1 \text { DE } 1}$

\section{OBJETIVO}

Estabelecer a sistemática para o descarte dos resíduos químicos gerados no laboratório durante a rotina diária e de pesquisa do LQA, assim como o descarte das amostras contaminadas.

\section{DOCUMENTOS COMPLEMENTARES}

Os resíduos químicos gerados são rotulados de acordo com o Diagrama de Perigo. Como orientação, há um documento disponível em http://www.ccsc.usp.br/residuos/rotulagem/index.html (acesso em 21 de outubro de 2017).

\section{PROCEDIMENTO}

Amostras são descartadas no ambiente.

Resíduos de caráter ácido e básico, cujos íons não apresentem riscos à saúde nem ao meio ambiente, são descartados no ambiente.

Resíduos que apresentem risco à saúde ou ao meio ambiente são identificados com o Diagrama de Perigo - DP (Anexo 1) e encaminhados ao laboratório responsável pelo descarte.

3.1 Preenchimento do Diagrama de Perigo

O Diagrama de Perigo é preenchido conforme a Ficha de Emergência ou Ficha de Informação de Segurança de Produtos Químicos (FISPQ). As fichas podem ser encontradas na pasta dos reagentes (com os certificados), em http://sistemasinter.cetesb.sp.gov.br/produtos/produto_ consulta_nome.asp, para uma busca por nome, ou em http://sistemasinter.cetesb.sp.gov.br/ produtos/produto_consulta_completa.asp, para a listagem completa de produtos (acesso em 21 de outubro de 2017).

Atenção à incompatibilidade de produtos ao misturar mais de um resíduo no mesmo frasco. Consulte o Anexo 2 - Incompatibilidade de Produtos para uma listagem resumida de incompatibilidade. Anexo extraído de http://www.ccsc.usp.br/residuos/rotulagem/ downloads/incompatibilidade.pdf (acesso em 21 de outubro de 2017).

\section{RESPONSABILIDADES}

Todos os pesquisadores do LQA.

\section{REGISTROS}

Diagrama de Perigo (DP).

\section{ANEXOS}

Anexo 1 - Diagrama de Perigo (DP).

Anexo 2 - Incompatibilidade de Produtos (IP).

\section{APROVAÇÕES}

\begin{tabular}{|l|l|l|}
\hline Autor & Aprovado/Assinatura & Data \\
\hline & & \\
\hline
\end{tabular}


Figura 67. Cópia ilustrativa do Anexo 1 - Diagrama de Perigo do POP 006 - Descarte de Resíduos Químicos

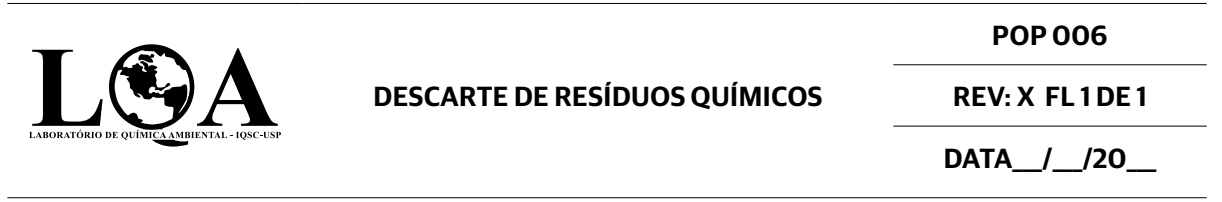

Etiqueta:

\begin{tabular}{|l|} 
PRODUTO QUÍMICO \\
\hline Produto Principal: \\
\hline Produto Secundário: \\
\hline Procedência: LQA \\
\hline Usuário:
\end{tabular}

Legenda:

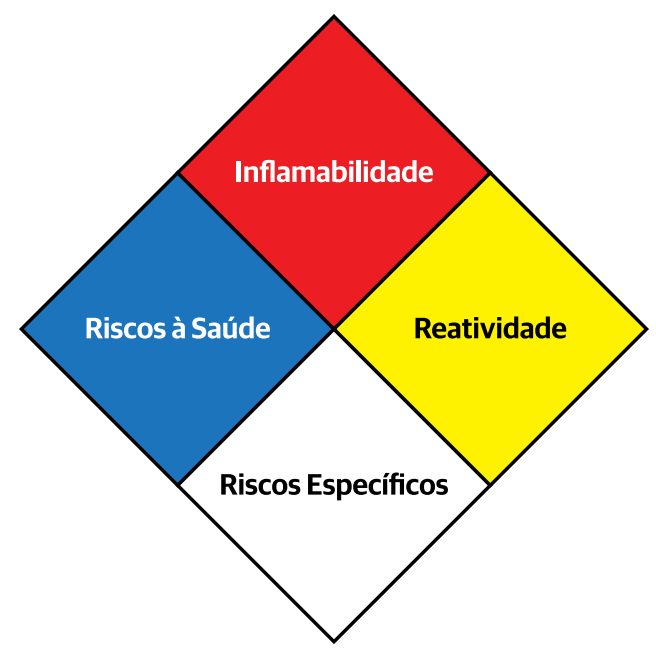

\begin{tabular}{|l|l|}
\hline Riscos à Saúde & Inflamabilidade \\
4 - Letal & 4 - Abaixo de $23^{\circ} \mathrm{C}$ \\
3 - Muito Perigoso & 3 - Abaixo de $38^{\circ} \mathrm{C}$ \\
2 - Perigoso & 2 - Abaixo de $93^{\circ} \mathrm{C}$ \\
1 - Risco Leve & 1 - Acima de $93^{\circ} \mathrm{C}$ \\
O - Material Normal & 0 - Não queima \\
\hline Riscos Especificos & Reatividade \\
OX - Oxidante & 4 - Pode explodir \\
ACID - Ácido & 3- Pode explodir com choque mecânico ou calor \\
ALK - Álcali (Base) & 2- Reação química violenta \\
COR - Corrosivo & 1 - Instável se aquecido \\
- Não misture com água & O - Estável \\
\hline
\end{tabular}


Figura 68. Cópia ilustrativa do POP 009 - Limpeza de Vidraria

LIMPEZA DE VIDRARIA $\frac{\text { POP } 009}{\text { REV:X FL 1DE } 2}$

\section{OBJETIVO}

Estabelecer a sistemática para limpeza de vidrarias e garantir que a limpeza não acrescente interferentes nos resultados analíticos.

\section{DOCUMENTOS COMPLEMENTARES}

IO 01 - Vidrarias e Instrumentos Volumétricos.

Guia nacional de coleta e preservação de amostras: água, sedimento, comunidades aquáticas e efluentes líquidos. Companhia Ambiental do Estado de São Paulo. Org.: Carlos Jesus Brandão et al. São Paulo: CETESB; Brasília: ANA, 2011.

OGCOO2 - Guia para Acreditação de Laboratórios Químicos, 18 de maio de 2011.

\section{PROCEDIMENTO}

3.1 Limpeza de vidraria utilizada no preparo de soluções estoque A vidraria utilizada no preparo de soluções estoque e/ou no manuseio de materiais de referência deve ser lavada separadamente, conforme procedimentos a seguir.

3.2 Limpeza básica de vidraria (Guia Nacional de Coleta e Preservação de Amostras, pg. 58 - 59)

a) Deixar os frascos e as tampas de molho em solução de extran (detergente alcalino) 0,1\% por tempo suficiente para facilitar a remoção dos resíduos da amostra e possíveis etiquetas.

b) Esfregar os frascos com gaspilhão.

c) VIDRARIAS NÃO CALIBRADAS: esfregar com esponja de aço e detergente neutro a parte externa dos frascos. VIDRARIAS CALIBRADAS: pular esta etapa. Obs.: jamais cole etiquetas nas vidrarias calibradas.

d) Enxaguar com água corrente.

e) Realizar o enxágue final com água destilada ou deionizada.

f) VIDRARIAS NÃO VOLUMÉTRICAS: colocar em estufa entre $70^{\circ} \mathrm{C}$ e $100^{\circ} \mathrm{C}$ durante 2 horas. VIDRARIAS VOLUMÉTRICAS NÃO CALIBRADAS: colocar na estufa entre $70^{\circ} \mathrm{C} \mathrm{e} 90^{\circ} \mathrm{C}$ durante 2 horas. VIDRARIAS CALIBRADAS: deixar secar com a boca virada para baixo sobre papel filtro absorvente.

NOTA: jamais secar a vidraria com qualquer utensílio (por exemplo: papel). Deixar secar no escorredor ou em estufa, de acordo com a classificação da vidraria.

g) Tampar e armazenar conforme 1001 - Vidrarias e Instrumentos Volumétricos.

Obs: No caso de recipientes descartáveis, enxaguar o frasco e a tampa com água destilada ou deionizada. É necessário realizar o teste de branco de vidraria para testar a limpeza dos frascos, conforme Guia Nacional de Coleta e Preservação de Amostras, pg. 77.

3.3 Secagem de vidraria em estufa ou mufla

3.3.1 "A lavagem e a secagem de vidrarias volumétricas devem ser feitas a uma temperatura inferior a $90^{\circ} \mathrm{C}$; acima de $150^{\circ} \mathrm{C}$ podem ocorrer alterações significativas da capacidade volumétrica do material de vidro borossilicatado e acima de $90^{\circ} \mathrm{C}$ para o material de vidro vulgar (soda-lime)." (OGCOO2, p. 5)

3.3.2 Vidrarias calibradas nunca são colocadas na estufa ou mufla nem em geladeira.

3.4 Limpeza especial

Consulte o Guia Nacional de Coleta e Preservação de Amostras, pg. 61 a 65, para a limpeza de vidrarias para ensaios microbiológicos e de mutagenicidade.
3.4.1 ENSAIOS DE METAIS, SEMIMETAIS, CROMO HEXAVALENTE E METAIS DISSOLVIDOS (Guia Nacional de Coleta e Preservação de Amostras, pg. 59)
a) Deixar os frascos e as tampas de molho em solução de ácido nítrico 10\% por 48 horas.
b) Enxaguar com água destilada ou deionizada.
c) Deixar secar com a boca virada para baixo sobre papel filtro absorvente.
d) Tampar e armazenar conforme IO 01 - Vidrarias e Instrumentos Volumétricos. 
Figura 68. Continuação...

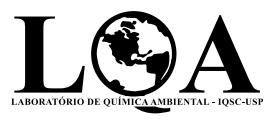

POP 009

REV: X FL 2 DE 2

DATA $/ 120$

3.4.2 ENSAIOS DE FOSFATOS E FÓSFORO TOTAL (Guia Nacional de Coleta e Preservação de Amostras, pg. 60)

a) Deixar os frascos e as tampas de molho em solução de ácido clorídrico $10 \%$ por 48 horas.

b) Enxaguar com água deionizada.

c) Deixar secar com a boca virada para baixo sobre papel filtro absorvente.

d) Tampar e armazenar conforme IO 01 - Vidrarias e Instrumentos Volumétricos.

3.4.3 ENSAIOS DE COMPOSTOS ORGÂNICOS SEMIVOLÁTEIS - fenóis por cromatografia, herbicidas fenoxiácidos, PAHs, benzo(a)pireno, pesticidas organoclorados, PCBs e pesticidas organofosforados (Guia Nacional de Coleta e Preservação de Amostras, pg. 60)

a) Remover os resíduos grosseiros dos frascos com água corrente quente.

b) Lavar com detergente enzimático 0,5\% ou similar com gaspilhão e esponja de limpeza.

c) Enxaguar abundantemente com água corrente quente (no mínimo, cinco vezes).

d) Enxaguar com água destilada.

e) Colocar os frascos na Mufla $01\left(270^{\circ} \mathrm{C}\right.$ a $\left.300^{\circ} \mathrm{C}\right)$ por, no mínimo, 8 horas ou enxaguar os frascos com metanol ou isopropanol para remover completamente qualquer composto orgânico (Obs.: nunca colocar vidrarias calibradas na mufla nem na estufa).

f) Tampar e armazenar conforme IO 01 - Vidrarias e Instrumentos Volumétricos.

3.4.4 ENSAIOS DE COMPOSTOS ORGÂNICOS VOLÁTEIS (Guia Nacional de Coleta e Preservação de Amostras, pg. 61)

a) Remover os resíduos grosseiros dos frascos com água corrente quente.

b) Lavar com detergente enzimático 0,5\% ou similar com gaspilhão e esponja de limpeza.

c) Enxaguar abundantemente com água corrente quente (no mínimo, cinco vezes).

d) Enxaguar com água destilada.

e) VIDRARIAS NÃO CALIBRADAS: secar em estufa entre $100^{\circ} \mathrm{C}$ e $150^{\circ} \mathrm{C}$ por, no mínimo, 1 hora. Septos de teflon e tampas em estufa até $105^{\circ} \mathrm{C}$. VIDRARIAS VOLUMÉTRICAS NÃO CALIBRADAS: colocar na estufa entre $70^{\circ} \mathrm{C}$ e $90^{\circ} \mathrm{C}$ por, no mínimo, 1 hora. VIDRARIAS CALIBRADAS: deixar secar com a boca virada para baixo sobre papel filtro absorvente.

f) Tampar e armazenar conforme 1001 - Vidrarias e Instrumentos Volumétricos.

\section{RESPONSABILIDADES}

Diretor acadêmico, gerente técnico, graduandos e pós-graduandos.

\section{APROVAÇÕES}

\begin{tabular}{|l|l|l|}
\hline Autor & Aprovado/ Assinatura & Data \\
\hline & & \\
\hline
\end{tabular}


Os pesquisadores internos, imediatamente ao ingressarem no LQA, têm pleno conhecimento de suas responsabilidades (POP 019).

Os pesquisadores internos do LQA desenvolvem suas pesquisas de acordo com um projeto de pesquisa supervisionado pela diretora acadêmica (POP 020). Qualquer amostra que chegue ao LQA, quer seja coletada no ambiente, quer seja produzida no LQA, deve ser amostrada de acordo com o POP 017. O LQA tem procedimento de identificação, manuseio, proteção, armazenamento e retenção das amostras, conforme os já referidos POP 020 e POP 017, e posterior descarte, de acordo com POP 006. As amostras determinadas no LQA podem pertencer a pesquisadores internos ou a pesquisadores externos/clientes. De acordo com o projeto de pesquisa ou com o interesse do pesquisador externo/cliente, iniciam-se as determinações analíticas. Quando necessário, utilizam-se outros laboratórios. A subcontratação é executada de acordo com os preceitos estabelecidos no POP 017 e com os objetivos da pesquisa (POP 015 e POP 020).

Todo e qualquer procedimento com as amostras é registrado na Agenda Mestra (POP 003). As substâncias químicas utilizadas nos ensaios têm seu uso reportado no registro de controle de reagentes ou de gases - os reagentes e solventes são testados, quando necessário (POP 011). A utilização de materiais de referência é reportada no POP 002. O registro de uso de todos os materiais e equipamentos é feito conforme POP 004. Quando as amostras são determinadas instrumentalmente, os equipamentos têm seu uso registrado no Registro de Gerenciamento referente à respectiva instrução operacional (IO) - POP 001. Se necessário, os treinamentos anteriores ao uso do equipamento para os estudos são realizados conforme POP 020. Oregistro correto de todas as atividades é o que permite a rastreabilidade dos dados e a correta avaliação dos resultados.

Deve-se ter especial cuidado com a limpeza da vidraria (POP 009) e com a limpeza do próprio laboratório (POP 005). Se houver necessidade de aquisição de serviços e de suprimentos, consultam-se o POP 010 e o POP 013. A metodologia não normatizada utilizada deve ser validada conforme POP 007 e POP 008 e monitorada segundo POP 018, de acordo com a norma ABNT NBR ISO/IEC 17025:2005. Se necessário, apresenta-se o cálculo da incerteza. Qualquer resultado inesperado ou não conforme é avaliado consoante o POP 014. Nessa etapa - não conformidade de resultados -, ações corretivas são tomadas e monitoradas.

Os resíduos químicos gerados eas amostras já utilizadas são descartados conforme POP 006.

Os resultados são avaliados criticamente e apresentados como relatórios deensaio(POP 017) ou submetidos ao crivo da comunidade científica, na forma de monografias, dissertações ou teses, artigos, livros, capítulos de livro, resumos em congressos, encontros, simpósios e reuniões científicas, patentes, palestras etc., de acordo com os projetos de pesquisa de cada pesquisador (POP 020). Vale ressaltarmos que métodos desenvolvidos durante as pesquisas, além da divulgação científica mencionada, são reportados conforme as instruções do POP 016 e POP 004, ficando disponibilizados para uso de outros pesquisadores do LQA.

O seguimento de um Sistema de Gestão da Qualidade garante a rastreabilidade dos dados, evitando que erros sejam perpetuados, e, assim, garante-se a confiabilidade dos resultados.

Os pesquisadores formados sob essa égide encontram-se aptos a comandar laboratórios de pesquisa ou de análises requeridos por órgãos do governo, como IBAMA, ANA, MAPA, Secretaria de Meio Ambiente do Estado de São Paulo e CETESB, para citar alguns ligados àárea ambiental.

No entanto, deve-se ter em conta que a tendência de qualquer laboratório organizado, principalmente naqueles em que há alta rotatividade de pesquisadores, é desorganizar-se. Buscando a melhoria constante do Sistema de Gestão da Qualidade, a qual faz parte da política do LQA, este laboratório estabeleceu um procedimento periódico, com cronograma preestabelecido, para uma análise crítica do Sistema de Gestão da Qualidade e das atividades 
de ensaio, e, assim, assegurar sua contínua adequação e eficácia e introduzir mudanças ou melhorias necessárias, conforme POP 012. No LQA, a análise crítica pela direção é realizada a cada 12 meses, normalmente entre janeiro e fevereiro, que são meses não letivos. A melhoria constante da qualidade baseia-se nos resultados da auditoria e nas ações de melhoria.

O Sistema de Gestão da Qualidade é constituído pelo Manual da Qualidade, por todos os procedimentos operacionais padrão e pelo compromisso com a melhoria contínua, graças ao controle constante da qualidade. 
